\title{
Targeted and Off-Target (Bystander and Abscopal) Effects of Radiation Therapy: Redox Mechanisms and Risk/Benefit Analysis
}

\author{
Jean-Pierre Pouget, Alexandros G. Georgakilas, and Jean-Luc Ravanat ${ }^{3}$
}

\begin{abstract}
Significance: Radiation therapy (from external beams to unsealed and sealed radionuclide sources) takes advantage of the detrimental effects of the clustered production of radicals and reactive oxygen species (ROS). Research has mainly focused on the interaction of radiation with water, which is the major constituent of living beings, and with nuclear DNA, which contains the genetic information. This led to the so-called target theory according to which cells have to be hit by ionizing particles to elicit an important biological response, including cell death. In cancer therapy, the Poisson law and linear quadratic mathematical models have been used to describe the probability of hits per cell as a function of the radiation dose.

Recent Advances: However, in the last 20 years, many studies have shown that radiation generates "danger" signals that propagate from irradiated to nonirradiated cells, leading to bystander and other off-target effects. Critical Issues: Like for targeted effects, redox mechanisms play a key role also in off-target effects through transmission of ROS and reactive nitrogen species (RNS), and also of cytokines, ATP, and extracellular DNA. Particularly, nuclear factor kappa B is essential for triggering self-sustained production of ROS and RNS, thus making the bystander response similar to inflammation. In some therapeutic cases, this phenomenon is associated with recruitment of immune cells that are involved in distant irradiation effects (called "away-fromtarget" i.e., abscopal effects).

Future Directions: Determining the contribution of targeted and off-target effects in the clinic is still challenging. This has important consequences not only in radiotherapy but also possibly in diagnostic procedures and in radiation protection. Antioxid. Redox Signal. 29, 1447-1487.
\end{abstract}

Keywords: bystander effects, nontargeted effects, abscopal effects, radiotherapy, radionuclide therapy, targeted effects

\section{Table of Contents}

I. Introduction

II. Targeted Effects: Oxidative Damage to DNA, Lipids, and Proteins 1448

A. DNA damage, targeted effects $\quad 1449$

1. Direct effect

1449

2. Indirect effect

Reviewing Editors: Munjal Acharya, Fred Bunz, John Cook, Ruud Dings, Michael Freeman, Michael Hitchler, Charles Limoli, and Robert Mairs

\footnotetext{
${ }^{1}$ Institut de Recherche en Cancérologie de Montpellier (IRCM), INSERM, Université de Montpellier, Institut Régional du Cancer de Montpellier (ICM), Montpellier, France.

${ }^{2}$ DNA Damage Laboratory, Physics Department, School of Applied Mathematical and Physical Sciences, National Technical University of Athens, Athens, Greece.

${ }^{3}$ Univ. Grenoble Alpes, CEA, CNRS INAC SyMMES UMR 5819, Grenoble, France.

(C) Jean-Pierre Pouget et al., 2018; Published by Mary Ann Liebert, Inc. This Open Access article is distributed under the terms of the Creative Commons License (http://creativecommons.org/licenses/by/4.0), which permits unrestricted use, distribution, and reproduction in any medium, provided the original work is properly cited.
} 
B. Effects of irradiation on lipids 1452

C. Protein damage 1453

D. Targeted effects: conclusions 1454

III. Nuclear-Centered View of the Cellular Response to Radiation 1454

A. DNA DSB repair 1454

B. Nuclear-centered view of the cellular response to radiation: conclusion 1456

IV. Off-Target Effects: An Integrated Cell Response to Radiation 1456

A. Bystander effects 1457

1. Intercellular communications between irradiated and nonirradiated cells 1457

2. Reactive oxygen and nitrogen species initiate and propagate bystander effects 1457

a. Mitochondria-dependent ROS production 1459

(1) Mitochondria and ROS endogenous production $r$

(2) Mitochondria and irradiation $r$

b. NAD(P)H oxidase-dependent ROS production 1460

c. ROS and RNS as second messengers $r$

3. Cell membrane response to radiation 1461

a. Cell membrane and lipid rafts 1461

b. Lipid rafts in mitochondria-ER-associated domains 1463

c. Caveolae, a subgroup of membrane lipid rafts 1463

d. Ion channels and lipid rafts 1463

e. The role of $\mathrm{Ca}^{2+}$ ions in bystander effects 1463

f. ROS/RNS and growth factor receptor activation 1464

g. MAPKs and the bystander response 1466

4. Central role of NF- $\kappa \mathrm{B}$ in the nuclear and extranuclear responses to radiation 1466

a. Nuclear factor kappa B 1466

b. NF- $\kappa \mathrm{B}$ and irradiation $\quad 1467$

5. The COX-2 and iNOS 1468

B. Distant/systemic effects 1468

1. Immune response as the mediator of radiation-induced systemic effects 1468

2. Abscopal effects: historical changes and clinical evidence 1470

C. Off-target effects: an integrated cell response to radiation: conclusion 1471

V. Benefit/Risk Analysis 1471

A. Target theory

B. The clinical relevance of off-target effects might be radiotherapy dependent 1472

C. Bystander effects and radiation protection 1472

D. The biology of low dose and low-dose rate might differ from that of high dose and high-dose rate 1473

E. Off-target effects and radiotherapy efficacy 1473

F. Benefit/risk analysis: conclusion 1474

VI. General Conclusion 1474

VII. Key Points 1475

\section{Introduction}

$\mathbf{F}$ OR ABOUT ONE CENTURY, the paradigm of radiation biology has been that cells need to be traversed by radiation to be killed. Therefore, in the context of the "targeted effects" of radiation, most research has focused on DNA because it was considered to be the main if not the only target. Radiation-induced DNA single- and double-strand breaks (SSBs and DSBs) and base damage have been identified and quantified. However, other nuclear components, such as lipids and proteins, can also be affected by radiation-targeted effects.

In the 1990s, a shift in the radiation biology paradigm occurred on the basis of the observation that biological effects could be observed also after irradiation of non-nuclear cell compartments $(248,276,335)$. Particularly, the existence of dynamic signaling pathways between the various subcellular compartments (nucleus, endoplasmic reticulum [ER], mitochondria, and cell membrane) needs to be taken into account when assessing radiation-induced effects. The rather naive idea that only the nucleus is sensitive to radiation and that the rest of the cell is inert was progressively replaced by a new view that considers intra- and intercellular signaling mechanisms, leading to the expansion of the cell response to radiation in time (long-lasting radiation-induced effects) and also in space (off-target effects, also called nontargeted effects, such as bystander and abscopal effects).

In this review, we first summarize the main targeted and off-target effects and the underlying molecular mechanisms. Then, we discuss the currently available models to predict the therapeutic efficacy and side effects of radiation exposure by taking into account both targeted and off-target effects.

\section{Targeted Effects: Oxidative Damage to DNA, Lipids, and Proteins}

The effect of ionizing radiation on cellular constituents has been extensively studied, particularly the formation of DNA lesions because the biological consequences of radiation were mostly attributed to the formation of DNA 
lesions. In contrast to other biomolecules that are continuously synthetized and decomposed within cells, the cell genome is replicated only once per cell cycle. Therefore, the integrity of the DNA structure is of major importance to maintain the genetic information. For this reason, cells have developed several repair systems to remove DNA lesions and restore DNA integrity. Conversely, altered RNA, protein, and lipid molecules are discarded and replaced by newly synthesized molecules.

\section{A. DNA damage, targeted effects}

Following irradiation, DNA damage can be produced via two different mechanisms: (i) direct effect that induces a direct ionization of DNA molecules, and (ii) indirect effect mediated by water radiolysis (214) (Fig. 1). Through this second mechanism, several reactive oxygen species (ROS) can be generated by water radiolysis that can then react with endogenous cellular constituents, including DNA. Most of the DNA damage is attributed to the highly reactive hydroxyl radical $\mathrm{HO}^{\circ}$.

During the last four decades, a considerable amount of work has been done to understand the chemical nature, the mechanism, and the yield of radiation-induced DNA lesions in irradiated cells. Concerning the chemical nature of the DNA modifications, most of the work was performed with isolated nucleosides used as DNA model systems (41). Today, about 80 different DNA modifications (including isomers) have been identified (45). The chemical nature of these modifications is not described in this review article, but in- formation can be found in previous publications $(41,44$, 254). Only few examples to highlight the complexity of the undergoing reactions are presented, focusing on lesions that have been observed at the cellular level.

1. Direct effect. Through the direct effect, DNA molecules are directly ionized (loss of an electron), thus generating a DNA radical cation. For each nucleoside, the decomposition of the corresponding radical cation has been described in detail, but the chemistry is different in double-stranded DNA (dsDNA) (46). Indeed, among the DNA constituents, guanine has the lowest oxidation potential. Therefore, even if oxidation occurs on another base or sugar moiety, a fast electron transfer reaction occurs from guanine to the generated radical cation, thus repairing the initially produced radical and generating a guanine radical cation $\left(\mathrm{G}^{\bullet+}\right)$.

Consequently, in dsDNA and in cells, the direct effect of radiation produces mostly unstable guanine radical cations that, after decomposition, give rise typically to two guanine chemical modifications (Fig. 2): 8-oxo-7'8-dihydro-2'deoxyguanosine (8-oxodGuo) following oxidation and the corresponding formamidopyrimidine derivative FapydGuo on reduction. Interestingly, it has been shown that in irradiated cells, FapydGuo production is two times higher than that of 8-oxodGuo, suggesting that cellular DNA is in a reducing environment.

2. Indirect effect. The radiation-induced DNA lesions produced through the indirect effect are mediated by the initial formation of ROS due to water radiolysis. Exposure of

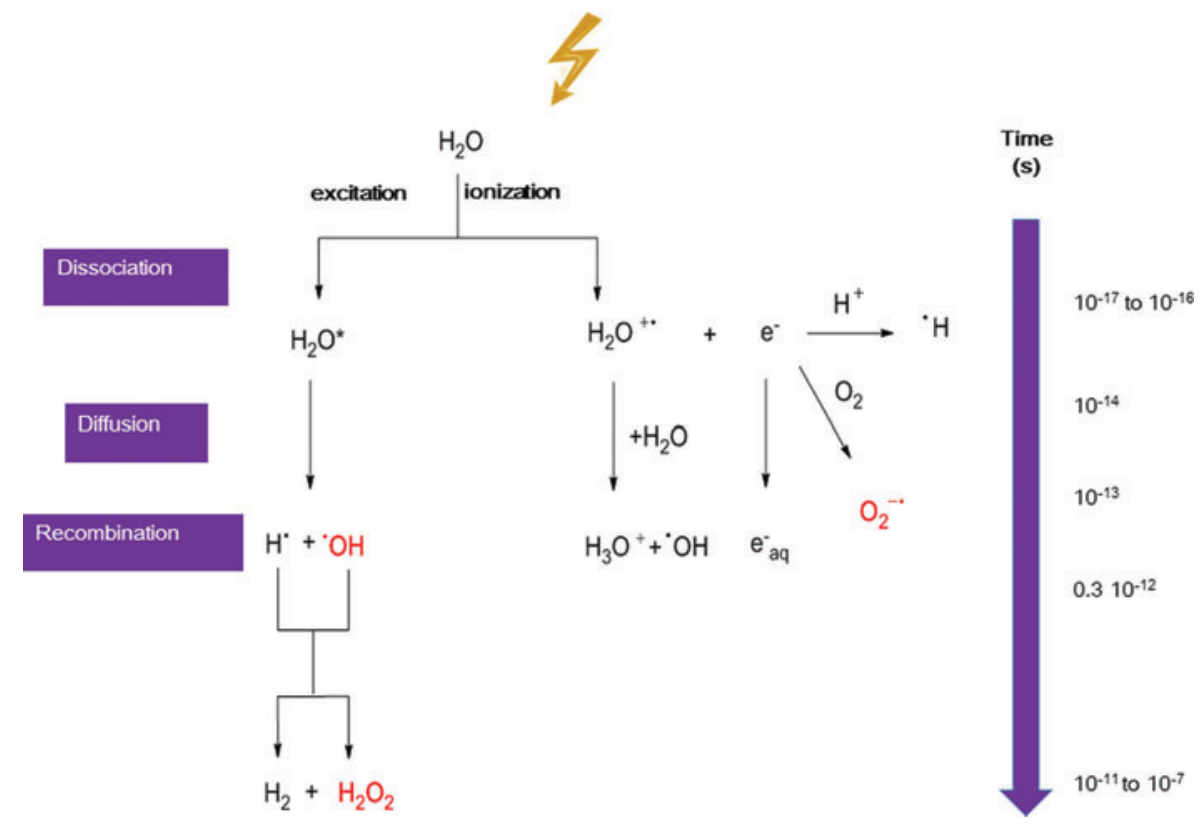

FIG. 1. Kinetic description of the ROS produced by water radiolysis. Ionizing radiation induces excitation and ionization of water molecules in a very short time. Excited $\mathrm{H}_{2} \mathrm{O}^{*}$ molecules can then dissociate to generate $\mathrm{H}^{\bullet}$ and highly reactive $\mathrm{HO}^{\bullet}$ that can be produced also by transfer of one proton from ionized water molecules $\mathrm{H}_{2} \mathrm{O}^{+\bullet}$. Ejected electrons can be thermalized to produce hydrated electrons $\mathrm{e}^{-}$aq. or react with $\mathrm{H}^{+}$or $\mathrm{O}_{2}$ to produce $\mathrm{H}^{\bullet}$ and $\mathrm{O}_{2}{ }^{\bullet}$ respectively. Radical recombination reactions also can occur, mostly after irradiation with high LET particles, leading to the production, for example, of $\mathrm{H}_{2} \mathrm{O}_{2}$ or $\mathrm{H}_{2}$ through recombination of two $\mathrm{HO}^{\bullet}$ or $\mathrm{H}^{\bullet}$ radicals, respectively. $\mathrm{H}_{2} \mathrm{O}_{2}$, hydrogen peroxide; LET, linear energy transfer; $\mathrm{O}_{2}^{-\bullet}$, superoxide anion; ROS, reactive oxygen species. To see this illustration in color, the reader is referred to the web version of this article at www.liebertpub.com/ars 


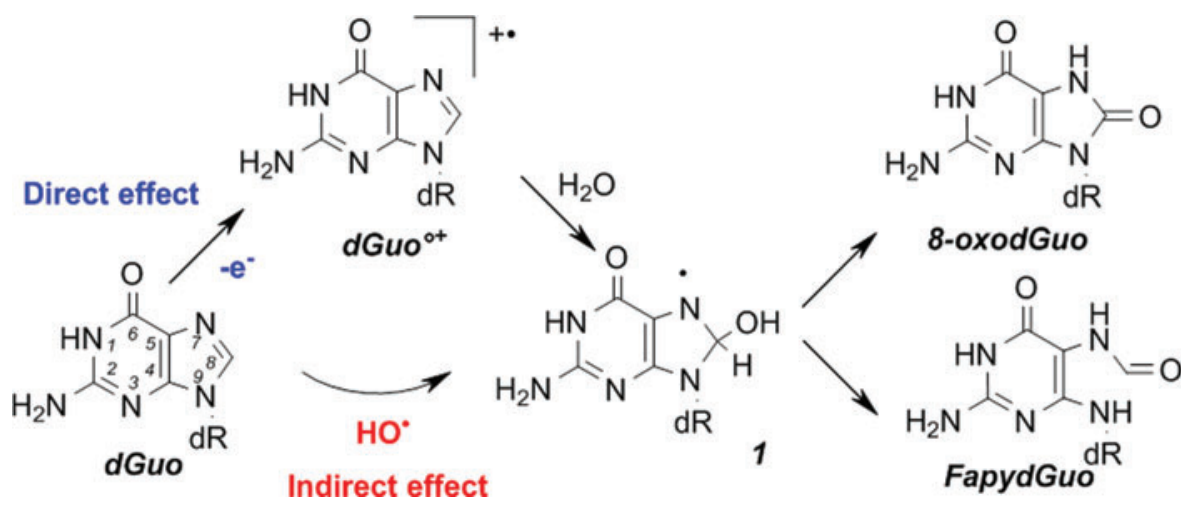

FIG. 2. Mechanisms of 8-oxodGuo and FapydGuo formation through direct or indirect effects of irradiation. The direct effect produces a guanine radical cation that, following dehydration, produces a neutral radical 1 that can also be formed by addition of $\mathrm{HO}^{\bullet}$ (produced through the indirect effect) onto the guanine moiety. Oxidation of 1 gives rise to 8-oxodGuo, whereas reduction of 1 leads to FapydGuo production. 8-oxodGuo, 8-oxo-7'8-dihydro-2'-deoxyguanosine; dGuo, 2'-deoxyguanosine. To see this illustration in color, the reader is referred to the web version of this article at www .liebertpub.com/ars

water to ionizing radiation rapidly leads to the generation of $\mathrm{HO}^{\bullet}$, ionized water $\left(\mathrm{H}_{2} \mathrm{O}^{+}\right)$, hydrogen radicals, and hydrated electrons. Then, the reaction of the initially produced radicals generates hydrogen peroxide $\left(\mathrm{H}_{2} \mathrm{O}_{2}\right)$ and superoxide anion $\left(\mathrm{O}_{2}{ }^{-\bullet}\right)$. As these $\mathrm{ROS}$ are also produced endogenously and their concentration is regulated by several antioxidant defense mechanisms, the radiation-induced increase of ROS cellular level could damage cellular constituents and also induce oxidative stress (113).

Among the ROS produced upon exposure to radiation, $\mathrm{HO}^{\bullet}$ plays a predominant role because it can react, at a diffusion-controlled rate, with almost all biological constituents. Its reactivity within DNA is well documented (43), and about $30 \%$ of $\mathrm{HO}^{\bullet}$ reacts with the sugar moiety or phosphate group of DNA. Such reaction (69) produces SSBs. HO ${ }^{\bullet}$ reaction with the four different DNA bases has been studied in detail. This reaction produces a plethora of DNA lesions, but is limited by $\mathrm{HO}^{\bullet}$ diffusion. Interestingly, the DNA lesions generated by such mechanism are not different from those produced via the direct effect, because similar radical intermediates are generated by the two mechanisms. For instance, concerning 8-oxodGuo, addition of $\mathrm{HO}^{\bullet}$ to the position $\mathrm{C} 8$ of guanine produces radical 1 (Fig. 2), also generated following hydration of guanine radical cations arising from direct oxidation of DNA. Similar observations have been made for all DNA bases. One-electron oxidation of DNA bases gives rise to similar chemical modifications as those produced by the indirect effect of irradiation, the only difference concerns their relative yields (42).

The relative importance of the direct and indirect effects in the formation of radiation-induced DNA lesions is still a matter of debate. The general idea is that for low LET (linear energy transfer) radiation such as X- or $\gamma$-rays, the direct effect accounts for about $30 \%$ of DNA lesions (and thus $70 \%$ is attributed to the indirect effect), and that this proportion increases for higher LET radiations such as protons, carbons, and $\alpha$-particles. A low mean LET of $0.2 \mathrm{keV} / \mu \mathrm{m}$ is observed with $\gamma / \mathrm{X}$-rays and beta radiation, while LET increases up to 4-26 keV/ $\mu \mathrm{m}$ with Auger electrons and up to $50-230 \mathrm{keV} / \mu \mathrm{m}$ with alpha particles. However, according to the chemical mechanism of formation of radiation-induced DNA lesions, the direct effect should mostly produce lesions on the gua- nine moiety (8-oxodGuo, e.g.) as explained above, due to fast electron transfer in DNA. Conversely, the indirect effect should generate lesions in all DNA bases and also strand breaks. Thus, an attempt has been made to determine the relative formation of 8-oxodGuo compared with other oxidative bases in cells after exposure to radiations with different LETs (78). To mimic the direct effect, a laser irradiation at $266 \mathrm{~nm}$ was used because it can produce direct DNA ionization following two-photon absorption. As expected, in these conditions, 8-oxodGuo was predominantly formed. This indicates that an efficient electron transfer reaction from guanine to other base radical cations (that are produced by two-photon ionization) takes place also within irradiated cells (vide supra). Conversely, the predominance of 8-oxodGuo formation relative to other oxidative DNA lesions in cellular DNA was not observed after gamma or high-LET radiation. Indeed, it has been shown that increasing the particle's LET does not increase the relative formation of 8-oxodGuo compared with other DNA lesions.

This suggests that the direct effect is not increased upon exposure to high LET radiation. Moreover, the strong correlation between $\mathrm{HO}^{\bullet}$ radiolytic yield and the number of produced DNA lesions strongly suggests that DNA lesions are predominantly produced via the indirect effect (242). Additional work is needed to clarify this point. Particularly, recent studies have highlighted the fact that the guanine radical cation decomposition is affected by its environment. Therefore, the measurement of a specific product generated via the direct effect of radiation would be much more informative than measuring 8-oxodGuo formation, because the latter can be produced through the two mechanisms. Indeed, it has been shown that some amino acids chemically repair $\mathrm{G}^{\bullet+}(192,193)$, and that addition of other amino acids as well as polyamines to the $\mathrm{C} 8$ position produces other DNA lesions $(235,285,338)$, including DNA-protein crosslink. Thus, monitoring lesions specifically produced by the direct effect of radiation could provide additional information to better estimate the direct effect relative contribution.

Finally, it is interesting to note that the chemical nature of radiation-induced DNA lesions is not different from that of DNA lesions produced in cells subject to endogenous 
oxidative stress (45). This is not surprising because ROS produced by radiation through water radiolysis are similar to those produced endogenously, for example, $\mathrm{HO}^{\bullet}$ through the Fenton reaction (204). However, the major difference concerns the lesion three-dimensional (3D) localization (212, $215,330)$. Endogenous oxidative stress produces oxidative lesions that should be randomly distributed on the DNA macromolecules. These lesions, including modified DNA bases and SSBs, can be rapidly and efficiently repaired by the cell machinery, simply by removing the modification and using the complementary strand to resynthesize the original DNA sequence. After exposure to ionizing radiations, ROS are locally produced along the particle track and this could generate several DNA modifications at the same site (called "multiple damage sites," MDS, or clustered DNA lesions) (Fig. 3). These lesions are defined as two or more modifications per helix turn $(172,219)$. DNA DSBs are one of the best examples of MDS. DSBs are produced in cells even after exposure to very low doses of radiations, and their formation yield increases almost linearly with the dose $(102,260,329)$.

In addition, high-LET radiations, which induce more dense ionizations, produce, relatively to SSBs, more DSBs compared with low-LET radiations. In fact, when the LET of the radiation increases, the number of DNA lesions per unit dose (Gy) decreases (242) (due to an increased probability of radical recombination), but at the same time, MDS complexity increases (i.e., the MDS includes more DNA damage types, such as base modifications and strand breaks). MDS repair by the cell machinery is much more difficult as soon as the two DNA strands are modified (262). Thus, this explains why the harmful effect of radiation increases with higher LET, and also why the effect of radiation is mostly attributed to cluster DNA lesions (including DSBs and non-DSB cluster lesions) produced by several ionizations.

However, recent works have highlighted the fact that a single oxidation event also can produce several modifications (called tandem lesions), composed of two adjacent modifications. For example, as illustrated in Figure 4 for a dG-dC sequence, in the absence of oxygen, crosslinks between two adjacent DNA bases could be produced, generating intrastrand crosslinks (G[8-5]C adduct) (128). Within the same sequence, in the presence of oxygen, the reaction of the initially produced radical with $\mathrm{O}_{2}$ produces a hydroperoxide radical that can add to the $\mathrm{C} 8$ position of an adjacent guanine (or adenine) base. The resulting unstable endoperoxide undergoes decomposition, producing tandem DNA lesions that involve two adjacent DNA modifications (253), such as 8oxodGuo and a formylamine residue (8-oxodGuo-dF, Fig. 4) (29). The latter observation, although obtained using isolated DNA, indicates that a radical produced on a DNA base can react with surrounding molecules and particularly with adjacent bases, giving rise to possibly two adjacent modifications.

Moreover, it has been shown that the repair of 8-oxodGuo involved in tandem lesions is significantly reduced compared with the repair of a single lesion (19). At the cellular level, the decomposition reactions of an initially produced radical will
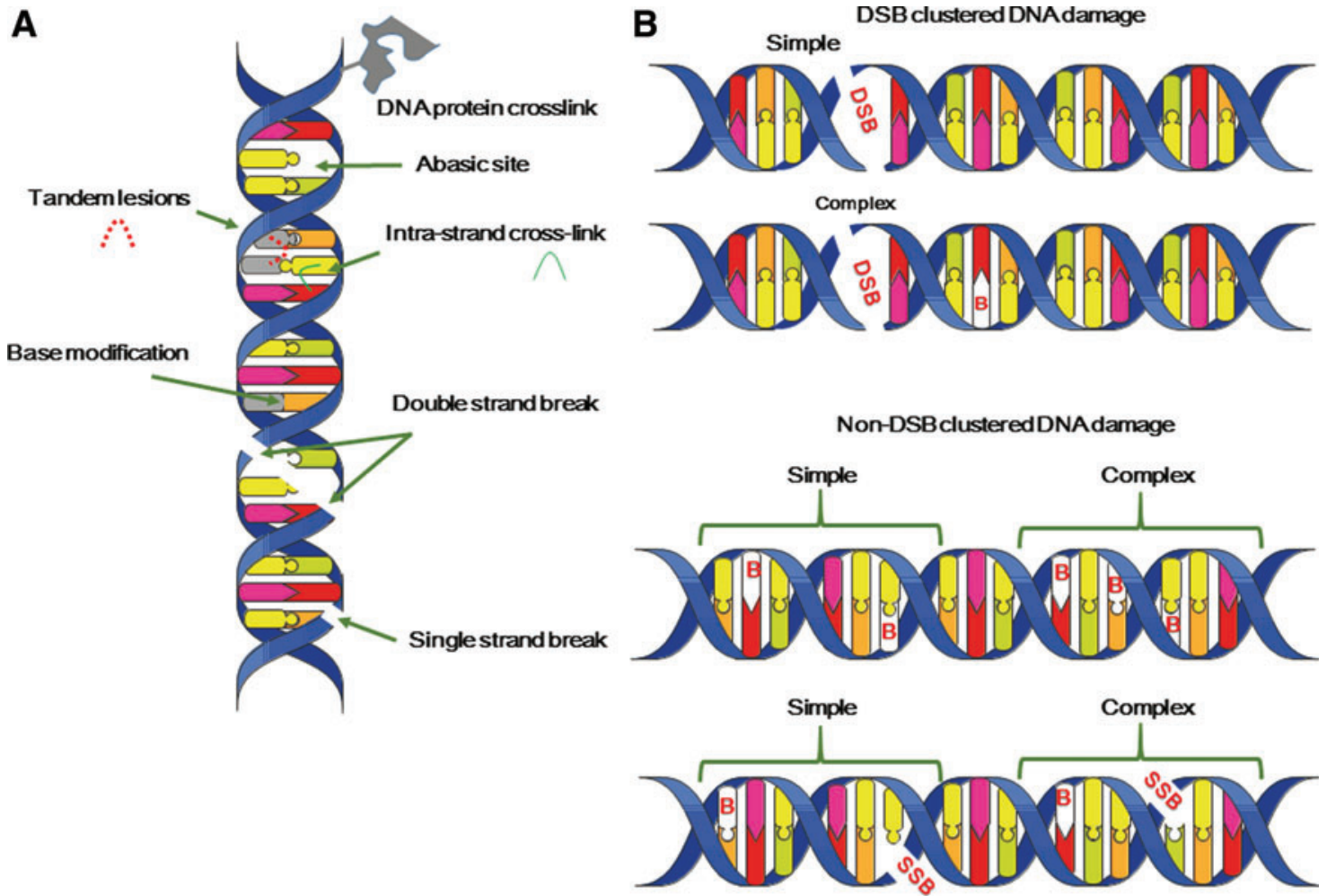

FIG. 3. Radiation-induced DNA damage. Different types of DNA lesions that could be produced by ionizing radiations, including (A) base (B) modifications, abasic sites, SSB or DSB, intrastrand crosslink, tandem DNA lesions involving two adjacent modifications. (B) Types of DSB and non-DSB clustered DNA lesions involving the combination of all possible DNA lesions in one or two DNA helix turns (82). DSB, double-strand break; SSB, single-strand break. To see this illustration in color, the reader is referred to the web version of this article at www.liebertpub.com/ars 


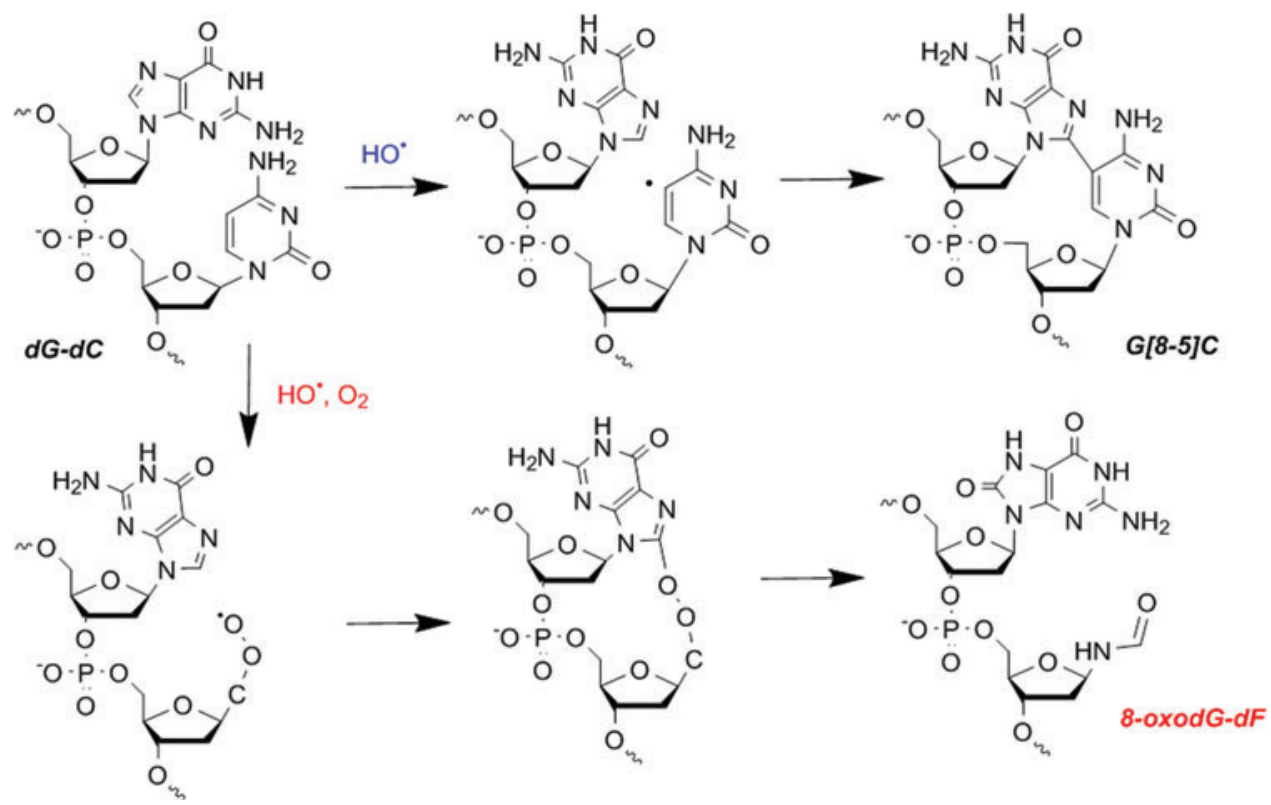

FIG. 4. Mechanisms of formation of complex DNA lesions (including tandem 8-oxodGuo-dF lesions and G[8-5]C intrastrand crosslinks) at dG-dC sequences mediated by a single oxidation event. After $\mathrm{HO}^{\bullet}$ reaction on the cytosine base, in the absence of oxygen, the produced radical can react with an adjacent guanine base, thus producing a G[8-6]C intrastrand crosslink. On the contrary, in the presence of oxygen, the cytosine radical is trapped by molecular oxygen, thus producing a peroxyl radical. This peroxyl radical can react with an adjacent purine base, thus generating an unstable endoperoxide that, on decomposition, gives rise to tandem lesions constituted of two adjacent oxidative DNA lesions. To see this illustration in color, the reader is referred to the web version of this article at www.liebertpub.com/ars

strongly depend on its environment. The fact that carboncentered radicals can react efficiently with molecular oxygen provides a partial explanation for the well-known oxygen enhancement effect, observed in radiation biology. As illustrated in Figure 4, the DNA lesions generated in the absence of oxygen could be different from those created in oxic conditions. Low oxygen concentration could indirectly increase the lifetime of the initially produced radicals, thus favoring the possibility of radical recombination and ultimately decreasing the amount of radiation-induced DNA lesions (250). In addition, the increased lifetime of radicals could also promote repair, for example, by electron donation from mild reducing amino acids (193) or antioxidant molecules that could be used as radioprotectors (192).

This could provide a possible explanation for the reduced level of lesions produced under hypoxic or anoxic conditions (154). Nevertheless, increasing the lifetime of a radical could also favor its reaction with other cellular constituents, leading to the generation of more complex DNA lesions that could compromise DNA repair (154). Indeed, the presence of polyamines, which are highly concentrated in the nucleus of eukaryotic cells, or of a nucleophilic amino acid could lead, respectively, to the formation of DNA adducts (285) and DNA-protein crosslinks (206). These DNA damage types are repaired less efficiently than single lesions (19). These examples illustrate the complexity of the chemical reactions that can occur in cellular DNA following exposure of cells to ionizing radiation (47) and that can vary in oxic and hypoxic conditions.

Although the literature on damage to mitochondrial DNA (mtDNA) is less abundant, mtDNA also is affected by irradiation (358), and additional work is needed to better un- derstand the consequences of this damage (143). This is also true for the nucleotide pool (110) and RNA that are more sensitive to oxidative stress (126) than DNA, which is compacted and protected within the nucleus.

\section{B. Effects of irradiation on lipids}

The lipid layer of cell membranes is also a radiation target $(59,296)$. Damage to lipids is mediated by ROS reaction with polyunsaturated fatty acids (PUFA) (209). The initial step involves the abstraction of the bisallylic position of PUFA (Fig. 5A) either by $\mathrm{HO}^{\bullet}$ or mediated by a thiyl radical ( $\mathrm{RS}^{\bullet}$ ). The produced carbon-centered radical is converted into a peroxyl radical after reaction with molecular oxygen at a diffusion-controlled rate. Then, the peroxyl radical can abstract a hydrogen atom from another PUFA, inducing the socalled peroxidation reactions (271). Decomposition of the hydroperoxide generates breakdown molecules that contain reactive carbonyl groups, such as malondialdehyde (MDA), acrolein, and 4-hydroxy-2-nonenal (4-HNE). These decomposition products could be used as markers of lipid peroxidation reactions. Moreover, if they are not trapped by the cellular defenses (particularly glutathione [GSH]), they could generate secondary decomposition products because they can react with cellular biomolecules (e.g., DNA, RNA, and also amino acids) to generate adducts.

Lipid peroxidation can cause various biological effects: increase in membrane permeability, disruption of ion gradients and transmembrane processes, as well as alteration of the activity of membrane-associated proteins. Besides peroxidation reactions, irradiation could also induce cis to trans 


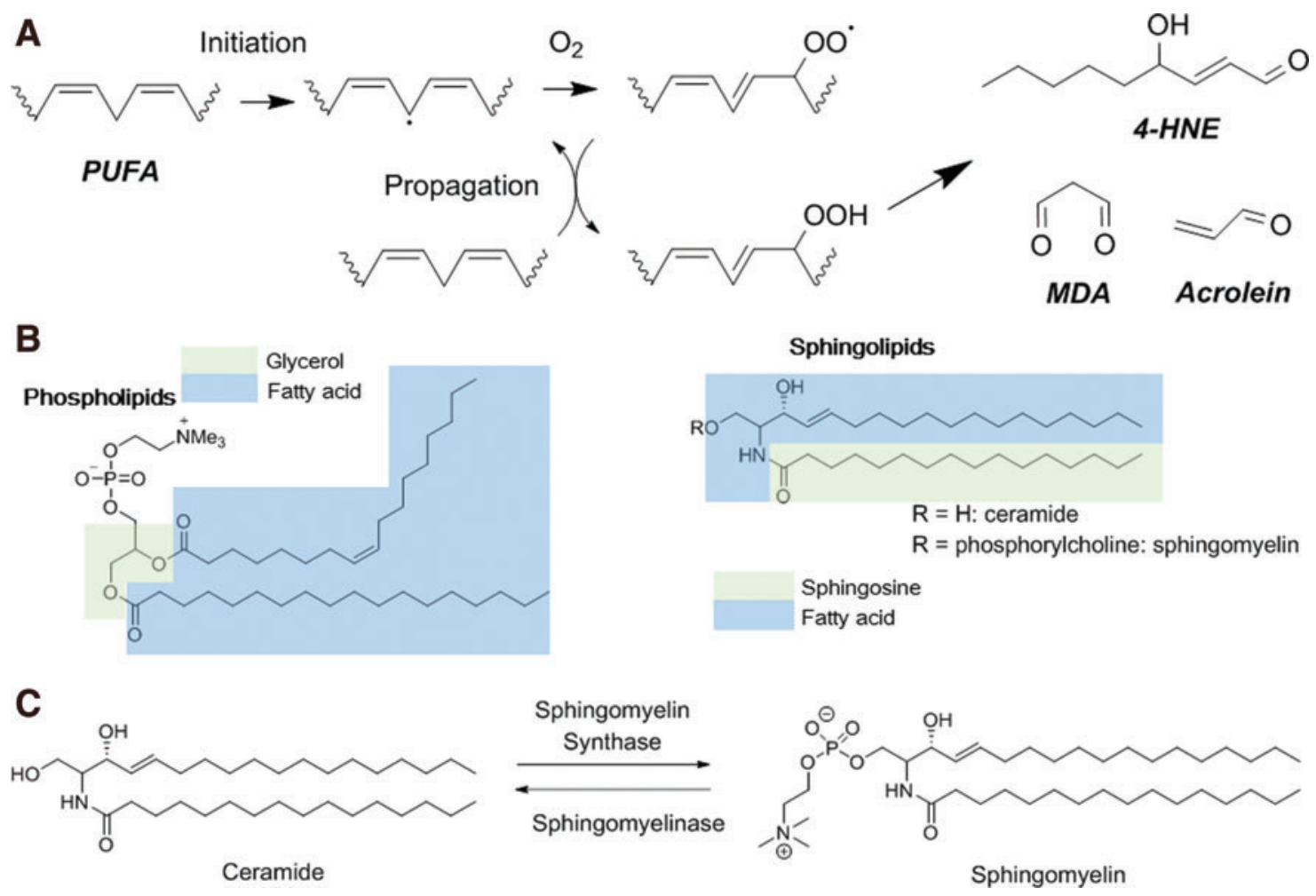

FIG. 5. Radiation-induced lipid peroxidation and sphingolipids. (A) Lipid peroxidation and formation of PUFA decomposition products. (B) Phospholipids contain two hydrophobic long-chain fatty acids linked to an alcohol (usually glycerol) and a hydrophilic group made of a phosphate group. Similarly, sphingolipids contain a long-chain sphingoid base (such as sphingosine) linked via an amide to long-chain fatty acids, and to one polar head group that makes them amphipathic molecules. Head groups differentiate sphingolipids from ceramides (phosphorylcholine constituting SM and hydroxyl group, respectively). (C) Irradiation induces rapid formation of ceramide through the hydrolysis of SM by ASMase. 4-HNE, 4-hydroxy-2-nonenal; ASMase, acid sphingomyelinase; MDA, malondialdehyde; PUFA, polyunsaturated fatty acids; SM, sphingomyelin. To see this illustration in color, the reader is referred to the web version of this article at www.liebertpub.com/ars

isomerization of PUFA (191), thus affecting the cellular membrane fluidity (194).

It has been clearly shown that the sphingolipid metabolism is altered following exposure to ionizing radiations. Sphingolipids are one of the four major lipid constituents of the cell membrane, in addition to phospholipids, sterols, and glycolipids. Irradiation induces rapid formation of ceramide through the hydrolysis of sphingolipid hydrolases and the concomitant decrease of sphingomyelin at the plasma membrane. Ceramide could be considered a second messenger that not only has an effect on the plasma membrane but also on intracellular signaling molecules (59).

\section{Protein damage}

An indirect evidence that ionizing radiations do not target only DNA but also highly abundant proteins is given by the effects of irradiation directed to the cytoplasm (353). The effects observed for doses as low as $1 \mathrm{~Gy}$ are changes in protein expression and activity that are mostly mediated by posttranscriptional modifications (302) and also by chemical modifications, including oxidation or carbonylation $(255,295)$.

Like for DNA, a considerable amount of work has been done to determine the reactivity of amino acids with radicals produced by irradiation (295). Due to its fast and high reactivity, $\mathrm{HO}^{\bullet}$ can react with all amino acids with a reaction rate between $10^{7}$ and $10^{10} M^{-1} \mathrm{~s}^{-1}$. With proteins, the reaction depends mostly on $\mathrm{HO}^{\bullet}$ accessibility to amino acids, used for hydroxyl radical footprinting by mass spectrometry to detect structural changes in protein conformation (130). The main reaction pathway involves hydrogen attraction to produce $\alpha$ carbonyl radicals. Such radicals react with molecular oxygen at a diffusion-controlled rate to produce the corresponding peroxyl radicals that further decompose, inducing fragmentation of the protein backbone. Hydrogen atom abstraction could also occur on the aliphatic chain of amino acids. Similar to what observed for lipids, following the reaction with molecular oxygen, the generated protein hydroperoxides could also induce chain reactions in proteins, leading to a greater loss of amino acids than for the initially formed radical (65). $\mathrm{HO}^{\bullet}$ reaction with aromatic amino acids occurs by addition onto the aromatic ring. Addition onto tyrosine (Tyr) residues produces the phenoxyl radical that could induce the formation of tyrosine dimers, involved in the formation of intra- or interprotein crosslinks. Cysteine residues have the lowest redox potential among amino acids; therefore, oxidation of their thiol groups is the major modification. Two-electron oxidation of these residues generates sulfenic acid as the initial cysteine oxidation product that may be converted to disulfides by GSH. Disulfides could be converted back to thiols by disulfide reductases. If not trapped by endogenous thiols, sulfenic acid can be oxidized to generate sulfinic and sulfonic acid. 
In addition to oxidation, proteins could also be modified by reduction, through reductant species produced by irradiation (i.e., $\mathrm{e}_{\mathrm{aq}}{ }^{-}$and $\mathrm{H}^{\bullet}$ ). These reductant species react mostly with thiol groups, and the reaction of $\mathrm{H}^{\bullet}$ with methionine generates a sulfuranyl radical that decomposes to produce a carboncentered radical. The latter is the precursor of homoserine. $\mathrm{H}^{\bullet}$ could also abstract a hydrogen atom and reduce cysteine to produce a thiyl radical. Methionine reaction with $\mathrm{e}_{\mathrm{aq}}{ }^{-}$induces a deamination reaction that causes a peptide break. In addition, $\mathrm{e}_{\mathrm{aq}}{ }^{-}$reaction with cysteine generates hydrosulfide ions and an alkyl radical, whereas reaction with disulfides produces a thiyl radical and a thiolate ion. Reactive aldehydes, derived from lipid peroxidation, also can react with proteins, mostly with the nucleophilic moieties of amino acids in proteins (209) or DNA bases (25) to generate adducts and crosslinks.

\section{Targeted effects: conclusions}

It is now very well documented that irradiation damages cellular biomolecules, such as DNA, RNA, proteins, and lipids. Most of the decomposition reactions of biomolecules mediated by ROS produced during irradiation have been identified. However, the complexity of the cellular media and the possible reaction of transiently produced radicals with the surrounding molecules lead to a great variety of cellular processes induced by radiation that makes almost impossible their precise description/identification. This is a matter of concern for DNA lesions and it cannot be totally excluded that not yet identified lesions are produced in cells exposed to ionizing radiation. The most harmful lesions are not necessarily those produced in higher yields, such as base lesions or SSBs that can be repaired rapidly and with high fidelity. Radiation-induced lesions are not different from those produced by endogenous oxidative stress. However, due to their special distribution in clusters, which hampers their repair, they can be very harmful for the cells.

\section{Nuclear-Centered View of the Cellular Response to Radiation}

While SSBs and base damages are efficiently repaired by SSB repair (SSBR), base excision repair (BER), and nucleotide excision repair (NER), DNA DSBs and clustered DNA lesions in general are mainly responsible for the final cellular outcome on irradiation (269).

\section{A. DNA DSB repair}

DNA DSBs are detected by surveillance proteins of the phosphatidylinositol-3-kinase (PI3K)-like kinase family, particularly the serine/threonine protein kinase ataxiatelangiectasia mutated (ATM), which is the main sensor of DNA damage, and ATM- and Rad3-related (ATR) protein (Fig. 6) $(185,231,282)$. Both are actively recruited to DNA DSB sites to monitor the DNA damage response (DDR).

DDR is activated to avoid the transmission of erroneous genetic information to daughter cells and to protect cells from deregulated metabolism. It includes mechanisms involved in DNA damage detection, signaling, and repair, when possible (135), or in the initiation of programmed cell death or senescence.
ATM activation is mediated via autophosphorylation on serine 1981 (a hallmark of activated human ATM); however, three additional autophosphorylation sites have been identified as well as a TIP60-mediated acetylation site [for review (282)] (Fig. 6). ATM activation leads to dissociation of ATM homodimers into monomers that will phosphorylate and activate downstream protein kinases. These molecules will act as transducers and effectors and in turn phosphorylate their own substrate(s). One of the first identified targets of ATM phosphorylation was p53 that plays a central role in the radiation response. In physiological conditions, p53 has a short half-life and is maintained at low levels by continuous ubiquitination catalyzed by mouse double minute 2 homologue (MDM2). Upon phosphorylation, p53 is stabilized and accumulates and can activate proteins such as p21 involved in cell cycle arrest by acting on cyclin-dependent kinases (CDK). G1-S, intra S, and G2-M arrest give time for the cells to repair lesions before entering mitosis. Moreover, p53 participates in the activation of the intrinsic apoptosis pathway, for instance, by activating proapoptotic molecules of the BCL2 family, such as p53 upregulated modulator of apoptosis (PUMA) that is involved in the release of proapoptotic factors (BAX/BAK) (Fig. 6). Therefore, p53 activity can drive the final outcome of irradiated cells toward DNA repair or apoptosis via a mitochondria-mediated cell death process.

However, ATM full activation requires the recruitment of the MRE11-RAD50-NBS1 (MRN) complex at DNA DSB sites before induction of the DDR systems (nonhomologous end-joining [NHEJ], and homology-directed repair, HDR). The MRN complex also is phosphorylated by ATM. This complex forms a bridge between DNA ends. Then, its nuclease activity, mediated by the nuclease MRE11, resects DNA DSB ends, a crucial step for homologous recombination repair (HRR) (282). Moreover, interaction between NBS1 and ATM is essential for maintaining ATM at DSB sites. Breast cancer type 1 (BRCA1) and p53-binding protein 1 (53BP1) are involved in this interaction. ATM also interacts with a mediator of DNA damage checkpoint protein 1 (MDC1) $(170,185,231,282)$. MDC1 is a DNA damage sensor protein located at DSB sites where it binds to phosphorylated histone $\mathrm{H} 2 \mathrm{AX}(\gamma \mathrm{H} 2 \mathrm{AX})$ and ATM. Additional $\mathrm{H} 2 \mathrm{AX}$ phosphorylation by ATM allows the recruitment of more MDC1 molecules that bind to ATM and $\gamma \mathrm{H} 2 \mathrm{AX}$ in a positive feedback loop, leading to ATM and $\gamma \mathrm{H} 2 \mathrm{AX}$ spread over large domains $(>500 \mathrm{~kb})$ around DNA breaks and amplification of DNA DSB signaling (136, 170, 185, 231, 282).

Other ATM substrates are proteins involved in G1-S (p21), intra-S (Fanconi anemia group D2 protein [FANCD2], BRCA1, and structural maintenance of chromosomes protein 1 [SMC1]), and G2-M cell cycle arrest (checkpoint kinase 2 [CHK2] or DNA repair [poly(ADP-ribose) polymerase 1 (PARP1), the nuclease Artemis, C-terminal-binding protein 1interacting protein (CtIP), DNA-dependent protein kinase (DNA-PK) cs84, polynucleotide kinase 3'-phosphatase, DNA-PK, and AKT]. These factors allow DNA repair according to the NHEJ pathway before replication and mitosis $(147,163)$. ATM is also activated and dissociated into monomers by ROS via TIP60 acetylation near the FRAP-ATMTRRAP C terminal (FATC) domains. Moreover, H2AX phosphorylation, sumoylation, and ubiquitination at DSB sites participate in the recruitment of BRCA1 and 53BP1, two 


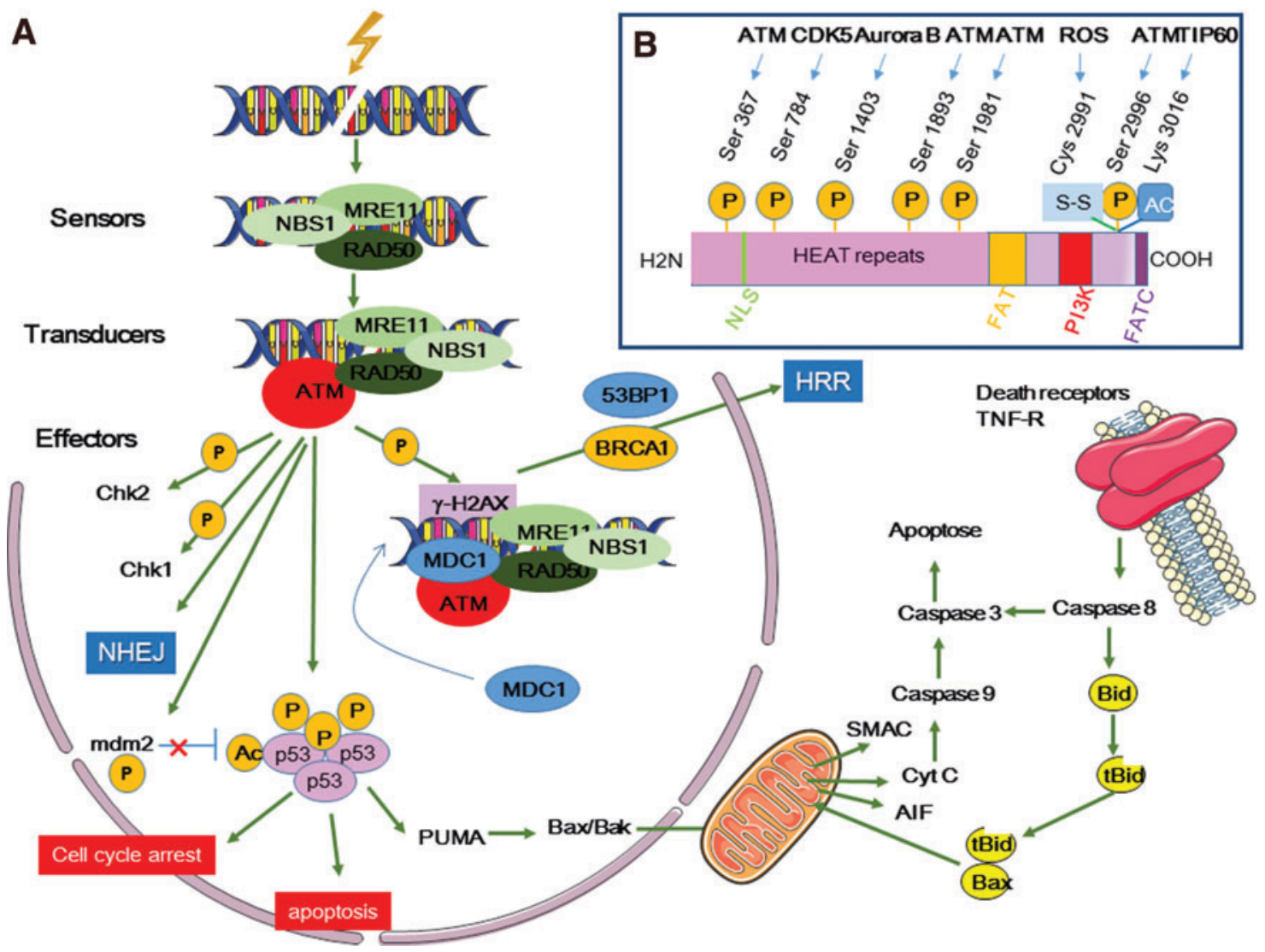

FIG. 6. DNA damage-mediated activation of ATM signaling pathways. (A) The DNA damage repair mechanism includes sensors, transducers, and effectors. Sensors, such as the MRN complex, recognize the DNA structure modifications induced by DNA DSBs. Transducers are ATM (and ATR involved in HRR) PI3K involved in phosphorylation of many effector proteins that control cell cycle progression (CHK1 and CHK2), DNA repair (via, for instance, NHEJ mechanisms), and apoptosis. The intrinsic apoptotic signaling pathway relies on p53 stabilization, followed by PUMA transcription and BAX activation. MDM2 ubiquitin ligase activity plays a central role in keeping a low p53 concentration in non-ATMactivated cells. On ATM activation, MDM2 ubiquitin ligase activity is inhibited and p53 stabilized. PUMA frees the proapoptotic BAX/BAK proteins (members of the BCL2-family) that can transfer to mitochondria where they promote cytochrome C, AIF, and SMAC release and further activation of caspases. In the extrinsic apoptotic signaling pathway, death receptor (TNF-R, TRAIL-R, and FAS) activation leads to BID cleavage by caspase 8 and further release of cytochrome C. ATM-mediated phosphorylation of H2AX triggers recruitment of MDC1, which in turn recruits more MRN complexes and activated ATM to the damaged chromatin. This promotes H2AX phosphorylation and spreads ATM and H2AX phosphorylation over a large chromatin domain. (B) ATM structure. ATM is a $350 \mathrm{kDa}$ protein (3056 amino acids) and a member of the PIKK family. It includes HEAT repeats, FAT, PI3K, and FATC domains. The HEAT repeats allow NBS1 binding. Post-translational modifications include autophosphorylation (at Ser 1981, Ser 367, Ser 1893, Ser 2996) and TIP 60 acetylation at Lys 3016 (170, 185, 231, 282). 53BP1, p53-binding protein 1; AIF, apoptosis-inducing factor; ATM, ataxia-telangiectasia mutated; ATR, ATM- and Rad3-related; BID, BH3 interacting-domain death agonist; BRCA1, breast cancer type 1; CHK1, checkpoint kinase 1; CHK2, checkpoint kinase 2; FAT, FRAP-ATM-TRRAP; FATC, FAT Cterminal; HEAT, Huntington-elongation factor 3-protein phosphatase 2A-TOR1; HRR, homologous recombination repair; MDC1, mediator of DNA damage checkpoint protein 1; MDM2, mouse double minute 2 homologue; MRN, MRE11RAD50-NBS1; NHEJ, nonhomologous end joining; PI3K, phosphatidylinositol-3-kinase; PIKK, phosphatidylinositol 3kinase-related kinase; PUMA, p53-upregulated modulator of apoptosis; SMAC, second mitochondria-derived activator of caspases; TNF, tumor necrosis factor; TRAIL, TNF-related apoptosis-inducing ligand. To see this illustration in color, the reader is referred to the web version of this article at www.liebertpub.com/ars

proteins involved in HRR promotion and repression, respectively $(135,141,142,185)$.

ATR recognizes DSBs, but can also be activated by many other DNA damage types. ATR is mainly involved in DNA DSB repair via HRR that requires duplicated DNA and occurs in S-phase cells with stalled replication forks or after the G2 phase. ATR recruitment requires single-strand DNA, as observed following DNA DSB end resection by nucleases that are phosphorylated by ATM (e.g., CtIP and exonuclease 1 [EXO1]). Then, there is a progressive switch from the ATM to the ATR signaling cascade. ATR phosphorylates checkpoint kinase 1 (CHK1) that is critical for the intra-S and G2-M checkpoint response and that phosphorylates BRCA1 to trigger HRR (185).

According to this school of thought, DNA DSBs are the central lesions on irradiation and their formation, repair, or 
nonrepair influences the cellular outcome through complex interplays between cell death and survival signals.

\section{B. Nuclear-centered view of the cellular response to radiation: conclusion}

DDR includes a complex network of proteins activated by DNA lesions, mainly DSBs, produced in irradiated cells. ATM/ATR and MRN play a major role in DDR by recruiting proteins involved in DNA lesion detection and repair, in cell cycle progression, and in cell metabolism (e.g., CHK1, CHK2, p53, BRCA1). However, accumulating evidence indicates that DNA lesions and DDR activation can also be observed in nonirradiated cells close to irradiated cells. This suggests that DDR is transmitted or initiated in these cells (151). We see below (in section IV.A) that the DDR response, specifically
ATM, activates the p38 and c-JUN N-terminal kinase (JNK) mitogen-activated protein kinase (MAPK) pathways and also nuclear factor-kappa B $(\mathrm{NF}-\kappa \mathrm{B})$ that participates in intercellular signaling.

\section{Off-Target Effects: An Integrated Cell Response to Radiation}

According to the United Nations Scientific Committee on the Effects of Atomic Radiation (UNSCEAR) 2006 report, "bystander effect" is "the ability of irradiated cells to convey manifestations of damage to neighboring cells not directly irradiated," and "abscopal effect" is "a significant response in a tissue that is physically separate from the region of the body exposed to radiation" (314). Similarly, the International Commission on Radiological Protection describes

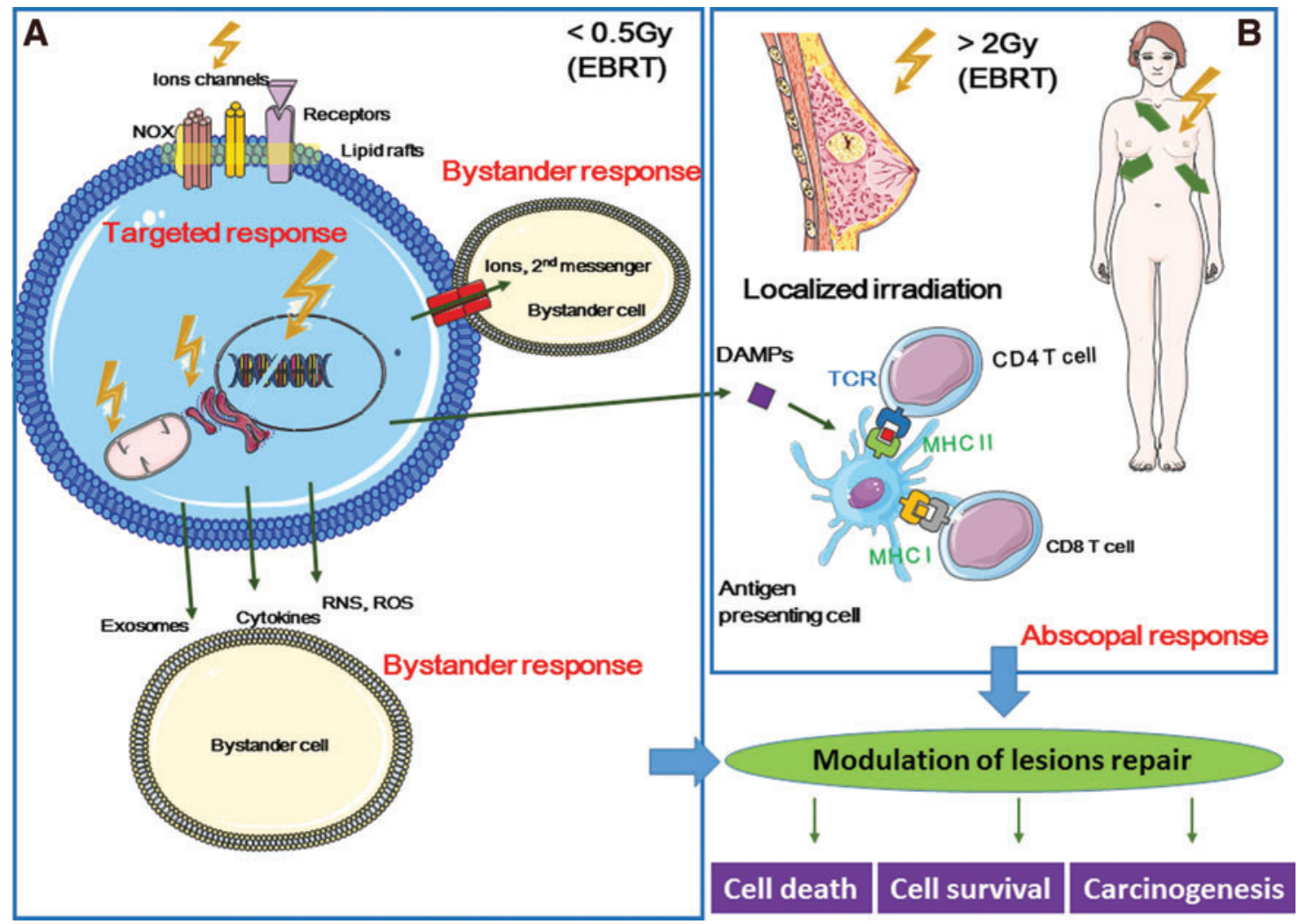

FIG. 7. Schematic representation of the bystander and abscopal responses. Targeted effects are observed only in irradiated cells, while nontargeted effects are observed in nonirradiated cells. Nontargeted effects include bystander and abscopal responses. (A) Radiation-induced targeted effects concern (i) nuclear DNA and extranuclear targets, (ii) mtDNA, $\mathrm{Ca}^{2+}$-mediated mitochondrial production of ROS and RNS, (iii) ER, as a $\mathrm{Ca}^{2+}$ storage place, and (iv) cell membrane, as the site of ion channels, NADPH oxidase, growth factor and death receptor localization, lipid peroxidation leading to 4-HNE or MDA production, and production of ceramide that acts as a second messenger or is involved in ceramide-enriched large platforms (lipid rafts). Bystander effects are observed in neighboring cells (in contact or not with the irradiated cells) that have not been crossed by ionizing particles. Intercellular cross talk is mediated by gap junctions (GJIC) or through the release of soluble factors, including cytokines, ROS, and RNS. Exosomes containing mRNA, microRNA, and DNA can also be released. (B) Abscopal effects are observed at long distance from the irradiation site (e.g., localized breast irradiation). Consequently, the biological effects must be investigated at the whole-body scale. Abscopal effects may involve the immune system through the release of DAMPs that are recognized by antigen-presenting cells (e.g., dendritic cells that will present antigenic peptides to CD4 and CD8 T lymphocytes for immune response activation). The cell response to targeted and nontargeted effects can result in cell death, cell transformation, or cell survival and these possible outcomes have to be taken into account in the field of cancer therapy and radiation protection. 4-HNE, 4-hydroxy-2-nonenal; DAMPs, damage-associated-molecular-patterns; EBRT, external beam radiotherapy; ER, endoplasmic reticulum; GJIC, gap junction intercellular communication; mtDNA, mitochondrial DNA; NAD $(\mathrm{P}) \mathrm{H}$, nicotine adenine dinucleotide phosphate; NOX, NAD $(\mathrm{P}) \mathrm{H}$ oxidase; RNS, reactive nitrogen species. To see this illustration in color, the reader is referred to the web version of this article at www.liebertpub.com/ars 
the bystander effect of radiation as the transmission of signals from irradiated to nonirradiated cells in a cell population, leading to biological changes in the recipient cells (133a, 307) (Fig. 7).

Off-target effects also include induced genomic instability. This is the delayed and stochastic appearance of genomic alterations (chromosomal aberrations, gene mutations, and reproductive cell death) in the offspring of irradiated (and also of bystander) cells, although these daughter cells were not irradiated (198, 199, 200, 201).

During the last 25 years, many studies have investigated the molecular mechanisms underlying off-target effects. They showed that off-target effects are the results of a huge dynamic and integrated process initiated in irradiated cells and transmitted to neighboring cells and to some extent to the whole organism through the activation of the immune system.

\section{A. Bystander effects}

Although off-target effects were first described by Parsons in 1954 (202), Nagasawa and Little performed one of the key early studies that highlighted the need to rethink radiobiology by also considering bystander effects. They used very low mean doses of alpha particles $(0.31 \mathrm{mGy})$ to demonstrate that although $<1 \%$ of cell nuclei were actually hit by radiation, $30 \%$ of cells showed an increased frequency of sister chromatid exchanges (205). Since then, many in vitro and in vivo studies on bystander effects (usually detrimental for the cells) have been performed using different radiation types (low $v s$. high LET) $(7,131,272,278)$, different cell types (normal and tumor cells) $(74,173,177)$ and culture systems (twodimensional and 3D cell cultures) (238), and different animal models (mammals, fish) $(16,153,183,292,331,339)$. Bystander effects were observed for different biological endpoints, such as cell death, apoptosis (166, 179), gene mutations (131, 357), cell differentiation (15), radiationinduced adaptive responses (RIARs) $(11,223)$, senescence (239), cell cycle distribution, gene expression, chromosomal aberrations, and genomic instability (173, 198-200).

These studies showed that bystander effects depend on the radiation dose, dose rate, and LET (104). They proposed that the contribution of bystander effects to radiation-induced biological effects in conventional external beam radiotherapy (EBRT) and also in therapies using heavy ions, protons, or radionuclides $(5,23,31,222,227,228,339)$ should be taken into account for future applications.

Many cellular components and functions contribute to the extranuclear response to radiation. They include ceramide production and lipid raft formation (111), tyrosine kinases such as epidermal growth factor receptor (EGFR) (270), cytoplasmic $\mathrm{Ca}^{2+}$ homeostasis mechanisms (304), protein kinase C (PKC), MAPKs, JNKs (297), phospholipase C (PLC), NF- $\kappa$ B-mediated cyclooxygenase-2 (COX-2) and nitric oxide (NO) synthase (NOS) activation, and cytokines.

Approaches for investigating bystander effects rely on conventional broadbeam and microbeam irradiation to selectively irradiate a single cell or its subcompartments while sparing neighboring cells, or on the transfer of conditioned culture medium from irradiated to nonirradiated cells. The main evidence for extranuclear radiation-induced effects came from cytoplasmic irradiation using microbeams (53, 276, 335). Moreover, Gaillard et al. showed that depending on the redox status of the irradiated cells, cytoplasm irradiation by particles could also result in nuclear damage at the origin of bystander signals (90).

ROS and reactive nitrogen species (RNS) initiate events in targeted cells and also participate in their propagation through self-sustained production, leading to similarities between bystander effects and inflammation/immune response. Indeed, the so-called damage-associated-molecular-patterns (DAMPs) released by irradiated tissue can be detected by the innate immune system, as observed for pathogen-associated molecular patterns. Released factors are then recognized by Toll-like receptors (TLRs), C-type lectin receptors, nucleotide binding oligomerization domain-like receptors, and cytosolic retinoic acid-inducible gene-like receptors (151) that are expressed at the surface of immune cells.

1. Intercellular communications between irradiated and nonirradiated cells. Bystander effects involve signaling from irradiated cells to nonirradiated cells. The nature of the communications between irradiated and nonirradiated cells depends on whether cells are in contact or not. This cross talk can be mediated by paracrine secretion in the extracellular space of soluble factors via hemichannels formed by the transmembrane protein connexins (Cxs) and pannexins (Panxs) $(182,327)$. Cxs and Panxs are members of the tetraspan family in which proteins are classified according to their molecular weight $(25-62 \mathrm{kDa}$ for Cxs and $1-3 \mathrm{kDa}$ for Panxs). These proteins allow the passage of ions $\left(\mathrm{Ca}^{2+}, \mathrm{Na}^{+}\right)$ and of low-molecular-weight molecules (nicotinamide adenine dinucleotide, ATP, glutamate, GSH, prostaglandin E2 [PGE2] and inositol trisphosphate $\left[\mathrm{IP}_{3}\right]$ ) between the intraand extracellular environment, thus controlling autocrine and paracrine signaling $(68,327)$. The role in bystander effects of Cx43, the most abundant Cx in mammals, was identified very early and has been largely investigated (9).

Cxs and Panxs can also form full channels that are called gap junctions and mediate gap junction intercellular communication (GJIC). These intercellular channels show much higher selectivity and allow direct diffusion of factors between the cytoplasm of adjacent cells. The factors involved in bystander effects and transiting through intercellular gap junctions are small molecules $(<1.5 \mathrm{kDa})$ and include ROS (9, 10), RNS (187), ions $\left(\mathrm{Ca}^{2+}, \mathrm{K}^{+}, \mathrm{Na}^{+}\right),(178,279)$, lipid peroxides (83), ATP (221), cyclic adenosine monophosphate (cAMP), glucose, glutamate, and GSH. As hemichannels are less selective than full gap junctions, it has been suggested that in normal conditions only GJIC plays a role. Conversely, in conditions of oxidative stress (e.g., on irradiation), both channel types might be involved $(224,279)$.

2. Reactive oxygen and nitrogen species initiate and propagate bystander effects. Early experiments highlighted the multiple roles of ROS and RNS in bystander effects. Specifically, they showed that radical scavengers (ascorbic acid, N-acetyl L-cysteine), NOS inhibitors (NGnitro-L-arginine methyl ester [L-NAME]), NO scavenger (2-4carboxyphenyl-4,4,5,5-tetramethylimidazoline-1-oxyl-3-oxide [c-PTIO] (281), antioxidant enzymes (superoxide dismutase [SOD], catalase) (10, 303), and DNA-binding antioxidants (methylproamine) (39) inhibit the appearance of bystander effects. For example, genomic instability due to bystander effects can be rescued by restoring mitochondrial function through 


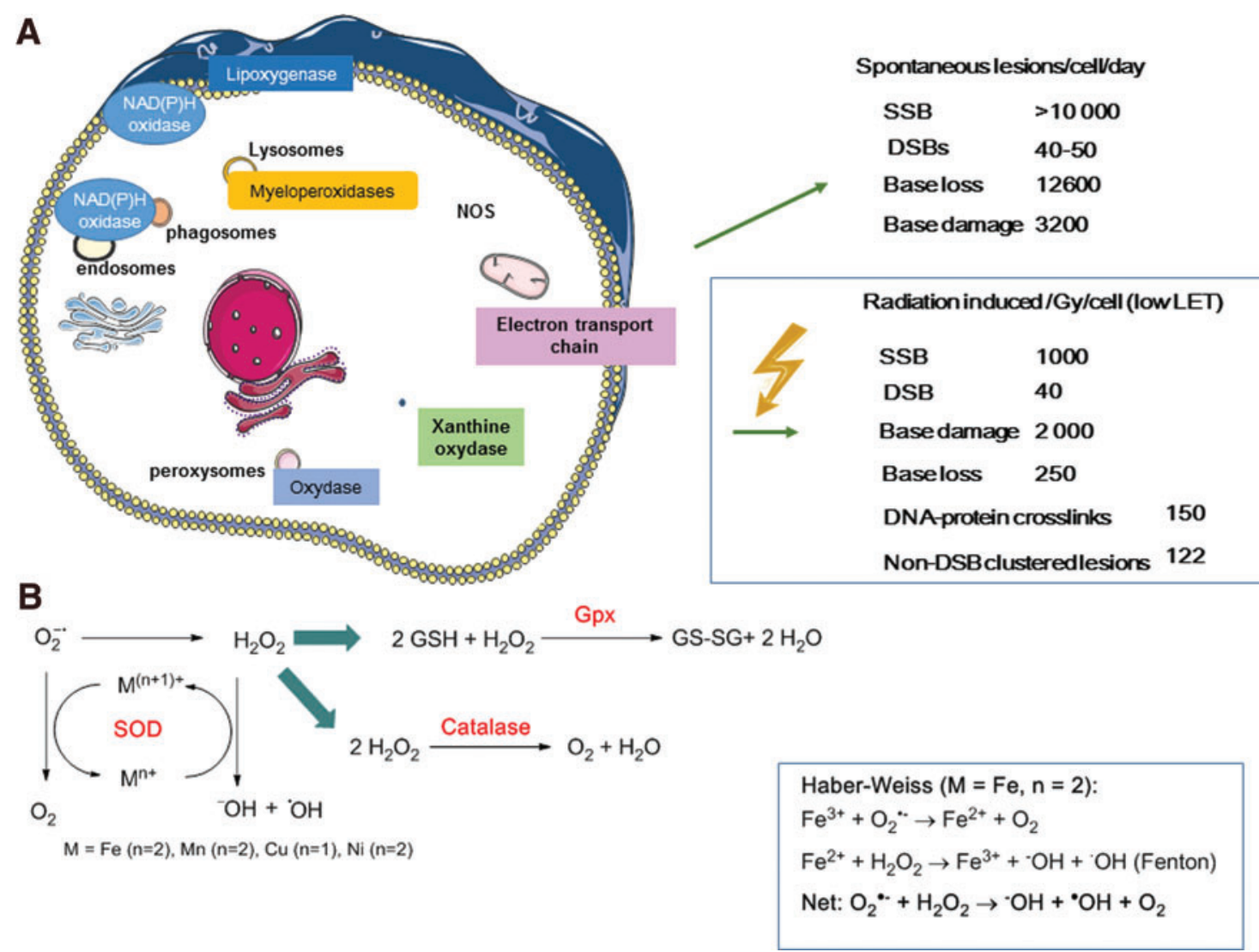

FIG. 8. Endogenous sources of ROS and enzymatic antioxidant defenses. (A) $\mathrm{O}_{2}^{-\bullet}$, hydroxyl radical $\left(\mathrm{HO}^{\bullet}\right)$, and $\mathrm{H}_{2} \mathrm{O}_{2}$ are produced by endogenous sources that reduce $\mathrm{O}_{2}$. The main sources are mitochondria through ATP production and oxidative (oxygenase, dehydrogenase, oxidase) enzymes, such as $\mathrm{NAD}(\mathrm{P}) \mathrm{H}$, and xanthine oxidase, lipoxygenase, myeloperoxidase. Oxygenase enzymes (e.g., lipoxygenase) oxidize substrates by transferring one electron, while oxidizing a cofactor $[$ e.g., $\mathrm{NAD}(\mathrm{P}) \mathrm{H}]$ in the presence of oxygen. Dehydrogenases use organic substrates as an electron acceptor (e.g., quinones, $\mathrm{NAD}^{+}$). Oxidases just use $\mathrm{O}_{2}$ as an electron acceptor. The yield of radiation-induced DNA lesions (/Gy/cell) is rather low compared with that produced by endogenous stress [averaged values from Goodhead (102), Pouget et al. (241, 245), Sage and Shikazono (262), and Ward (329)]. (B) Superoxide can be dismuted into $\mathrm{H}_{2} \mathrm{O}_{2}$ by the action of superoxide dismutase enzymes that possess a metal transition ion $\left(\mathrm{Mn}^{3+}, \mathrm{Cu}^{2+}, \mathrm{Fe}^{3+}\right.$, or $\left.\mathrm{Ni}^{3+}\right)$ to catalyze the reaction. In the presence of $\mathrm{M}^{(\mathrm{n})+}$ metal ions, the resulting $\mathrm{H}_{2} \mathrm{O}_{2}$ can be broken down into $\mathrm{HO}^{\bullet}+\mathrm{OH}^{-}$and $\mathrm{M}^{(\mathrm{n}+1)}$, according to the Fenton reaction. The latter reaction can also be mediated by catalase and GPx $(22,76,80)$. GPx, glutathione peroxidase; NOS, nitric oxide synthase; SOD, superoxide dismutase. To see this illustration in color, the reader is referred to the web version of this article at www.liebertpub.com/ars

overexpression of manganese-dependent superoxide dismutase (MnSOD) (103).

Oxidative processes that involve ROS and RNS continuously occur in cells because at low concentrations (0.01$0.001 \mathrm{n} M$ for $\mathrm{O}_{2}^{-\bullet}$ and $1-100 \mathrm{n} M$ for $\mathrm{H}_{2} \mathrm{O}_{2}$ ), these molecules contribute to essential cellular functions (Fig. 8). At higher concentrations, they could be involved in the defense mechanisms against pathogens and they cause endogenous oxidative damage (22). It is thought that between ten and fifty DNA DSBs are produced per cell each day due to natural ionizing radiation, ROS, DNA replication errors, and unintended cleavage by nuclear enzymes $(52,262)$. In the cell, the concentrations of free radicals $\left(\mathrm{O}_{2}^{-\bullet}, \mathrm{HO}^{\bullet}, \mathrm{NO}^{\bullet}\right)$ and nonradical reactive species $\left(\mathrm{H}_{2} \mathrm{O}_{2}, \mathrm{ONO}_{2}\right)$ are controlled by the balance between their production and clearance rates that are regulated by antioxidant compounds and enzymes, such as SOD, glutathione peroxidase (GPx), and catalase, as well as nonenzymatic compounds, such as $\alpha$-tocopherol (vitamin $\mathrm{E}$ ), $\beta$-carotene, ascorbate (vitamin $\mathrm{C}$ ), and the cellular thiol/ disulfide systems that include GSH/GSSH, thioredoxin
(TRX1 [-SH2/-SS-]), and cysteine/cystine. Antioxidants can compete for oxidation with oxidizable substrates (at low concentration) and ultimately delay or inhibit the oxidation of these substrates (114). It must be noted that free amino acids, peptides, and proteins, some of which are present at high concentrations in cells (cysteine, tryptophan, histidine, tyrosine), also act as ROS scavengers (80). Reactions between ROS and redox active amino acid residues (e.g., cysteine) can modulate the activity of transcription factors (AP- $1, \mathrm{NF}-\kappa \mathrm{B}$, and hypoxia-inducible factor 1 [HIF-1]) and enzymes (e.g., protein tyrosine phosphatases, acid sphingomyelinase [ASMase]) (168).

$\mathrm{O}_{2}{ }^{-\bullet}$ is one of the main endogenous cellular ROS compounds (Fig. 8). It is produced by reduction of ground-state molecular oxygen $\left({ }^{3} \mathrm{O}_{2}\right)$ by enzymatic (nicotine adenine dinucleotide phosphate $[\mathrm{NAD}(\mathrm{P}) \mathrm{H}]$, xanthine oxidase) or nonenzymatic (semi-ubiquinone $\mathrm{Q}^{-}$, a compound of the mitochondrial electron transport chain [ETC]) systems (80).

Peroxisomes also contain enzymes, namely D-amino-acidoxidase that contains flavin adenine dinucleotide (FAD) as 
cofactor and urate-oxidase oxidizing substrate by transferring $\mathrm{H}$ to $\mathrm{O}_{2}$, leading to the formation of $\mathrm{H}_{2} \mathrm{O}_{2}$.

$\mathrm{O}_{2}{ }^{-\bullet}$ concentration is also regulated by three SODs, namely the cytoplasmic $\mathrm{Cu}-\mathrm{Zn}$-dependent superoxide dismutase (CuZnSOD or SOD1), the mitochondrial MnSOD (or SOD2), and the extracellular SOD (ECSOD or SOD3), that catalyze $\mathrm{O}_{2}{ }^{-\bullet}$ dismutation into the less reactive $\mathrm{H}_{2} \mathrm{O}_{2}$. This reaction requires reduced transition metals, such as iron or copper ions, and leads to the formation of the precursors of the highly damaging hydroxyl radicals $\left(\mathrm{HO}^{\bullet}\right)$, according to the Fenton reaction (Fig. 8). In cells and in mitochondria, $\mathrm{H}_{2} \mathrm{O}_{2}$ can be decomposed into $\mathrm{H}_{2} \mathrm{O}$ and $\mathrm{O}_{2}$ by GPx, catalase, or peroxiredoxins (Fig. 8).

The initial production of ROS by water radiolysis is limited in time, space, and quantity. If one considers that 2000 ionization events are produced per cell per Gy (for low LET radiation), clinical doses of 2 Gy produce much less ROS than the amount generated during standard cell metabolism (329). For instance, a dose of $1 \mathrm{~Gy}$ would produce $1 \times 10^{3}$ DNA breaks per cell (about 1000 SSBs and 40 DSBs) (102, 241, 245), while endogenous metabolism would produce more than $10 \times 10^{3}$ DNA breaks per day $(262,318)$.
Therefore, radiotherapy efficacy in tumor cells can be partly explained by the amplification and prolongation in time (hours and weeks) of the initial radiation-induced ROS production. This would involve ROS- and RNSmediated activation of signaling pathways and signal transmission to neighboring cells. The main sources of endogenous ROS that participate in this amplification process include mitochondria, $\mathrm{NAD}(\mathrm{P}) \mathrm{H}$ oxidases, and other oxidases, such as xanthine oxidase, lipoxygenases, and peroxisomes (80).

a. Mitochondria-dependent ROS production. Humanhamster hybrid AL cells with normal $\left(\rho^{+}\right)$or depleted $\left(\rho^{0}\right)$ mtDNA were used to demonstrate the contribution of mitochondrial functions in the generation of bystander signals from irradiated cells $(53,127,355)$.

(1) Mitochondria and ROS endogenous production. Mitochondria produce energy through the oxidative metabolism of carbohydrates, lipids, and amino acids that generate NADH via the ETC. They are also in charge of different metabolic processes, such as the synthesis of heme,

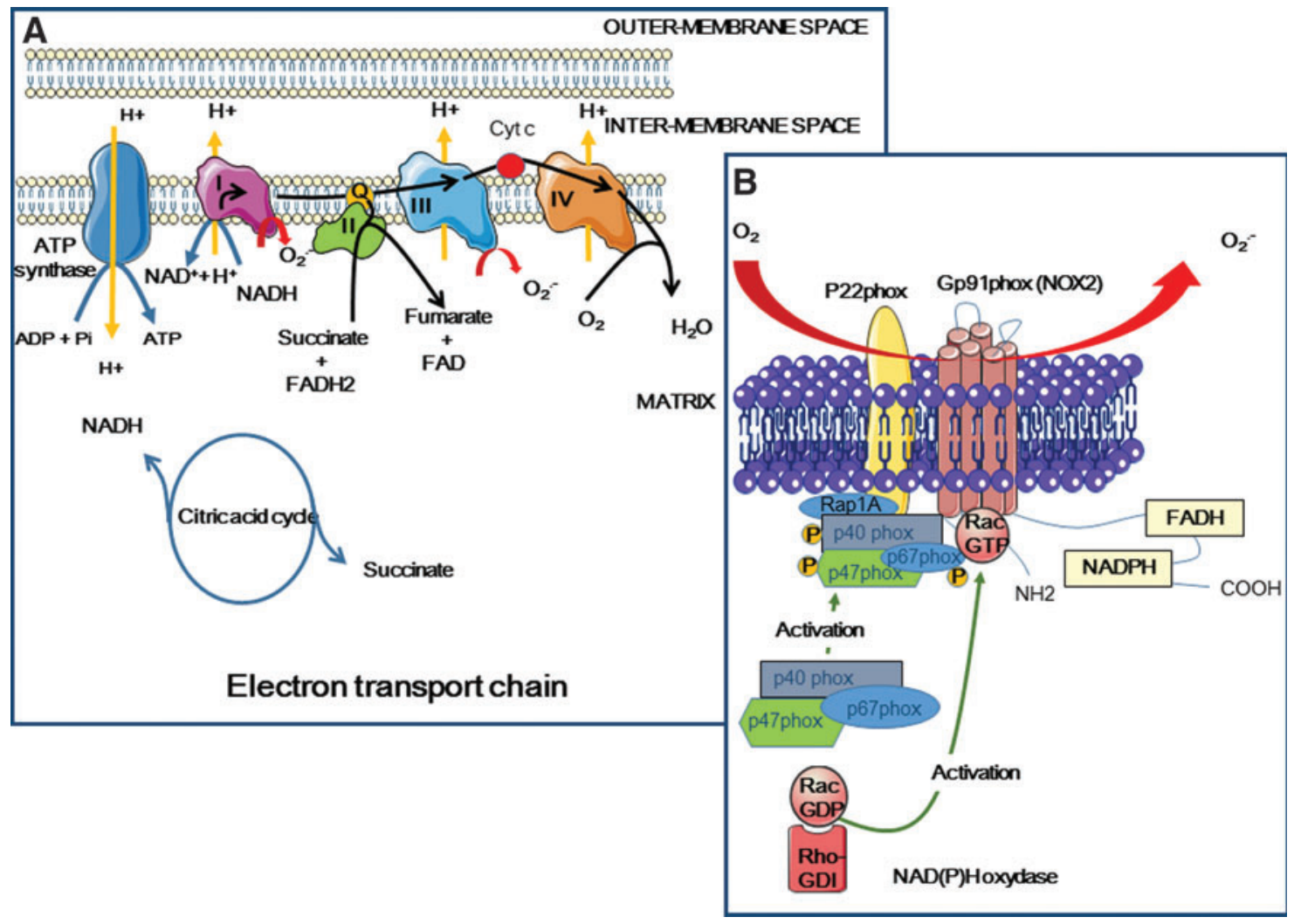

FIG. 9. Mitochondrial electron transport chain and NAD(P)H oxidase as endogenous source of ROS. (A) NADH and succinate produced during the citric acid cycle are used as electron donors for ATP synthesis by the ETC. ETC consists of complex I (NADH coenzyme Q reductase), complex II (succinate dehydrogenase coenzyme Q), complex III (coenzyme $\mathrm{Q}$ cytochrome $\mathrm{C}$ reductase), and complex IV (cytochrome C oxidase). The final acceptor molecule $\mathrm{O}_{2}$ is reduced to $\mathrm{H}_{2} \mathrm{O}$. However, a small percentage of electrons can leak at complex I and complex III and can reduce $\mathrm{O}_{2}$ into $\mathrm{O}_{2}^{-\bullet}$. (B) The second major source of ROS is NOX. NOX contains membrane proteins (gp91 ${ }^{\text {phox }}$ or NOX-2 and p22 $2^{\text {phox }}$ that constitute the flavocytochrome b558, and the small G Rap1A protein). During NOX activation (for instance, in neutrophils, or by Ca ${ }^{2+}$ or radiation), cytosolic proteins (p40 ${ }^{\text {phox }}, \mathrm{p} 47^{\text {phox }}, \mathrm{p} 67^{\text {phox }}$ and $\mathrm{G}$ Rac2) are recruited to the membrane and NADPH binds to NOX and transfer electrons to FAD and further across the membrane to $\mathrm{O}_{2}(108,208)$. ETC, electron transport chain; FAD, flavin adenine dinucleotide. To see this illustration in color, the reader is referred to the web version of this article at www.liebertpub.com/ars 
nucleotides, lipids, and amino acids. They mediate the intracellular homeostasis of inorganic ions. The ETC is composed of four multisubunit enzyme complexes (Fig. 9): complex I with NADH coenzyme Q reductase activity, complex II with succinate dehydrogenase coenzyme $\mathrm{Q}$ activity, complex III with coenzyme $\mathrm{Q}$ cytochrome $\mathrm{C}$ reductase activity, and complex IV with cytochrome C oxidase activity. Coenzyme Q (or ubiquinone) allows the electron transfer from complex I to III, while cytochrome $\mathrm{C}$ is involved in the transfer between complex III and IV. Electrons are finally transferred to $\mathrm{O}_{2}$, leading to water formation. Intermediate products, such as $\mathrm{O}_{2}^{-\bullet}$ and $\mathrm{H}_{2} \mathrm{O}_{2}$, may also be liberated, particularly at complex I (NADH dehydrogenase) (107) and III (310), during or after premature leakage of electrons between ubiquinone and cytochrome $\mathrm{C}$, and at complex II, to a lower extent $(151,348)$.

(2) Mitochondria and irradiation. Mitochondria are essential in the intrinsic apoptosis pathway (but not in the death receptor-mediated extrinsic pathway). Specifically, mitochondrial membrane permeabilization and cytochrome $\mathrm{C}$ release are followed by caspase activation. The intrinsic apoptosis pathway involves PUMA, a proapoptotic protein that allows BAX and/or BAK translocation to mitochondria to signal apoptosis.

The total cellular mitochondrial volume is high (4-25\% of the cell volume, depending on the cell type and state), and therefore, mitochondria represent a fairly substantial target for cytoplasmic irradiation. Radiation produces many different types of mitochondrial damage, including mtDNA damage. mtDNA is a circular double-stranded genome that encodes proteins, transfer RNA, and ribosomal RNA. It lacks protective histones and shows limited repair capability. Therefore, on radiation exposure, mtDNA could be preferentially damaged or lost (217), leading to loss of mitochondrial function $(149,316)$. Moreover, it has been shown that microbeam irradiation with carbon ions leads to depolarization of mitochondria (323). Exposure to direct gamma radiation causes mitochondrial mass increases (218), and alphaparticle microbeam irradiation leads to mitochondrial fragmentation, involving dynamin-related protein 1 (DRP1), a member of the dynamin family involved in mitochondrial fusion and fission (348).

Cytoplasmic irradiation also has been associated with altered protein synthesis and irregular mitochondrial oxidative phosphorylation $(66,217,348)$, leading to persistent oxidative stress $(162,345)$. Yoshida et al. detected dysfunction of complex I at $12 \mathrm{~h}$ postgamma irradiation, after early and transient production of intracellular ROS (in the first minutes). This was followed by increased mitochondrial ROS levels and mtDNA damage at $24 \mathrm{~h} \mathrm{(345).} \mathrm{These} \mathrm{observations}$ suggest that mitochondria participate in the amplification of the initial oxidative stress through transmission of oxidative events from one mitochondrion to the entire mitochondrial population of a given cell. This process might involve transient $\mathrm{Ca}^{2+}$-dependent mitochondrial permeability to adjacent mitochondria, resulting in enhanced ROS/RNS generation $(53,162)$.

Chen et al. showed that in mtDNA-depleted and wild-type AL cells treated with mitochondrial respiratory chain function inhibitors, $\gamma \mathrm{H} 2 \mathrm{AX}$ induction is attenuated in bystander cells (53). Incubation of HepG2 (liver cancer) cells with cyclosporin $\mathrm{A}$, an inhibitor of cytochrome $\mathrm{C}$ release, before irradiation demonstrated that cytochrome $\mathrm{C}$ release regulates bystander effect-induced formation of micronuclei (MN) and production of NO, but not of ROS (117). This indicates that cytochrome $\mathrm{C}$ has an effect on inducible NOS (iNOS) that catalyzes NO production.

Zhou et al. showed that on alpha-particle microbeam irradiation, the frequency of DNA mutations is decreased in bystander cells in cultures of skin fibroblasts with reduced $\left(\rho^{0}\right)$ mitochondrial functions compared with wild-type $\left(\rho^{+}\right)$ cells. Moreover, incubation with a pharmacologic inhibitor of $\mathrm{NF}-\kappa \mathrm{B}$ activation (Bay 11-7082) or with the NO scavenger c-PTIO reduced the DNA mutation frequency in both mutant $\left(\rho^{0}\right)$ and wild-type $\left(\rho^{+}\right)$cells, highlighting the role of NF- $\kappa \mathrm{B}$ and of activation of its downstream NF- $\kappa \mathrm{B} / \mathrm{iNOS}$ and NF$\kappa \mathrm{B} / \mathrm{COX}-2$ signaling pathways (355).

Finally, mitochondria are affected also in nonirradiated cells grown in culture medium from irradiated cells. Specifically, changes of mitochondrial distribution, loss of mitochondrial membrane potential, and mitochondrial mass (218), increased ROS and RNS production, and increased apoptosis rates have been observed in such cells. These effects can be blocked by antioxidant treatments (180).

b. NAD $(P) H$ oxidase-dependent ROS production. The plasma membrane-bound $\mathrm{NAD}(\mathrm{P}) \mathrm{H}$ oxidase (NOX) is another endogenous source of ROS. It is found in phagocytic cells, such as macrophages and neutrophils (innate immunity), where it was first identified $(14,259)$. NOX-1 participates in pathogen killing via the formation of $\mathrm{O}_{2}^{-\bullet}$ by transferring one electron from NADH or NADPH (Fig. 9) (80), which are located on the cytoplasmic face of the plasma, endosomal, or phagosomal membranes, to $\mathrm{O}_{2}$, which is found in the extracellular space, or in the lumen of endosomes and phagosomes. $\mathrm{O}_{2}^{-}$can next dismute spontaneously or via peroxidase into $\mathrm{H}_{2} \mathrm{O}_{2}$ that can be transformed into hypochlorous acid (HOCl) and contribute to the antimicrobial activity of neutrophils (208).

NOX includes several subunits, such as membrane proteins (gp91 ${ }^{\text {phox }}$ or NOX-2 and $\mathrm{p} 22^{\text {phox }}$ that constitute flavocytochrome b558, and the small $G$ Rap1A protein) and cytosolic proteins (p40 ${ }^{\text {phox }}, \mathrm{p} 47^{\text {phox }}, \mathrm{p} 67^{\text {phox }}$, and the G Rac2 protein). Flavocytochrome b558 contains heme subunits with low oxydo-reduction potential ( -225 and $-265 \mathrm{mV}$ at $\mathrm{pH} 7.0$ ) and is mainly involved, via its $\mathrm{p} 67^{\text {phox }}$-mediated activation, in $\mathrm{O}_{2}$ reduction by binding to NADPH and FAD (14). An electron chain transport then occurs from NADPH to $\mathrm{O}_{2}$ via FAD and heme (108). Six human NOX isoforms have been identified in nonphagocytic cells. NOX-1, NOX-3, and NOX4 show similarities with NOX-2, while the DUOX (dual oxidase) group includes DUOX-1, DUOX-2, and NOX-5. DUOX-2 peroxidase activity leads to $\mathrm{H}_{2} \mathrm{O}_{2}$ formation and is involved in the biosynthesis of thyroid hormones. NOX proteins play different roles according to the cell types where they are expressed and to the levels of ROS production (14).

In irradiated fibroblasts, NOX activation does not require direct nuclear or cellular "hits" by alpha particles and leads to $\mathrm{O}_{2}^{-\bullet}$ and $\mathrm{H}_{2} \mathrm{O}_{2}$ generation, and also to persistent ROS production in bystander cells (207). NOX is located in ceramide-enriched lipid raft domains, the disruption of which leads to NOX activity inhibition (347). For instance, transforming growth factor (TGF) $\beta 1$ secreted by irradiated cells 
activates NOX-1 and the subsequent $\mathrm{O}_{2}^{-\bullet}$ production in bystander cells (277). Moreover, TGF $\beta 1$-mediated activation of DUOX proteins and the release of the peroxidase domain by metalloproteases (1) are required for the $\mathrm{HOCl}$ signaling pathways. $\mathrm{O}_{2}{ }^{-}$production by NOX might participate in the activation of ASMase, leading to NOX activation in ceramide-enriched domains (337). It was shown that irradiation induces NOX/DUOX-1-dependent $\mathrm{H}_{2} \mathrm{O}_{2}$ production for several days (6). This process involves p38 MAPK-mediated activation of NOX via IL-13 expression. NOX can then promote the amplification and long-term persistence of oxidative stress signals (6).

c. ROS and RNS as second messengers. Most ROS, such as $\mathrm{HO}^{\bullet}$, are very reactive and have a very short life, and thus react within a few $\mathrm{nm}$ range from their site of production. They cannot be transmitted to neighboring cells. However, $\mathrm{H}_{2} \mathrm{O}_{2}$ and $\mathrm{NO}$ can diffuse through the cell membrane. $\mathrm{H}_{2} \mathrm{O}_{2}$ can cross membranes through aquaporin channels (21) and can diffuse through the cytoplasm and plasma membranes of neighboring cells along several cell diameters $(13,340)$. NO, one of the main RNS, can damage DNA (211), is mutagenic, and is involved in proapoptotic signal transduction (211). NO also plays a role in blood compartment functions, including smooth muscle tone and blood pressure regulation, platelet activation, and vascular cell signaling. Thanks to its lipophilic properties and relative stability, NO can activate signaling processes in adjacent cells (161).

NO is upregulated on oxidative stress and therefore can compete for substrates with SOD by reacting with $\mathrm{O}_{2}^{-\bullet}$ to form the diffusible peroxynitrite $\left(\mathrm{ONOO}^{-}\right)(13,340)$. In agreement, incubation with L-NAME (an NOS inhibitor), but not with rotenone (an inhibitor of electron entry into complex I of the mitochondrial ETC), leads to an increase of oxidative stress. This suggests that constitutive levels of NO production contribute to the regulation of mitochondrion-derived intracellular oxidant generation (99). When NO concentration increases to the level of SOD, $\mathrm{ONOO}^{-}$can rearrange into biologically inert nitrite $\left(\mathrm{NO}_{2}{ }^{-}\right)$or react with $\mathrm{GSH}$ to form the NO donor GSNO (161). However, it can also spontaneously and rapidly decompose to nitrogen dioxide $\left(\mathrm{NO}_{2}\right)$ and $\mathrm{HO}^{\circ}$, thereby oxidizing lipids, thiols, amino acid residues, DNA bases, and low-molecular-weight antioxidants, as done by ROS cellular constituents (13). NO can also modify proteins, leading to S-nitrosylation $(80,164)$ or nitration, mainly tyrosine nitration, a marker of tissue inflammation. This posttranslational modification participates in the regulation of cellular functions. For example, NO affects the DNA repair mechanisms by downregulating the expression of BRCA1, involved in HRR and cell cycle checkpoint control, while promoting the error-prone NHEJ mechanisms. This regulation seems to be mediated via tyrosine nitration of protein phosphatase 2A (PP2A). PP2A then controls the formation of the retinoblastoma-like protein 2 (RBL2)/E2F4 inhibitory complex that recognizes and binds to the proximal BRCA1 promoter (341).

NO production from L-arginine is catalyzed by one of the NOS isoforms, such as constitutive NOS (cNOS), including neuronal NOS (nNOS or NOS1) and endothelial NOS (eNOS or NOS3) and iNOS (known as NOS2) that are present in the cytoplasm and subcellular organelles. Different from NOS and eNOS, iNOS activation is independent of $\mathrm{Ca}^{2+}$. Irradia- tion stimulates cNOS transient activation with a maximal activity $5 \mathrm{~min}$ after exposure to clinical doses of $2 \mathrm{~Gy}$ (161).

Pretreatment with the NO scavenger c-PTIO of cells exposed to microbeam with alpha particles abolishes MN formation in bystander cells (280). Moreover, incubation of a mouse leukemic monocyte macrophage cell line (RAW 264.7) with lipopolysaccharide (LPS) induces iNOS activity and NO generation, thereby increasing DNA damage in bystander EL-4 lymphoma cells (97).

3. Cell membrane response to radiation. Compared with DNA-centered approaches, relatively few radiobiological studies have investigated the role of radiation targeted at the cell membrane that, for long time, was considered to be just an inactive phospholipid bilayer. However, in the 1990s, several studies showed the production of ceramide, a cellular second messenger of apoptosis involved in the sphingomyelin signaling pathway, during membrane irradiation (111). Using lymphoblasts from patients with Niemann-Pick disease (deficiency in ASMase activity), it was demonstrated that this enzyme is required for radiation-induced production of ceramide and apoptosis (263). Many studies now strongly support the ceramide-mediated cell membrane role in the biological effects of radiation, including cell death. Moreover, radiation resistance in Burkitt's lymphoma cells has been associated with defective ceramide signaling (189). Finally, structure-modulating agents (e.g., cholesterol) and antioxidants (e.g., tocopherol, eugenol) can modify the membrane response to stress $(194,230)$.

a. Cell membrane and lipid rafts. Cell membrane contains lipids (sphingolipids and glycerophospholipids), proteins, and sterols (Fig. 5B).

Lipids, such as PUFA, are susceptible to free radicalinitiated oxidation (49), leading to lipid hydroperoxide formation that can then be reduced by peroxidases. If not efficiently reduced, lipid hydroperoxides can be degraded into hydroxyalkenals (such as 4-HNE) that show great reactivity toward DNA, proteins, and lipids (49).

Cholesterol and sphingolipids, among which sphingomyelin is the prevalent, mainly localize in the outer leaflet of the cell membrane. They play a crucial role in signal transduction and participate in cell growth, senescence, differentiation, and apoptosis (122). Sphingolipids contain a longchain sphingoid base (such as sphingosine) linked via an amide to long-chain fatty acids and to one polar head group, making them amphipathic molecules (Fig. 5B). Head groups are different in sphingolipids (phosphorylcholine), ceramides (hydroxyl group), and glycerophospholipids (carbohydrates) (256). Ceramide is composed of D-erythro-sphingosine and of a fatty acid that contains 2-28 carbon atoms in the acyl chain. Similarly, a hydrophobic moiety forms the backbone of sphingomyelin and of other complex sphingolipids, such as cerebrosides and gangliosides.

The concept of the cell membrane as a fluid mosaic (289) is based on the finding that most physiological phospholipids exhibit low melting temperatures and, therefore, most likely exist in a liquid disordered phase. For instance, in Escherichia coli, the fatty acid composition of phospholipids depends on the temperature. Specifically, the proportion of unsaturated acids increases as the temperature decreases (67). At physiological temperature $\left(37^{\circ} \mathrm{C}\right), 22 \%$ of the 
phospholipid molecules have two unsaturated acyl chain molecules, whereas this proportion is two times higher at $17^{\circ} \mathrm{C}(67)$.

However, the notion of fluid mosaic has been reconsidered because mammalian membranes contain very small domains that are in a liquid ordered phase $(35,287)$. Indeed, sphingolipids, which have a much higher melting temperature than other phospholipids in the cell membrane, interact with each other via hydrophilic interactions between the sphingolipid head groups. These complexes are stabilized by cholesterol that fills the gaps between the large sphingolipid molecules. The resulting domains are resistant to cold detergent extraction (2) or mechanical disruption and are called lipid rafts because they seem to float in the membrane. With a size of about $50 \mathrm{~nm}$, they correspond to lateral subcompartments in the cell membrane and allow the cell membrane to exert its cellular functions by segregation of molecules, reorganization of receptor molecules and of membrane signaling and trafficking.

Lipid rafts can be converted into larger membrane platforms by ASMase activity that hydrolyzes sphingomyelin to ceramide in rafts (Fig. 5B). Ceramide molecules then spontaneously associate to form ceramide-enriched microdomains that fuse into large ceramide-enriched membrane platforms, thus altering the biophysical properties of these membrane domains (167) (Fig. 10). ASMase is activated by multiple stimuli, including CD95, CD40, DR5/TNF-related apoptosis-inducing ligand (TRAIL), CD20, FcgRII, CD5, LFA-1, CD28, cytokines, and chemotherapeutic drugs (doxorubicin, cisplatin), and also by ionizing radiation. Ceramide is considered the second messenger of many factors. For instance, ceramide acts as a messenger of inflammatory cytokines by binding and exerting a dual effect on the cytosolic phospholipase A2 (cPLA2) involved in eicosanoid formation (132). Ceramide is also involved in apoptosis. Its binding to the endosomal acidic aspartate protease cathepsin $\mathrm{D}$ results in the autocatalysis of the $52 \mathrm{kDa}$ prepro-cathepsin D into the enzymatically active $48 / 32 \mathrm{kDa}$ cathepsin D isoforms that mediate oxidative stress-induced apoptosis (120).

It has been proposed that oxidation of cysteine 629 in ASMase C-terminus by $\mathrm{HO}^{\bullet}$ could be responsible for a possible mechanism leading to increased ASMase enzymatic

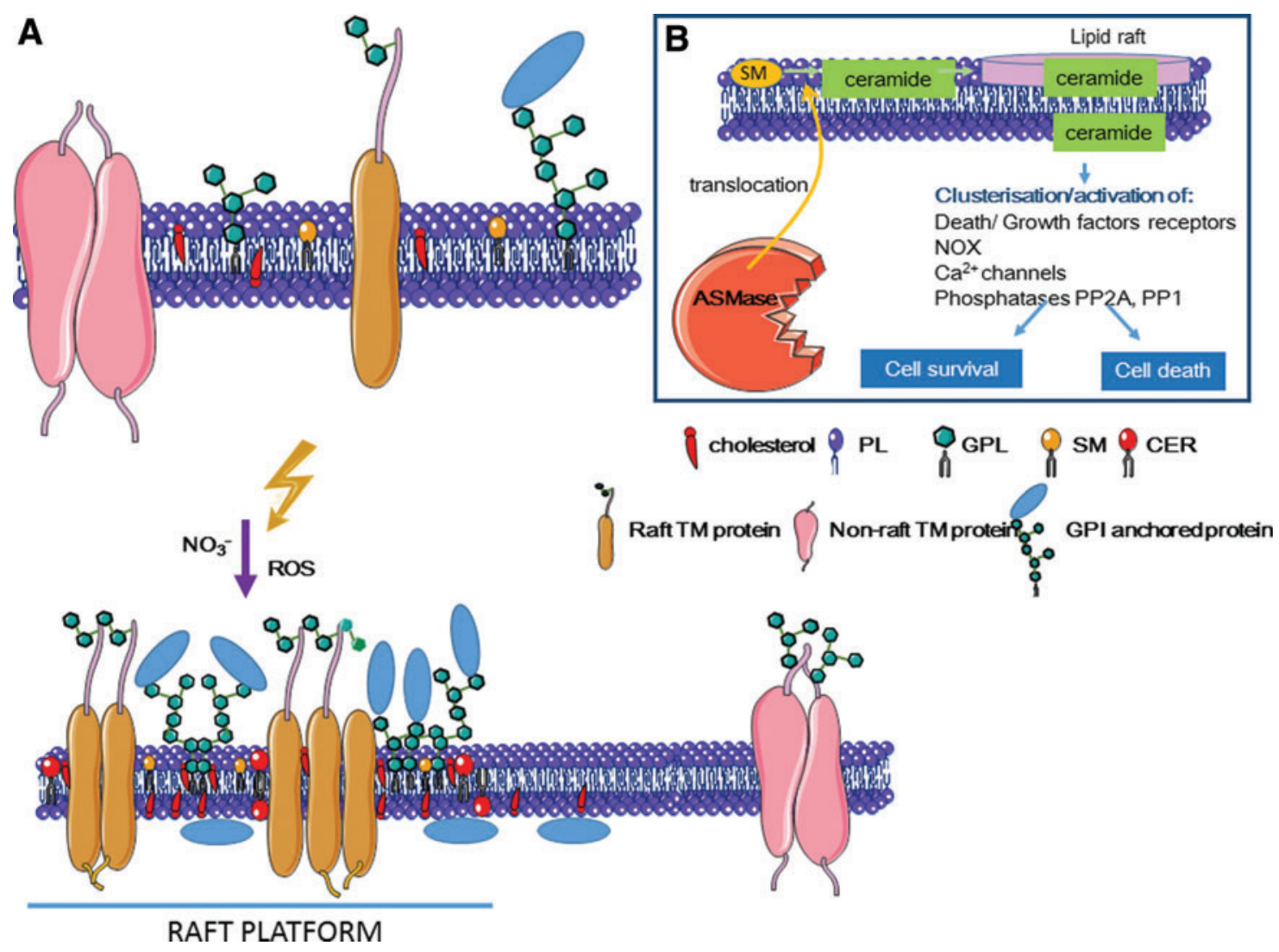

FIG. 10. Lipid rafts: ceramide-enriched large platforms. (A) The cell membrane consists of a lipid bilayer that includes proteins and cholesterol. According to the fluid-mosaic model, lipids can rotate laterally and between bilayers. The lipid distribution in the cell membrane is associated with specific cellular functions. Specifically, the cell membrane can include glycolipids, phospholipids (e.g., phosphatidylcholine, phosphatidylserine, phosphatidylethanolamine), and sphingolipids, among which SM is predominant. Their resistance to disruption allowed the identification of membrane domains enriched in ceramide. Ceramide is produced via ASMase-mediated hydrolysis of SM following RNS and ROS activation and ASMase translocation to the outer layer of the cell membrane. Interaction between the resulting lipids and proteins leads to the coalescence of microdomains (lipid rafts) into ceramide-enriched large platforms. (B) These platforms can promote clustering of receptors and activation of signaling pathways. Besides its role in lipid rafts, ceramide is also a second messenger $(58,167,346)$. CER, ceramide; GPL, glycophospholipids; TM, transmembrane. To see this illustration in color, the reader is referred to the web version of this article at www.liebertpub.com/ars 
activity (251). Moreover, the RNS $\mathrm{ONOO}^{-}$specifically activates ASMase (48).

Ceramide is generated by ASMase in the outer leaflet of the cell membrane or within intracellular vesicles. It might also flip to the cytoplasmic leaflet and then interact with intracellular molecules. Although the mechanisms of ceramide translocation from one membrane leaflet to another are unknown, ceramide can interact and activate serine/threonine phosphatases, namely PP2A and PP1 $(50,58)$ (Fig. 10). Once activated, these phosphatases act on different signaling proteins, including MAPKs (AKT, c-JUN), PKC isoforms (PKC $\alpha$ and $\zeta$ ), kinase suppressor of Ras (KSR), pRB, and BCL-2 $(28,349)$.

b. Lipid rafts in mitochondria-ER-associated domains. Several recent studies indicate that ceramide is also present in mitochondria (122). Mitochondrial ceramide could be generated via the de novo synthesis pathway through reverse activity of ceramidase and activity of ASMase, residing in the space between the inner and outer mitochondrial membrane. Lipid raft domains might be involved in contact regions between ER and mitochondria, leading to the direct transfer of $\mathrm{Ca}^{2+}$ released from ER to mitochondria (98). It has been reported that mitochondria-ER-associated domains contain ROS generating proteins and $\mathrm{IP}_{3}$ receptors (98). These receptors are upregulated by irradiation and are involved in ATP-mediated $\mathrm{Ca}^{2+}$ release from ER (343). $\mathrm{Ca}^{2+}, \mathrm{NO}, \mathrm{ROS}$, and molecules modulated by irradiation, such as AKT, promote $\mathrm{IP}_{3}$ receptor expression. For instance, it was shown that inhibitors of PI3K, an upstream AKT activator, can block $\mathrm{Ca}^{2+}$ release from ER (342).

c. Caveolae, a subgroup of membrane lipid rafts. Caveolae are a subset of membrane lipid rafts that make small invaginations in the plasma membrane, ER, and Golgi apparatus. They contain caveolins that act as organizing centers for cellular signal transduction (233). Caveolin-1 contains a tyrosine 14 phosphorylation site and its phosphorylation leads to its accumulation at focal adhesion sites (i.e., mechanical and biochemical hubs between cells and extracellular matrix) and to the subsequent transmission of extracellular signals via intracellular pathways (118). Caveolin-1 phosphorylation at tyrosine 14 by the protooncogene tyrosine protein kinase Src is involved in EGFR and AKT activation. Caveolins serve as scaffolding proteins and can dock signaling molecules, such as the Src kinase, PI3K, eNOS, protein kinase A, PKC, and extracellular signalrelated kinase (ERK). The interaction between caveolin-1, beta1 integrin, and focal adhesion kinase (FAK) enhances cell adhesion and radioresistance by promoting phosphorylation of AKT and GSK-3beta, two factors involved in prosurvival pathways (118).

d. Ion channels and lipid rafts. Ceramide-enriched membrane platforms are involved in the regulation of potassium (27) and calcium (56) channels. Calcium ion cytoplasmic level is critical for many cellular functions via interaction with various signaling cascades, such as those that involve the activation of the calcium-dependent PKC (112) or $\mathrm{Ca}^{2+} /$ calmodulin kinase (81).

Intracellular $\mathrm{Ca}^{2+}$ can activate NOX and iNOS, thereby promoting ROS and RNS formation, respectively. It can also modulate the activity of the transcription factors NF- $\kappa \mathrm{B}$ and AP1 that are involved in COX-2 and iNOS transactivation and the subsequent release of ROS, RNS, and cytokines. Moreover, it activates kinases, including PI3K/AKT and MAPK.

In response to irradiation, $\mathrm{Ca}^{2+}$ levels increase $(112,319$, 352 ). These changes can be described as oscillations or single transient changes within minutes to days after irradiation. The concentration of free $\mathrm{Ca}^{2+}$ in the cytoplasm is low $(\sim 100 \mathrm{n} M)$ in normal physiological conditions. It is controlled by modulating its cellular entry from the extracellular environment through, for example, ROS-mediated activation of plasma membrane $\mathrm{Ca}^{2+}$ channels, or by release from internal storages where it is present at higher concentrations (up to $\mathrm{mM}$ ). ER is the main $\mathrm{Ca}^{2+}$ store (Fig. 11). As shown by experiments using the PLC gamma inhibitor U73122, $\mathrm{Ca}^{2+}$ release is regulated by PLC-mediated generation of the second messenger $\mathrm{IP}_{3}$ that binds to the $\mathrm{IP}_{3}$ receptors located at the ER membrane $(20,305)$ (Fig. 11). This process is mediated by activation of plasma membrane-associated receptor tyrosine kinases, such as ERBB3 and HER1. HO ${ }^{\bullet}$ and exogenous NO induce the release of calcium from intracellular $\mathrm{IP}_{3}$ receptor-sensitive stores and they modulate the open/ closed status of $\mathrm{Cx}$ channels. Moreover, ROS can activate PLC (40, 229). An increase in $\mathrm{IP}_{3}$ receptor level was observed after a dose of $3 \mathrm{~Gy}$ in lymphoblastoid cells (343). Moreover, $\mathrm{IP}_{3}$ receptor phosphorylation by AKT is associated with reduced $\mathrm{Ca}^{2+}$ flux from the ER to mitochondria and subsequently with reduced apoptosis (299).

e. The role of $\mathrm{Ca}^{2+}$ ions in bystander effects. $\mathrm{Ca}^{2+}$ ion role as second messenger has been highlighted by several studies using calcium chelators or blockage of voltage-gated $L$-type $\mathrm{Ca}^{2+}$ channels. A rapid intracellular calcium increase was observed in bystander keratinocytes on addition of medium from X-ray irradiated keratinocytes. This phenomenon was associated with increased ROS production, decreased mitochondrial membrane potential, and apoptosis $(178,279)$. Moreover, membrane signaling and $\mathrm{Ca}^{2+}$ influx induced in bystander cells by ROS-activated signaling factors released from irradiated cells lead to ROS production in bystander cells (176). Several factors could mediate the propagation of the increased intracellular $\mathrm{Ca}^{2+}$ levels. Specifically, it was shown that ATP released by irradiated astrocytes is the determinant of calcium wave propagation over large distances $(100-250 \mu \mathrm{m})(30)$. ATP may act as an extracellular signaling molecule by diffusing via channels that involve Cxs (61), Panxs (298), or purinergic P2XR7 receptor channels (221, $306,311,313)$. Once in the extracellular space, ATP can activate $\mathrm{Ca}^{2+}$-permeable channels or G-protein-coupled receptors (GPCRs) on neighboring cells, thus inducing PLCmediated $\mathrm{IP}_{3}$ synthesis (68). $\mathrm{IP}_{3}$ can also diffuse via membrane gap junctions (266) (Fig. 11) and activate PLC in neighboring cells.

$\mathrm{Ca}^{2+}$ released from ER can be transferred to mitochondria through voltage-dependent anion channels (VDACs) and mitochondrial $\mathrm{Ca}^{2+}$ uniporter $(79,257)$. Accumulated $\mathrm{Ca}^{2+}$ can then activate mitochondrial metabolic functions and stimulate energy production via ATP synthase (252), and subsequently ROS and RNS production and release of the proapoptotic factors cytochrome $\mathrm{C}$ and caspase 3 . Moreover, irradiation can modulate the expression of GRP75 and mitofusin 1 and 2 (MFN 1/2), involved in ER-mitochondrial 


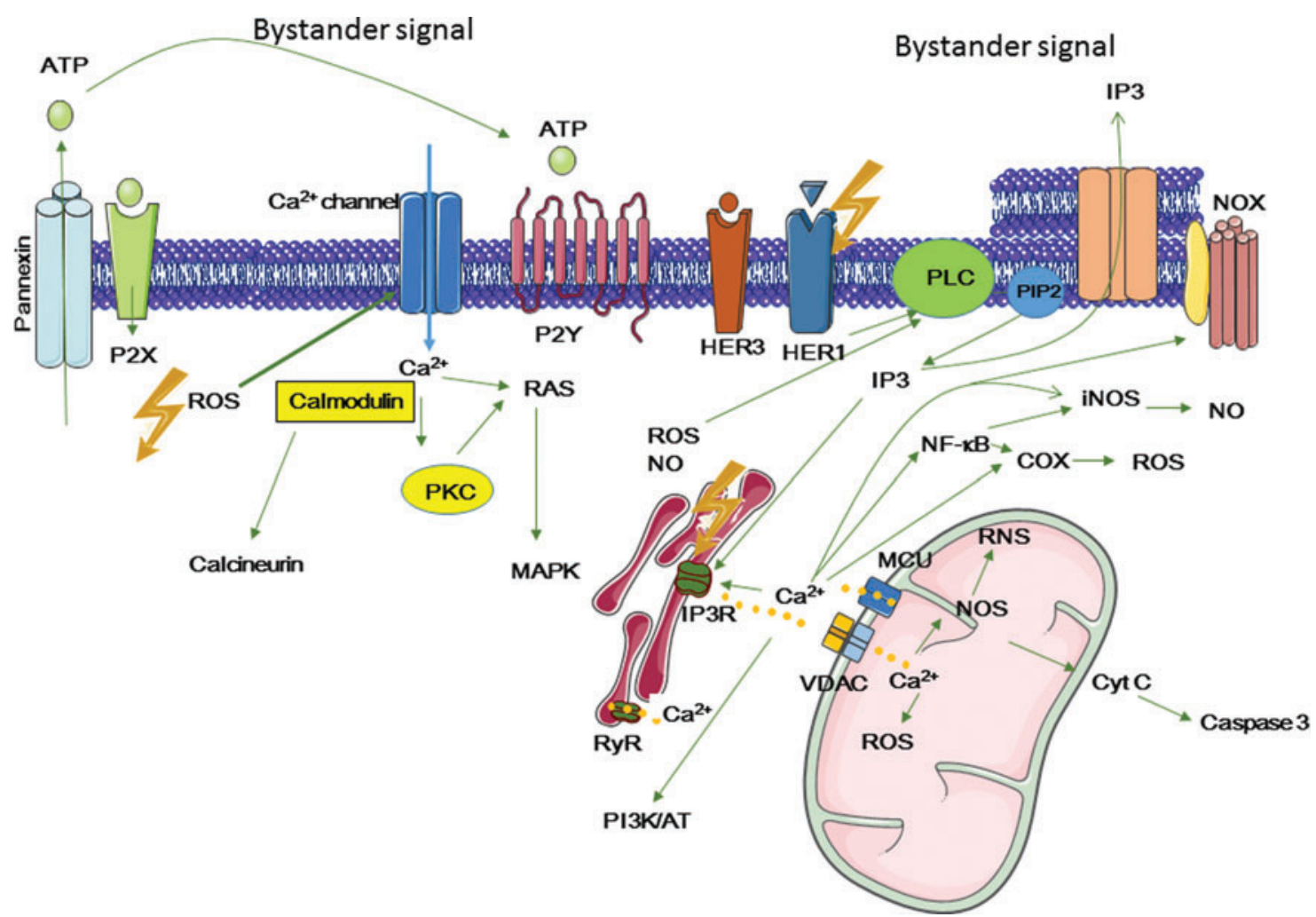

FIG. 11. Interplay between $\mathrm{Ca}^{2+}$ and radiation-induced oxidative stress [extensively reviewed in Decrock et al. (68)]. Irradiation increases the intracellular $\mathrm{Ca}^{2+}$ level (oscillations or single transient changes occurring within minutes to days after irradiation). Radiation-induced ATP release by irradiated cells can activate ATP-gated P2X receptor cation channels (P2X receptors) present on the cell membrane, thus allowing $\mathrm{Ca}^{2+}$ entry into the cell. It can also activate P2Y receptors that have been identified as phospholipase $\mathrm{C}$ activators. $\mathrm{Ca}^{2+}$ can also be released from the ER through calciuminduced calcium release mechanisms that involve $\mathrm{IP}_{3} \mathrm{Rs}$ or RyRs. $\mathrm{IP}_{3}$ is produced (with diacylglycerol) during hydrolysis of phosphatidylinositol 4,5-bisphosphate (PIP2) by phospholipase C. Phospholipase C is activated by Ca ${ }^{2+}$, GPCRs, ROS, RNS, receptor and nonreceptor tyrosine kinase (e.g., HER1 and 3). $\mathrm{Ca}^{2+}$ can activate ion channels and binds to calmodulin before activation of the serine/threonine protein phosphatase calcineurin. $\mathrm{Ca}^{2+}$ can also activate protein kinase $\mathrm{C}$ that in turn activates, by phosphorylation, the MAPK pathway and phospholipase A2, at the origin of COX-2 activity modulation. It can activate transcription factors (NF- $\kappa \mathrm{B}, \mathrm{AP} 1$ ) that promote various downstream pathways (iNOS, COX-2). Released Ca ${ }^{2+}$ can also be taken up by mitochondria via VDAC and MCU and modulation by the ER-mitochondria-tethering proteins GRP75 (mitochondrial heat shot protein HSP70) and MFN 1 and 2 (involved in mitochondrial fusion). The increase in mitochondrial $\mathrm{Ca}^{2+}$ level is accompanied by ROS, an RNS increase, mtDNA damage, altered ATP synthesis, mitochondrial depolarization, and release of cytochrome $\mathrm{C}$ and caspase 3 that will amplify $\mathrm{IP}_{3} \mathrm{R}$ activity. COX-2, cyclooxygenase-2; GPCRs, G-protein-coupled receptors; iNOS, inducible nitric oxide synthase; $\mathrm{IP}_{3}$, inositol trisphosphate; $\mathrm{IP}_{3} \mathrm{Rs}$, $\mathrm{IP}_{3}$ receptors; MAPK, mitogen-activated protein kinase; MCU, mitochondrial $\mathrm{Ca}^{2+}$ uniporter; MFN, mitofusin; NF- $\kappa \mathrm{B}$, nuclear factor kappa B; RyRs, ryanodine receptors; VDAC, voltage-dependent anion channel. To see this illustration in color, the reader is referred to the web version of this article at www.liebertpub.com/ars

cross talk. It can also regulate $\mathrm{Cx} 43$ and $\mathrm{Cx} 30$ translocation to the inner membrane of mitochondria where they participate, as hemichannels, in $\mathrm{Ca}^{2+}$ homeostasis (68).

Studies in which human keratinocytes were incubated with conditioned medium from gamma particle-irradiated cells in the presence of EGTA, verapamil, nifedipine, or thapsigargin (known to act on calcium homeostasis) showed the involvement of calcium and the activation of multiple MAPK pathways, such as the ERK, JNK, and p38, in the production of radiation-induced bystander effects (178). Similar results were obtained during in vitro radionuclide therapy using Auger electron emitters (228). Other studies reported calcium ion role in NO-mediated bystander effects through calciumdependent NO generation via cNOS (NOS1) or eNOS (NOS3) $(115,279)$. Inhibition of cNOS leads to a decrease in radiation-induced ERK1/2 kinase activity (161). f. ROS/RNS and growth factor receptor activation. Lipid raft-mediated membrane reorganization can lead to activation of receptor and nonreceptor tyrosine kinases, such as ERBB1, that can homodimerize or heterodimerize with other members of the ERBB receptor family (ERBB2, ERBB3, and ERBB4) (91), insulin-like growth factor-1 (IGF-1) receptors, and death receptors (Fig. 12). Binding of growth factors to their tyrosine kinase receptors leads to activation of MAPK and PI3K/AKT signaling pathways. These processes are mediated by similar signaling pathways. Indeed, activation of ERBB1, 2, and 3 leads to activation of RAS family members (K-RAS, N-RAs, H-RAS) and further downstream signaling pathways that involve MAP3K (MEKK2/3, RAF-1/B-RAF), MAP2K (MEK1/2; MEK5), and MAPK (ERK1/2) and in turn activate transcription factors, such as AP1, NF- $\kappa \mathrm{B}$, and CREB (315). Similarly, death receptors activate two other 


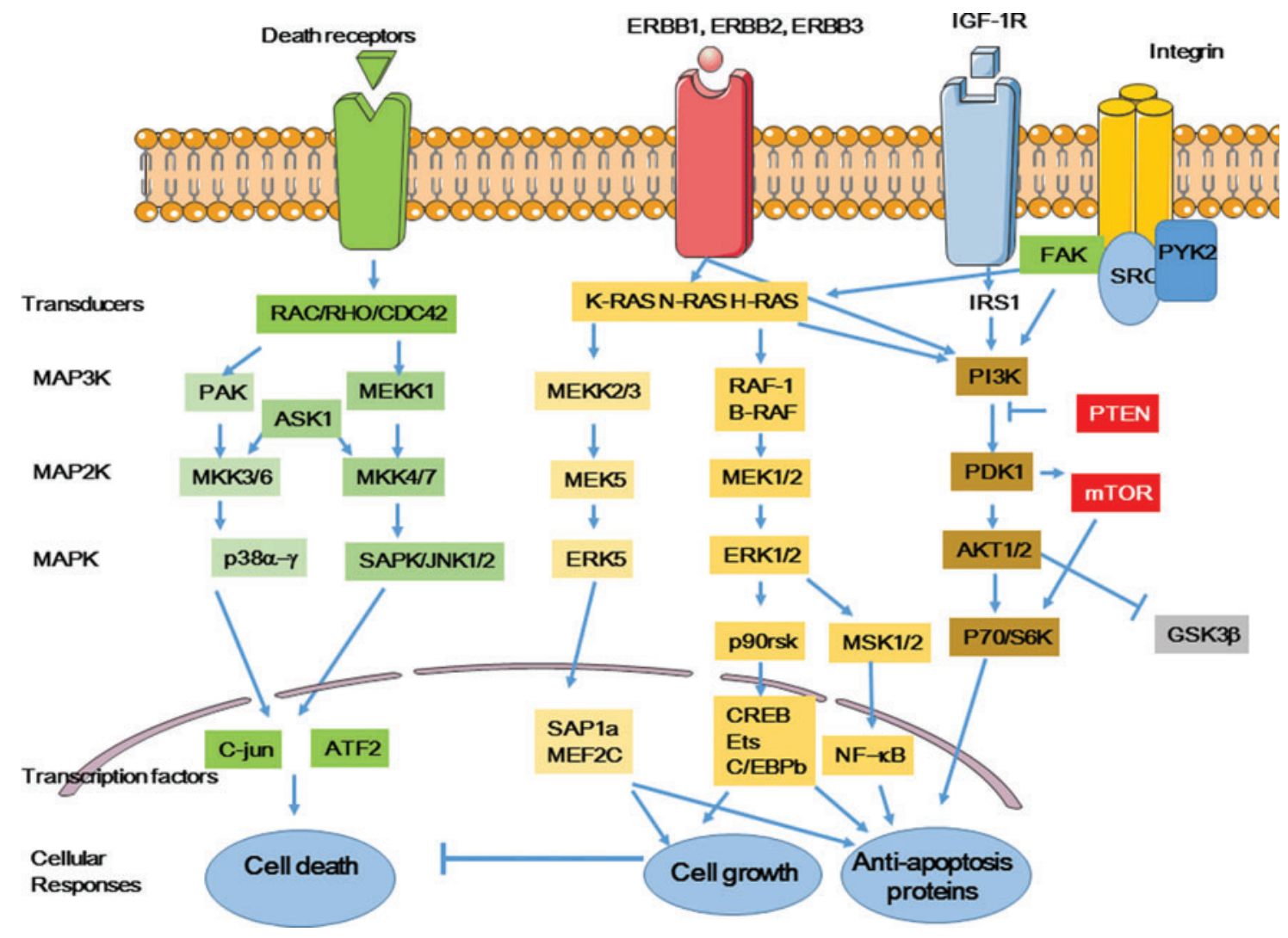

FIG. 12. The MAPK and PI3K signaling pathways. The four major MAPK signaling pathways (ERK1/2, ERK5, JNK1/ 2, and p38) regulate cell survival (ERK1/2 and ERK5) and apoptosis (JNK1/2 and p38) via the expression of transcription factors. The PI3K signaling pathway is involved in cell growth via AKT1/2 proteins. Death (Fas/CD95, TNF-R, DR3-5) and growth (HER family and IGF-1 receptors) receptors are located in lipid rafts and can be activated during coalescence of ceramide-enriched raft platform. They facilitate the cross talk between death or growth signaling from the membrane environment and intracellular signaling cascades. FAK and PYK-2 serve as scaffold proteins to facilitate the functional integration of focal adhesion proteins, such as paxillin, involved in $\mathrm{Ca}^{2+}$ homeostasis and can phosphorylate PI3K. ERK, extracellular signal-related kinase; FAK, focal adhesion kinase; IGF-1, insulin-like growth factor 1; JNK, c-JUN N-terminal kinase; PTEN, prime time entertainment network. To see this illustration in color, the reader is referred to the web version of this article at www.liebertpub.com/ars

MAP3K/MAP2K/MAPK pathways resulting in the activation of p38 $(\alpha-\gamma)$ kinases and JNKs $(1 / 2)$. Finally, IGF-1 receptor and its downstream kinases PI3K, PDK1, and AKT participate in mTOR activation and GSK-3 regulation. Ultimately, all these different pathways result in the activation of transcription factors involved in cell death or survival.

Radiation can modulate the production and expression of cytokine and growth factor receptors $(54,270,305)$. For example, a 2 Gy dose can modulate the expression of cell surface receptors, such as ERBB1 (HER1) (305). As described above, NO and ROS produced by radiation can lead to defective mitochondrial function due to leakage of mitochondrial membranes, allowing the amplification of the initial signal through massive release into the cytosol, via $\mathrm{Ca}^{2+}$-dependent mechanisms, of $\mathrm{O}_{2}^{-\bullet}$ anions and RNS. These, in turn, may inhibit the activity of protein tyrosine phosphatase by oxidation and/or nitrosylation of a key cysteine residue in the active site, leading to increased phosphorylation of many proteins, such as ERBB1 (308). Cells lacking functional mitochondria ( $\rho^{0}$ cells $)$ cannot inhibit such phosphatase activities (162). Similar results were reported on ROS scavenging by $N$-acetyl cysteine.
The PI3K pathway, which plays a role in the long-term effects of cell survival, can also be activated on irradiation (315).

It was shown that activation of growth receptors is modulated by radiation according to waves. For example, Dent et al. found that EGFR is first activated early and for few minutes $(0-5 \mathrm{~min})$ after irradiation. This is followed by a second prolonged activation at 90-240 min postirradiation (73). The MAPK pathways activate membrane-bound matrix metalloproteinase (MMP) activities that promote cleavage of proforms/zymogens of multiple growth factors into their functionally activated forms that can in turn activate, later after irradiation, cell surface receptors. For example, EGFR activation could in turn promote cleavage and release of presynthesized paracrine ligands, such as pro-TGF $\alpha$ (109, 315 ) that could contribute to sustained MAPK signaling via an autocrine positive feedback loop involving EGFR, the Ras-MAPK signaling pathway, and a ligand-releasing protease (284). Released factors could then bind to cells that express EGFR or be transmitted in a paracrine way for longdistance effects (abscopal effects). The observation that a broad-spectrum MMP inhibitor (marimastat, BB2516), 
known to affect tumor invasion, inhibits also growth of head and neck squamous cell carcinoma (HNSCC) cells that overexpress EGFR, highlighted the MMP role (e.g., MMP9) in cleaving HER ligands from membrane-anchored precursors into their functionally activated states (218a). Inhibition of ERK/MAPK (by PD98059 or U0126) and PI3K (by LY294002 or wortmannin) leads to a marked reduction of both basal and induced MMP9 activity, indicating that the MAPK signaling pathways are also required in an autocrine loop for HER1 activation (218a).

g. MAPKs and the bystander response. The four major MAPK signaling pathways in mammalian cells (ERK1/2, ERK5, JNK1/2, and p38) can regulate either survival (ERK1/ 2 and ERK5) or apoptosis ( JNK1/2 and p38). Inhibitors of the ERK pathway (PD98059 and U0126), JNK pathway (SP600125), and p38 pathway (SB203580, SB202190) helped demonstrating the role of these signaling pathways in bystander cell death induced by gamma/X-ray $(55,178)$, alpha particle (89), or carbon ion (77) exposure. Similar results were obtained after radionuclide therapy with Auger electron (228) or alpha particle-emitters (unpublished data). ROS and RNS have a role in MAPK direct and indirect activation. Incubation of confluent cultures of human diploid fibroblasts with CuZnSOD or catalase after irradiation with $0.003-0.03$ Gy of alpha particles inhibits p21 (WAF1) upregulation by MAPK and the induction of MN formation in bystander cells (10). Moreover, p21 knockout results in inactivation of MAPK signal pathway kinases (55), and cNOS inhibition leads to reduction of ERK1/2 kinase activity (cytoprotective effect) (161), suggesting that diffusible NO could mediate MAPK activation in bystander cells.

4. Central role of NF- $\kappa \mathrm{B}$ in the nuclear and extranuclear responses to radiation. Experiments showing that ATM activates NF- $\kappa \mathrm{B}$, which is involved in iNOS and COX activity, demonstrated the link between inflammation and DDR
(336). Therefore, as the bystander and inflammatory responses share homologies, studying the role of $\mathrm{NF}-\kappa \mathrm{B}$ in bystander effects can be of major relevance.

a. Nuclear factor kappa $B$. NF- $\kappa \mathrm{B}$ is a redox-sensitive transcription factor made of five different subunits that are organized in homo- or heterodimers: p50 (e.g., p50/p105 constitutes NF- $\kappa \mathrm{B} 1)$, p52 (e.g., p52/p100 constitutes NF$\kappa \mathrm{B} 2$ ), p65 ${ }^{\mathrm{RelA}}$, RelB, and c-Rel (Fig. 13). All subunits have a 300-amino acid N terminal sequence (Rel Homology Domain) that mediates dimerization, nuclear translocation, DNA binding, and I- $\kappa \mathrm{B}$ binding. NF- $\kappa \mathrm{B}$ is involved in innate and adaptive immunity and chronic inflammation, thereby linking the immune response to radiation response (121). Moreover, it is a transactivator of genes involved in cell proliferation and suppression of apoptosis induced by tumor necrosis factor (TNF) $\alpha$ by blocking caspase- 8 activation (326) by induction of BCL2 $(325,326)$ and by transactivation of TNF receptor-associated factor 1 (TRAF1), TNF receptorassociated factor 2 (TRAF2), and the inhibitor-of-apoptosis (IAP) proteins c-IAP1 and c-IAP2. It is also involved in autophagy, angiogenesis, metastasis formation, tumor progression, and oncogenesis $(121,246)$, and is considered a molecular target for cancer therapy (322). It participates in the antioxidant defenses by promoting SOD expression (139). Its inactive form binds to the inhibitor I- $\kappa \mathrm{B}$ that masks $\mathrm{NF}-\kappa \mathrm{B}$ nuclear localization signal and sequesters it in the cytoplasm. Upon irradiation, it can be released and transferred to the nucleus (226).

Specifically, TNF $\alpha$ binding to its receptor (TNFR) leads to a conformational change of TNFR that is accompanied by binding of TNFR type 1-associated DEATH domain protein (TRADD) to TNFR death domain. Two proteins, TRAF2 and receptor-interacting protein (RIP), are then recruited and in turn recruit the $\mathrm{I} \kappa \mathrm{B}$ kinase (IKK) complex, which is made of IKK- $\alpha$ (IKK1), IKK- $\beta$ (IKK2), and the regulatory subunit IKK $-\gamma / \mathrm{NF}-\kappa \mathrm{B}$ essential modulator (NEMO) (Fig. 13). IKK is

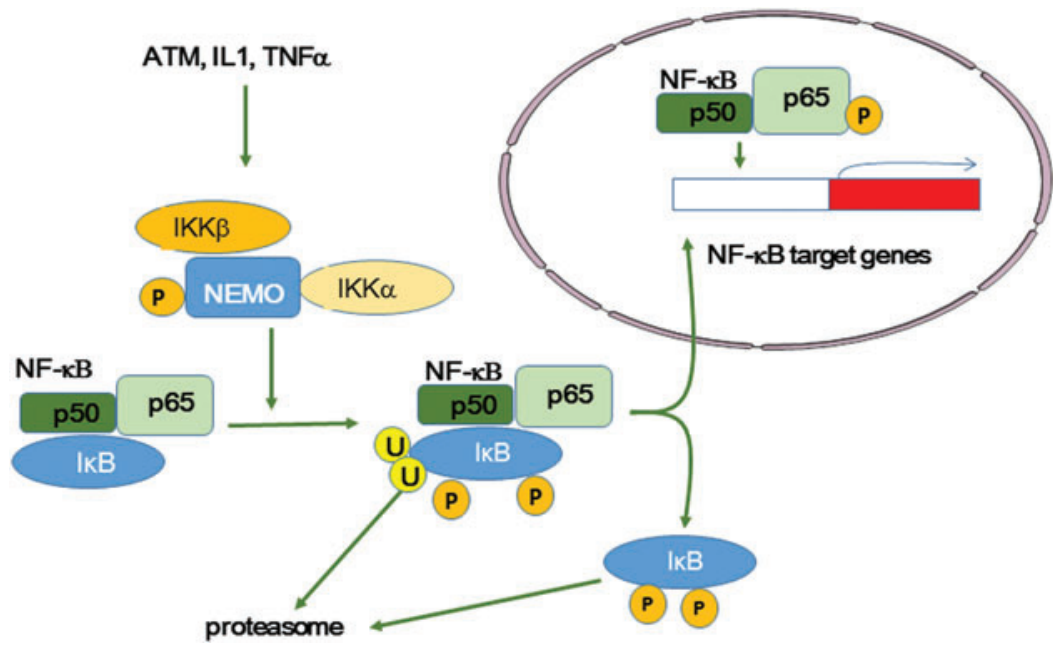

FIG. 13. NF-кB activation mechanisms. The antiapoptotic NF- $\kappa$ B consists of five heterodimers, among which the most common form involves $\mathrm{p} 65$ and p50. It is kept in the cytoplasm by its interaction with $\mathrm{I} \kappa \mathrm{B}$. On activation (e.g., by ATM, $\mathrm{TNF} \alpha$, IL1), the IKK complex, which is made of IKK- $\alpha$ (IKK1), IKK- $\beta$ (IKK2), and the regulatory subunit IKK- $\gamma / \mathrm{NEMO}$, phosphorylates and targets $\mathrm{I} \kappa \mathrm{B}$ for ubiquitination and degradation by the proteasome, while NF- $\kappa \mathrm{B}$ can enter the nucleus and activate its target genes. IKK, I $\kappa \mathrm{B}$ kinase; NEMO, NF- $\kappa \mathrm{B}$ essential modulator. To see this illustration in color, the reader is referred to the web version of this article at www.liebertpub.com/ars 
then activated and phosphorylates $\mathrm{I} \kappa \mathrm{B}$ before ubiquitination and proteosomal degradation to release NF- $\kappa \mathrm{B}(121,124)$. Among the plethora of targets with NF- $\kappa \mathrm{B}$ responsive element sequences, COX-2, iNOS, and also cytokines (TNF $\alpha$, IL1, IL6, IL33), chemokines (IL8, MCP-1), VEGF, ICAM1, and VCAM1 have been identified as major factors that can modify the microenvironment and trigger inflammation (95). These molecules may also be involved in oncogenesis (246).

b. $N F-\kappa B$ and irradiation. NF- $\kappa \mathrm{B}$ can be activated by doses as low as 0.1 Gy of X-rays, but participates in the RIAR (84) also at higher doses (2-50 Gy) (32). RIAR was demonstrated by the observation that a priming dose (generally $>0.005 \mathrm{~Gy}$ ) reduces the detrimental effects of the challenging dose administered a few hours later $(186,333)$. This can be a beneficial effect for low-dose radiation, but might induce radioresistance during radiotherapy. Indeed, RIAR has been associated with reduced chromosome aberrations, MN formation, and mutation induction $(223,344,356)$. RIAR shares similarities with inflammation. It was shown that low irradiation doses lead to ATM phosphorylation that contributes to $\mathrm{NF}-\kappa \mathrm{B}$ activation and to cell survival, in a process involving also ERK (but not p38/JNK) $(4,151)$. ATM participates in NF- $\kappa \mathrm{B}$ activation by phosphorylating $\mathrm{I} \kappa \mathrm{B}$ and NEMO (165) that mediate NF- $\kappa \mathrm{B}$ inhibition. NF- $\kappa \mathrm{B}$ activation by low-dose irradiation leads to the expression of MnSOD 15 min postirradiation, and small interfering RNAs (siRNAs) against MnSOD reduce RIAR (84).

RIAR is also observed in bystander cells. Indeed, a priming dose of $0.02 \mathrm{~Gy}$ of $\gamma$-rays, delivered $6 \mathrm{~h}$ before single-cell microbeam irradiation, inhibited $50 \%$ of the bystander effects observed in control cells (no priming dose) (265).
Optimal NF- $\kappa$ B activation is observed at doses between 7 and $10 \mathrm{~Gy}$ and with high LET (90-230 $\mathrm{keV} / \mu \mathrm{m})$. In these conditions, NF- $\kappa \mathrm{B}$ activation is mediated by ATM recruited at DNA DSB sites (336) and is an alternative pathway leading to p53-mediated signaling. p53 participates in cellular redox status by transactivating p53-induced genes (PIGs) that encode antioxidant molecules (GPx). In irradiated cells, p53 transactivates genes encoding ROS-generating enzymes, such as quinone oxidoreductase (NQO1, PIG3) and proline oxidase (POX, PIG6), BAX, PUMA, and p66SHC, thereby leading to oxidative stress and apoptosis $(168,240)$. However, the ATM-activated p53 signaling pathway is not required for the bystander response (95), as indicated by the finding that bystander effects can be observed in p53-null cells exposed to gamma rays (350) or to Auger-emitting radionuclides (227).

Several studies reported that common p53-regulated radiation response genes, such as cyclin-dependent kinase inhibitor 1 (CDKN1A known as p21 $\left.{ }^{\mathrm{Waf} 1}\right)$, are upregulated in alpha particle-irradiated normal human lung fibroblasts, and also in bystander cells $(8,90)$. Genes regulated by $\mathrm{NF}-\kappa \mathrm{B}$, such as COX-2, IL8, and BCL2A1, also are similarly expressed in bystander and irradiated cells (95).

Following gamma or alpha irradiation, activation of NF$\kappa \mathrm{B}$ signaling leads to the production of cytokines and chemokines, such as IL- $1 \alpha$ and $\beta$, IL-6, TNF $\alpha$, CXCL1, CXCL2, and CXCL8 $(121,158)$ (Fig. 14). Activation can occur within few hours following irradiation and might be ATM dependent. A second activation wave can be observed after $24 \mathrm{~h}$ and this might be related to receptor binding by secreted cytokines, such as TNF $\alpha$ (24). Therefore, NF- $\kappa \mathrm{B}$ could modulate
FIG. 14. The NF-кB and cytokine receptor pathways in the bystander response. DNA DSBs in irradiated cells activate ATM and NEMO that in turn assemble IKK before $\mathrm{I} \kappa \mathrm{B}$ ubiquitination and proteosomal degradation. Released NF- $\kappa \mathrm{B}$ enters the nucleus and induces the transcription of target genes, such as those encoding cytokines. Secreted cytokines can in turn bind to receptors on bystander cells. On binding, receptors will activate NF- $\kappa \mathrm{B}$ responsive element-containing molecules (e.g., cytokines, COX-2, and iNOS), thus contributing to ROS and RNS production and transmission of bystander signals in a self-sustained process. The MAPK and JAK2-STAT3 pathways are also activated by IL8 and IL6, respectively. The TGF $\beta$ receptor also can activate NOS. $\beta$-Cat, $\beta$ catenin; JAK2, Janus kinase 2; PGE2, prostaglandin E2; STAT3, signal transducer and activator of transcription 3; TGF, transforming growth factor. To see this illustration in color, the reader is referred to the web version of this article at www.liebert pub.com/ars
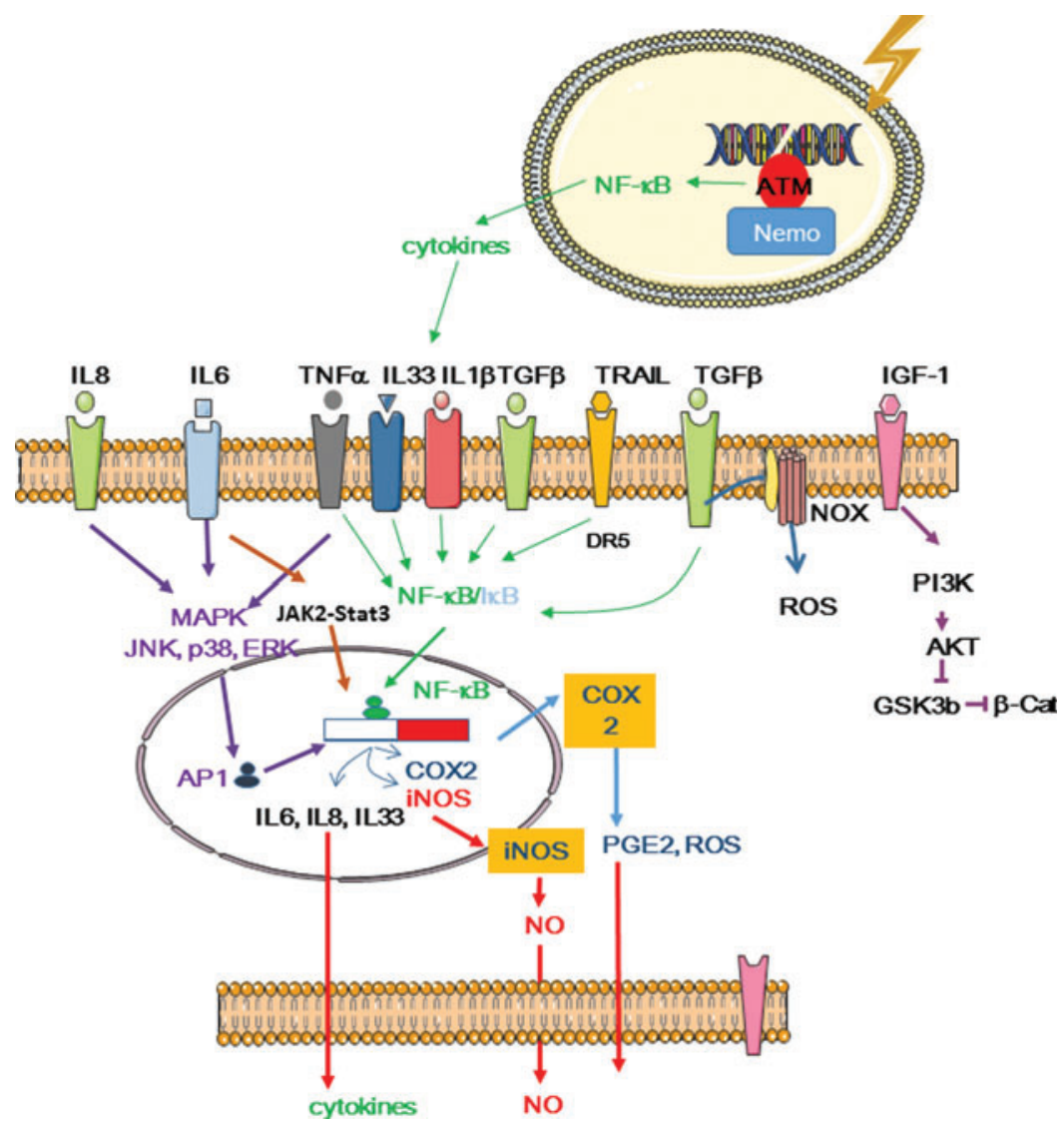
the response of directly irradiated cells and also alert neighboring nonirradiated cells via autocrine and paracrine pathways.

$\mathrm{NF}-\kappa \mathrm{B}$ regulates cytokine production in irradiated cells, but it is controlled by cytokine signaling in bystander cells (151). NF- $\kappa \mathrm{B}$-dependent expression of IL6 via IL6-receptor complex activates the Janus kinase 2 (JAK2)-signal transducer and activator of transcription 3 (STAT3) pathway and STAT3-dependent gene expression, thus establishing a link between ATM, NF- $\kappa \mathrm{B}$, and STAT3. STAT3 is a transcription factor located in the cytoplasm and transferred to nucleus on activation. It also maintains constitutive NF- $\kappa \mathrm{B}$ activation by prolonging NF- $\kappa \mathrm{B}$ nuclear retention $(105,106)$. NF- $\kappa \mathrm{B}$ also transactivates IGF-1 receptor, thereby promoting $\mathrm{PI} 3 \mathrm{~K} /$ AKT-GSK3b- $\beta$-catenin signaling pathways in both irradiated and bystander cells $(94,119,210)$ (Fig. 14).

$\mathrm{NF}-\kappa \mathrm{B}$ can also interfere with the main MAPK signaling. More specifically, it suppresses the JNK cascade and ROS activity $(36,232)$. It must be noted that TRADD, a TNFR1associated signal transducer, can also bind to TRAF2 that activates NF- $\kappa \mathrm{B}$ and Fas-associated protein with death domain (FADD), two proapoptotic factors, whereas NF- $\kappa \mathrm{B}$ is a potent antiapoptotic agent (129).

NF- $\kappa$ B also controls IGF-1 receptor that can activate the downstream (PI3K)-AKT survival pathway in both directly irradiated and bystander fibroblasts (94). In bystander cells, GSK $3 \beta$ phosphorylation by AKT is accompanied by stabilization of beta catenin that acts as a nuclear activator of transcription after GSK3b phosphorylation by WNT signaling (86).

5. The COX-2 and iNOS. The NOS and COX systems include constitutive forms (NOS1, NOS3, and COX-1), which are expressed in many cell types and are mostly involved in housekeeping tasks, and inducible forms (iNOS known as NOS2 and COX-2), which are activated in stress conditions (294). For example, activated macrophages produce clastogenic factors, via superoxide and $\mathrm{NO}$, and can induce gene mutations, DNA base modifications, DNA strand breaks, and cytogenetic damage in neighboring cells.

NOS1 and NOS3 are $\mathrm{Ca}^{2+} /$ calmodulin dependent, while NOS2 is much less. Inducible forms lead to NO production from L-arginine and can be activated by irradiation (181). For example, iNOS activation has been observed as early as $3 \mathrm{~h}$ after X-ray irradiation and lasts over $24 \mathrm{~h}$ (187). Similarly, NOS 1 can be activated by therapeutic doses ( 2 Gy) and blocks the cytoprotective effects of radiation-induced ERK1/ 2 activity (161).

COX-2, also known as prostaglandin endoperoxide synthase 2 (PTGS2), converts arachidonic acid into prostaglandin endoperoxide H2 (PGH2), a precursor of PGE2 involved in inflammation. During this reaction, singlet oxygen can also be released. COX-2 is an inducible enzyme responsible for the generation of ROS and of proinflammatory PGE2 (355).

Expression of iNOS (12) and COX-2 (133) is also controlled by $\mathrm{NF}-\kappa \mathrm{B}$ and is involved in secondary proinflammatory waves following irradiation. Conversely, cNOS can stimulate the early signaling effects of low-dose irradiation (161).

COX-2 is also upregulated in bystander normal human fibroblasts and its inhibition by NS-398 in bystander cells reduces mutagenesis and genetic instability (354). COX-2 is a downstream target of MAPK pathways, such as ERK, JNK, and p38 kinase. Zhou et al. showed that inhibition of ERK phosphorylation suppresses COX-2-mediated bystander response (354). Therefore, as a downstream target of the NF$\kappa \mathrm{B}$ and MAPK/AP1 pathways, COX-2 can be induced by a variety of molecules (TNF $\alpha$, TGF $\beta$, IL6, IL8, IL33, TRAIL, and IGF-1) (293). Finally, radiation-induced activation of $\mathrm{NF}-\kappa \mathrm{B}$ and of its downstream regulated genes that encode cytokines, such as IL-8, IL-6, COX-2-generated PGE2, and IL-33, can lead to COX-2 activation in bystander cells, via autocrine/paracrine stimulation of the NF- $\kappa \mathrm{B}$ and MAPK pathways (134).

Zhou et al. also showed that radiation-induced bystander effects require mitochondria-dependent NF- $\kappa \mathrm{B} / \mathrm{iNOS} / \mathrm{NO}$ and $\mathrm{NF}-\kappa \mathrm{B} / \mathrm{COX}-2 / \mathrm{PGE} 2$ signaling pathways (355). While COX-2 leads to ROS production, it is interesting to note that MnSOD is also activated by $\mathrm{NF}-\kappa \mathrm{B}$ (139), thus providing an antioxidant role for $\mathrm{NF}-\kappa \mathrm{B}$ in agreement with its antiapoptotic and proliferation properties.

We mentioned above that post-translational modifications of p53, through phosphorylation by ATM and also by other kinases, such as CHK2 and homeodomain-interacting protein kinase 2 (HIPK2), contribute to its stabilization and subsequent induction of transcription of downstream genes involved in cell cycle arrest, programmed cell death, or cell metabolism. Accumulation of p53 also attenuates iNOS induction because p53 interacts with TATA binding protein and/or NF- $\kappa \mathrm{B}$ that are essential for $i N O S$ expression (85).

\section{B. Distant/systemic effects}

1. Immune response as the mediator of radiation-induced systemic effects. As discussed above, ionizing radiation can cause a variety of effects in cells directly exposed to radiation and also in neighboring and distant nonirradiated cells (i.e., off-target effects or systemic effects). Recent reviews on the topic describe extensively the biological and chemical molecules that induce and/or participate in the propagation of these various off-target effects. The growing number of data supports the necessity of using different approaches (i.e., bioinformatics and meta-analyses) to have a correct picture of the governing mechanisms and type of biological molecules that contribute to the different off-target effects. The most recent bioinformatic studies and metaanalyses have confirmed the interactions between mediators of systemic effects and DNA damage response/repair (DDR/R) components, as well as interactions between pivotal components of the innate immune response, such as pattern recognition receptors (PRRs), and DNA repair proteins (BRCA1, XRCC1, DNA-PK, Ku70/80, and others) (213).

Nikitaki et al. generated a detailed list of proteins involved in different categories of radiation-induced systemic effects, including the clinically relevant abscopal phenomenon, by using improved methodologies of literature text-mining and various bioinformatic tools. Many of these proteins belong to the DDR complex network and have been found as central hubs in the various protein/protein interaction (PPi) networks, indicating that the key pathways involved in off-target effects are apoptosis, TLR-like, and NOD-like receptor signaling pathways (213) (Fig. 15). PRRs are expressed by the cells of the innate immune system to recognize two classes of molecules and various "danger" signals: pathogen-associated 
Complex DNA damage leads to immune signalling

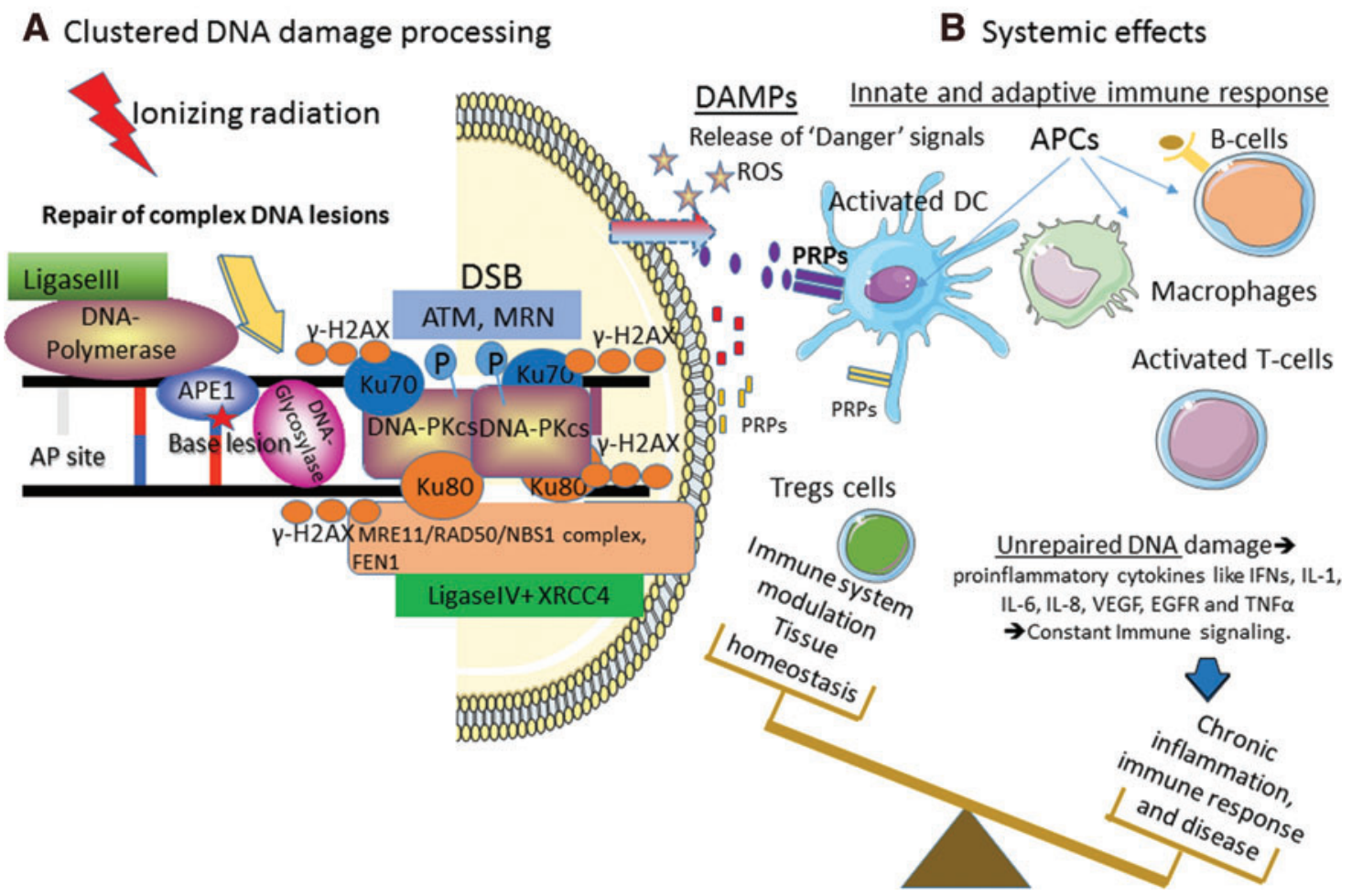

FIG. 15. Complex DNA damage leads to immune signaling. (A) Repair of a clustered damaged DNA site: a challenging task. On induction by ionizing radiation of complex DNA damage, such as a DSB and two oxidative DNA lesions (a damaged base, red star, and an apurinic/apyrimidinic, AP, site), at least two DNA repair pathways and several DNA repair proteins will be activated. For the base damage, BER is the main repair pathway, while for the DSB, only NHEJ will be considered here for simplicity. In all cases, the most basic proteins and enzymes are described. For short-patch BER, a DNA glycosylase will recognize and remove the damaged base and the repair should be completed by the concerted activity of AP endonuclease 1 (APE1), a DNA polymerase, and ligase III to seal the broken ends. In the nearby DSB area (a few bp apart), the Ku heterodimer (Ku70/80) initiates NHEJ by binding to the free DNA ends and engaging other NHEJ factors, such as DNA-PK, XRCC4, and DNA ligase IV, to the DSB site. DNA-PK becomes activated on DNA binding and then phosphorylates a number of substrates, including p53, Ku, and the DNA ligase IV cofactor XRCC4. Phosphorylation of these factors is believed to further facilitate DSB processing. For ligation, the ends must be partially processed by the nucleases Artemis, MRE11/RAD50/NBS1 complex, and FEN-1. Moreover, as shown by advanced fluorescence microscopy, the formation of each DSB is rapidly accompanied by phosphorylation of thousands of histone $\mathrm{H} 2 \mathrm{AX}$ molecules $(\gamma \mathrm{H} 2 \mathrm{AX})$. The MRN complex functions as a sensor of DNA ends and activates the ATM kinase that phosphorylates CHK2, p53, and H2AX in flanking chromosomal regions. (B). Systemic effects. Processing of clustered DNA damage can lead to unrepaired and persistent DNA damage that can cause cell senescence or cell death (i.e., apoptosis). This can trigger the extracellular release of different "danger" signals or damage-associated molecular patterns (DAMPs: ATP, short DNAs/RNAs, ROS, heat shock proteins [HSPs], high-mobility group box [HMGB]-1, S100 proteins, and others). DAMPs activate different PRRs, such as TLRs and the formation of inflammasomes, a process that leads usually to inflammation and immune-related pathologies. Interestingly, recent evidence (see section IV.B.1) suggests a direct interaction between different PRRs and DNA repair proteins. Cell damage or death can also lead to the release of several cytokines and chemokines that can regulate immune responses. PRR activation usually results in NF- $\kappa \mathrm{B}$-mediated release of various proinflammatory cytokines, such as IFNs, IL-1, IL-6, IL-8, VEGF, EGFR, and TNF $\alpha$. The activation of APCs, for instance, dendritic cells and macrophages, will induce primarily the innate immune response (activation of T cells) and most rarely the adaptive immune response (mediated by B cells). In all cases, the constant triggering of the immune system might generate many detrimental systemic effects for the organism. Positive immunomodulation is usually mediated by the action of regulatory (suppressor) T cells (i.e., Treg cells), suppressor macrophages, and immunosuppressive cytokines to maintain overall tissue homeostasis. APCs, antigen-presenting cells; BER, base excision repair; DNA-PK, DNA-dependent protein kinase; EGFR, epidermal growth factor receptor; PRRs, pattern recognition receptors; Treg cells, regulatory T cells; TLRs, Toll-like receptors. To see this illustration in color, the reader is referred to the web version of this article at www.liebertpub.com/ars

molecular patterns (PAMPs), which are associated with microbial pathogens, and DAMPs, which are associated with cellular components that are produced after cell damage or death. In general, PRRs can recognize abnormal molecular complexes as a consequence of infection, inflammation, or other types of cellular stress (195). DAMPs seem to play an important role in the communication of this stress system-wide and in different organisms, from plants, fish, rats to humans, as reviewed in Ref. (188). Several studies have shown that radiation exposure results in the initiation of various triggering 
mechanisms associated with the inflammation and immune responses of the host organism, including the release of proinflammatory cytokines and chemokines by monocytes and macrophages. Radiation-induced cytokine gene upregulation is frequently observed, and several genes encoding inflammation-related cytokines (e.g., IFNs, IL-1, IL-6, IL-8, VEGF, EGFR, and TNF $\alpha$ ) are considered to be "early response" genes that are activated within minutes to hours after irradiation. This process is considered a genuine "danger" signal in response to radiation injury and it is the main source of de novo ROS production. This secondary ROS production can partially explain the late increase in the expression of inflammatory cytokines in irradiated cells (268). Radiationgenerated cytokines are responsible for the formation of inflammatory lesions and work together with DAMPs to create the proinflammatory, pro-oxidant microenvironment necessary to characterize this site as a "stress" site and to induce a systemic response. This is expected to promote maturation of dendritic cells and, in cancer treatment, the development of an effector $\mathrm{T}$ cell response (i.e., innate response to tumorassociated antigens) (Fig. 15). This process is completed by the attraction of cellular components of the immune system, such as neutrophils, and then macrophages and lymphocytes (268).

Overall, the immune response to radiation is highly related also to the radiation sensitivity (i.e., propensity to undergo apoptosis) of the various immune cell subsets, depending on the lineage, maturity, and activation status. B cells and naive $\mathrm{T}$ helper (Th) cells are radiation sensitive, whereas T memory cells, natural killer T cells, and regulatory T cells (Tregs) are more resistant (267). As presented in Figure 15, the final balance between controlled immune response and excessive, pathologically chronic immunogenic response is not easily understood. Certainly, the induction of repair-resistant complex DNA damage on exposure to ionizing radiation is expected to trigger a persistent immune signaling through the continuous activation of the various DNA damage checkpoints that freeze cell cycle until damage is repaired, or direct the cell toward senescence or apoptosis (92). For example, in mice in which the ERCC1-XPF DNA repair endonuclease has been knocked down in all cells or only in adipocytes, DNA damage signaling activates a chronic autoinflammatory response resulting in fat depletion. This response is cell autonomous and most importantly requires ATM, a well-known DNA damage signaling molecule (146).

The role of the innate immune system in coordinating these response types is a rapidly emerging research area (146). As discussed by Gasser et al. (93), the immune system uses mislocalized or damaged DNA to discover infected or otherwise diseased and malfunctioning cells. Conversely, genomic DNA and mtDNA in healthy cells are usually overlooked by the DNA recognition pathways. Furthermore, cells have a limited ability to degrade mislocalized DNA and to repair any damaged DNA, possibly to prevent the unplanned activation of DNA sensor pathways and of the inflammation and immune systems. It is generally accepted that there is a multivariable alliance between DDR and immune signaling and the modulating parameters are not always understood (234). One of the most coherent immune rebalancing activities involves shifting the $\mathrm{T}$ cell equilibrium toward regulatory (suppressor) T cells (i.e., Treg cells), and this can occur after radiotherapy (267). In addition, immunomodulation can be achieved also by the action of suppressor macrophages and immunosuppressive cytokines to secure overall tissue homeostasis (268).

2. Abscopal effects: historical changes and clinical evidence. Although modern radiotherapy is getting progressively closer to its ideal target size or volume, still there are unresolved questions; particularly, it is not clear whether radiation effects are be really limited and localized. The idea of distant, abscopal effects was introduced for the first time by Mole in 1953 (196). Abscopal is made of the " $A b$ " prefix, which means "away from," and "scopos" (Latin), which means shooting mark or target. Therefore, this adjective describes the idea of "off-target" or "away from target" effects and supports the hypothesis of the interdependence of all body cells (196). As suggested by Mole, this practically means that damage to one cell will unavoidably affect the body as a whole. This initial hypothesis was based on the finding that in rats, the thyroid gland synthetic activity was reduced to $25 \%$ of the normal 3 days after localized irradiation with 6-10 Gy. However, this was not caused by whole body irradiation or direct irradiation of the thyroid or the pituitary gland. Moreover, the thyroid function reduction was observed only when a sufficiently large volume of the abdomen was irradiated (196).

Although the idea of abscopal effects seems logical, it has been disregarded in radiotherapy for many years. It took about 50 years to show clear mechanistic evidence, at least in mice, about the immune system's role in this phenomenon (72). Specifically, mice bearing one syngeneic mammary carcinoma (mouse 67NR cells derived from mammary gland malignant neoplasms) in each flank were treated with the growth factor Flt3-Ligand (Flt3-L; daily for 10 days) to boost dendritic cell production, after local radiotherapy (or not) to only one of the two tumors (single dose of 2 or 6 Gy). Growth of the nonirradiated tumor was impaired only in mice that received unilateral radiotherapy and Flt3-L, but not in animals treated only with Flt3-L. This result indicates that immunity is involved in the abscopal effect. Radiotherapy immunostimulatory effects have created a wide interest due to the preclinical and clinical observations that tumorlocalized radiotherapy can occasionally prompt anticancer immune responses that facilitate the regression of distant and nonirradiated metastatic tumors, as recently reviewed in Wennerberg et al. (332).

Although circumstantial evidence existed since the 1950s, abscopal effects are still considered in some cases as unexplained, obscure, or of limited clinical value due to the high specificity and dependence on the type of host organism, tumor, radiation, and so on. In the 1960s, Law and Mole (159) showed direct (i.e., targeted) and abscopal effects of X-ray radiation on the thymus of weanling rats. More recently, many studies using primarily mice or rats described a variety of "off-target" effects $(34,57,137,155,156,184,216,320$, 321 ). Additional work is needed to precisely evaluate the type and degree of abscopal effects in a variety of model organisms [mice (264), rats, earthworms (197)] and different targeted organs (head, thorax, etc.) $(101,152,190,236)$. Very recently, Ventura et al. exploited synchrotron radiation to study targeted radiation-induced "off-target" effects in C57BL/6 mice (317). Under different radiation settings, irradiation of a small leg area induced pronounced persistent systemic genotoxic effects (such as complex DNA damage 
and cell apoptosis) also in nonirradiated areas. These genotoxic events were accompanied by changes in the plasma concentrations of macrophage-derived cytokines, eotaxin, IL10, TIMP1, VEGF, TGF $\beta 1$, and TGF $\beta 2$, as well as changes in the tissue proportion of macrophages, neutrophils, and $\mathrm{T}$ lymphocytes, underlying the strong links between response to radiation and immune system.

It is now quite safe to suggest that local irradiation of a tumor leads to cell death and tissue damage and the release of ROS, cytokines, and danger signals, several of which can trigger an innate immune response (144), although clinical evidence is still rare. One of the first clinical evidences was the description in 2009 of an abscopal effect in a patient with chronic lymphocytic leukemia during radiation therapy (157). One week after X-ray radiotherapy, the lymph nodes in the neck that were not irradiated and distant from the irradiated area started to regress, and after 2 weeks of radiotherapy, they showed complete regression (157). The same year, another patient was diagnosed with acute radiation pneumonitis and other signs of radiation toxicity after spine irradiation. The authors suggested that this should alert clinicians on the toxicity risk for nontarget organs that receive low-dose or zero radiation (283). For a list of the reported clinical cases concerning abscopal effects in patients with nonhematological malignancies and treated by conventional radiation (patient characteristics, treatment strategy, and outcomes), the reader can refer to a relatively recent review by Siva et al. (291).

Currently, the idea that abscopal effects exist and can be modulated primarily via the immune system is progressively more accepted $(87,125,174,261)$. Encouraging results based on case reports and preclinical data suggest that radiotherapy and immunotherapy may synergize to create a scenario of off-target responses away from the radiation field that could be beneficial for the patient $(2,51,60,70,71,116,171,273$, 301). DDR mechanisms and inflammatory responses have been recently observed in patients undergoing radiotherapy for nonsmall-cell lung cancer. The observed abscopal effect was also linked to changes in the plasma levels of MDC/ CCL22 and MIP-1alpha/CCL3 cytokines (290). Undoubtedly, one of the major breakthroughs is the finding that the combination of radiation and immunotherapy to boost the immune system (e.g., with the human monoclonal antiCTLA-4 antibody ipilimumab) induces immune-mediated abscopal effects in poorly immunogenic preclinical tumor models and in patients with metastatic melanoma or other cancer types $(62,100,237)$. The suggested mechanism for this therapeutic type is that the anti-CTLA4 monoclonal antibody binds to CTLA4 expressed on the surface of T cells and inhibits the CTLA4-mediated downregulation of $\mathrm{T}$ cell activation (75). This consequently leads to a boosted cytotoxic $\mathrm{T}$ lymphocyte (CTL)-mediated synergistic immune response against cancer cells and high tumor immunity, especially when combined with radiation. Currently, the National Cancer Institute (NCI) lists only one Phase I clinical trial for solid cancers or lymphoma. This is a multicenter study to evaluate the safety of an anti-CTLA-4 human monoclonal antibody (AGEN1884) and to estimate the maximum tolerated dose in subjects with advanced or refractory cancer (Clinicaltrials.gov ID: NCT02694822).

Another early example of regression of hepatocellular carcinoma was observed after radiotherapy (total dose of 36
Gy) for bone metastasis (220). Doses of 2 and 6 Gy have been used in combination with the dendritic cell growth factor Fms-related tyrosine kinase 3 (FLT3) or with injection of dendritic cells in tumors as immune therapy $(72,150)$. In mice with melanoma tumors, a single fraction of 15 Gy showed similar results as $3 \times 5$ Gy and was accompanied by the generation of tumor antigen-specific effector cells that traffic to the tumor (175). The combination of anti-CTLA4 antibodies with fractionated irradiation $(3 \times 8$ Gy or $5 \times 6$ Gy), but not single-dose irradiation ( $20 \mathrm{~Gy}$ ), showed tumor growth delay outside the field of irradiation in preclinical models (300).

\section{Off-target effects: an integrated cell response to radiation: conclusion}

It was initially thought that the harmful effects of ionizing radiation were caused by clusters of DNA lesions, involving DNA DSBs, in irradiated cells. However, several observations progressively modified this DNA-centered paradigm view of radiobiology. First, the yields of radiation-induced ROS and RNS formation and subsequently of DNA lesions were relatively low compared with the endogenous production [mainly by mitochondria, $\mathrm{NAD}(\mathrm{P}) \mathrm{H}$ oxidases]. Second, DNA lesions involving DDR activation were observed in cells that had not been traversed by radiation, but that were close to irradiated cells (bystander effects). These bystander effects are the consequence of oxidative stress signals initiated in irradiated cells and propagated to neighboring cells. In this context, not only the initial nuclear DNA breaks but also all the cell compartments (cell membrane, mitochondria, ER) and associated complex networks that involve $\mathrm{Ca}^{2+}$ release and ROS/RNS production through NF- $\kappa \mathrm{B}$, iNOS, and COX activation have to be considered. Increased oxidative stress in irradiated cells and its transmission also to neighboring cells can amplify the initial response.

Distant systemic effects of radiation, which in the clinic are often called abscopal effects, are generally accepted nowadays and probably complete the picture of radiation effects in the whole body. Similarly to bystander effects, they are initiated by local DNA damage in irradiated cells or tissue. This can be considered the triggering effect that marks the irradiated area as a "stress" area in the body. Distant radiation effects involve the release of short and long distance messengers to convey the stress signal to distant sites by the mediation of well-conserved inflammatory and immune response networks. In the clinic, the most extreme manifestation of this phenomenon is tumor shrinkage in distant sites not reached by irradiation. This knowledge could pave the way to clinical applications of this systemic effect of radiation treatment.

\section{Benefit/Risk Analysis}

In the clinic, irradiation is used to destroy tumor cells by triggering cell death mechanisms. Innovative technologies and procedures have been developed in conventional EBRT, and the use of radionuclides for both imaging and therapy has progressively gained interest in the last two decades. Predicting the potential consequences of off-target effects is required for both radiation effectiveness and radiation risk assessment (247). 


\section{A. Target theory}

The prediction of therapeutic efficacy and of side effects of radiation exposure relies on the establishment of dose/effect relationships between radiation dose and tissue reactions. Most radiobiological studies have used EBRT, generally with gamma and X-rays (244). The biological effects induced by radiation at medium ( $0.5-5 \mathrm{~Gy})$ to high doses $(5-15 \mathrm{~Gy})$ are quite well known (140). They are usually subdivided as follows: (i) nonstochastic effects (also called deterministic or tissue reaction effects) that occur above a certain threshold $(>0.5 \mathrm{~Gy})$ and the severity of which increases with the dose; and (ii) stochastic effects (genetic risks in offspring and cancer) for which there is no threshold, but only a probability of occurrence. The tumor tissue response to radiation (assimilated to the tumor control probability, TCP) belongs to the nonstochastic effects category. In EBRT, it is proportional to the dose according to a sigmoid curve. At the molecular level, this curve reflects the eradication of the most radioresistant clonogenic malignant cells present in the tumor. TCP can be described using mathematical models, and cell killing can be analyzed using the Poisson law as statistical model. The " $N$ " in the Poisson law defines the probability for targets to be hit $N$ times $(160,351)$. Therefore, the survival fraction $(\mathrm{S})$ is the survival probability $[p(0)]$ for a cell that receives no lethal hit $[\mathrm{S}=p(0)=\exp (-\tilde{N}), \tilde{N}$ being the average number of lethal lesions] (324).

This model has been later replaced by a linear quadratic (LQ) model [S $=\exp \left(-\alpha \mathrm{D}-\beta \mathrm{D}^{2}\right)$ where $\alpha$ and $\beta$ are constant parameters and $\mathrm{D}$ is the dose. $\tilde{N}$ contains linear $(\alpha \mathrm{D})$ and quadratic $\left(\beta \mathrm{D}^{2}\right)$ terms, indicating that lethal lesions could be caused by one single track $\left(\alpha \mathrm{D}\right.$ term) or two tracks $\left(\beta \mathrm{D}^{2}\right.$ term). In this model, two tracks $\left(\beta \mathrm{D}^{2}\right.$ term) produce less severe lesions (called sublethal lesions) that, taken individually, could be repaired in the absence of the second track deleterious effects. Conversely, the single track of the $(\alpha \mathrm{D})$ term corresponds to a lethal lesion. The $(\alpha / \beta)$ ratio refers to the cell repair capacity and radiosensitivity. This formulation has the advantage of considering both physical hits and molecular response (148). The $\alpha / \beta$ ratio has been determined clinically for normal tissues and tumors $(17,18,63,64,138$, 288 ). Tissues with small $\alpha / \beta$ ratio values have greater repair capacity and are more sensitive to dose fractionation than tissues with high ratio values.

In this context, tumor eradication means that no clonogenic cell survives. Therefore, TCP is strictly proportional to the number of clonogenic cells, depending on the dose: TCP $=$ $\exp (-N \mathrm{~s})$ where $N \mathrm{~s}$ is the number of clonogenic cells and contains the $\left(-\alpha \mathrm{D}-\beta \mathrm{D}^{2}\right)$ expression (138).

\section{$B$. The clinical relevance of off-target effects might be radiotherapy dependent}

On the contrary, a general rule about the benefit/risk ratio of off-target effects in radiotherapy might not exist because this response is influenced by many parameters: type of radiotherapy, dose ranges, dose rates, dose fractionation, and radiation type (photons vs. charged particles). In conventional EBRT, X-rays (usually 2 Gy fractions for $1-2 \mathrm{~min}$ ) are delivered over several days and weeks to reach the final tumor biological effective dose. Improvement in conforming irradiation to the tumor volume to protect healthy tissues has led to the development of 3D-conformal radiation therapy and more recently to intensity-modulated radiation therapy (IMRT) and image-guided radiation therapy using computed tomography, positron emission tomography, or magnetic resonance imaging. Other irradiation modalities, including tomotherapy, stereotactic radiosurgery, stereotactic body radiation therapy (SBRT), involved-field radiation therapy, have been developed (247). Therefore, it is becoming difficult to extrapolate radiobiology notions for conventional treatment with $2 \mathrm{~Gy} \cdot \mathrm{min}^{-1}$ to other irradiation methods, for instance, SBRT with high doses of radiation. High LET particles, such as heavy carbon ions and protons, are now routinely used in the clinic $(21,222)$. They take advantage of the spread out Bragg peak (145).

Radionuclide therapy is another procedure where offtarget effects have to be considered. Radionuclides are used for the treatment of various diseases, such as thyroid cancer with ${ }^{131} \mathrm{I}$, lymphoma with radiolabeled anti-CD20 monoclonal antibodies $\left({ }^{90} \mathrm{Y}\right.$-ibributomab tiuxetan; Zevalin $\left.{ }^{\mathrm{TM}}\right)$, neuroendocrine tumors with ${ }^{177} \mathrm{Lu}$-DOTA0-Tyr3-octreotate $\left(\right.$ Lutathera $\left.^{\mathrm{TM}}\right)$, neuroblastoma, carcinoid tumor, pheochromocytoma, paraganglioma with ${ }^{131}$ I-meta-iodobenzylguanidine (MIBG), bone metastases from prostate cancer with ${ }^{223} \mathrm{RaCl}_{2}$, and hepatocellular carcinoma with ${ }^{90} \mathrm{Y}$ microspheres. Other radionuclides are used for palliative treatment of bone metastases $\left({ }^{89} \mathrm{Sr},{ }^{153} \mathrm{mSr},{ }^{186} \mathrm{Re},{ }^{188} \mathrm{Re},{ }^{223} \mathrm{Ra}\right.$ ) (33), and many other radiolabeled antibodies or peptides are currently assessed in clinical trials.

The particularity of radionuclide therapy is that radionuclides are targeted by conjugation with peptides or antibodies and are then injected in the circulation. The dose is delivered over several hours and days, at a relatively low-dose rate. The delivered dose can be strongly heterogeneous because of tumor-site accessibility issues and also because of the particles used (beta, alpha, and Auger electrons). Heterogeneity also occurs at the whole-body scale because the whole body may be irradiated (at variable doses), although the highest dose is delivered to the tumor. Moreover, the interplay between the radiation effects and the biological effects of the vector should also be considered (243). Because of its physical features, radionuclide therapy could be, to some extent, assimilated to low-dose rate brachytherapy using sealed sources of ${ }^{125} \mathrm{I}$ for prostate cancer treatment. Moreover, as some of the radionuclides $\left(e . g .,{ }^{223} \mathrm{Ra},{ }^{213} \mathrm{Bi},{ }^{225} \mathrm{Ac}\right.$, ${ }^{211} \mathrm{At},{ }^{212} \mathrm{~Pb} /{ }^{212} \mathrm{Bi}$ ) are high-LET particle emitters, some forms of targeted radionuclide therapy show similarities, to some extent, with external radiotherapy using other types of high-LET particles, such as heavy ions or protons. Therefore, there is not one form of radiotherapy but many. Consequently, the assessment of the contribution of off-target effects should be considered a major field of research without a universal rule. For instance, Mairs's team showed that the bystander response to the same MIBG molecule labeled with alpha, Auger, or beta emitters produces different effects (31).

\section{Bystander effects and radiation protection}

There is evidence of in vivo $(16,33,228,243,339)$ and $e x$ vivo (16) bystander effects during EBRT and radionuclide therapy. In conventional EBRT, bystander effects are mainly expected to contribute significantly to the cell outcome at low doses $(<0.5 \mathrm{~Gy})(248,274)$. This is due to the observation that 
targeted effects increase with the dose, while bystander effects saturate as the dose increases. Therefore, targeted effects predominate at high dose compared with bystander effects. Conversely, Mothersill and Seymour showed that in vitro, cell death caused by gamma-ray doses comprised between 0.01 and $0.5 \mathrm{~Gy}$ is only due to bystander effects (274). However, bystander effects are also observed after high-dose irradiation (26).

At doses below 0.1-0.2 Gy, only stochastic effects, including cancer, are relevant for assessing the tissue response. Such doses can be encountered during environmental exposures and also during treatment in nontumor tissues located at the margin of the irradiation field, or in the presence of dose gradients, particularly in IMRT, tomotherapy, and heavy ion particle therapy. It also concerns diagnostic radiological procedures and possibly also nuclear medicine. It must be also noted that the assessment of the dose delivered to the tumor and healthy tissues is more difficult and challenging during radionuclide therapy than EBRT, making risk assessment even more complicated.

The effects of such low doses, essentially cancer induction, could be predicted by extrapolating from assessments at high dose and by correcting for factors that account for low-dose rate and low dose, according to a linear no-threshold (LNT) model. The LNT model assumes that detrimental effects decrease according to the dose rate and are proportional to the dose. According to the "target theory" that relies mainly on a DNA-centered view of radiobiology (3), detrimental effects of radiation (mutagenesis, carcinogenesis, and cell death) are only observed in irradiated cells (more precisely in their nucleus) and in their progeny. This view is now challenged by the identification of harmful effects of radiation also in nonirradiated cells (off-target effects) and their amplification. However, the subject is still a matter of debate because there are many experimental and epidemiological evidences showing that it makes sense to extrapolate the risk from high to low doses. Nevertheless, many other studies highlight some of the weaknesses of the target theory (140).

The theory behind off-target and bystander effects considers that cells can die without being crossed by particles, that is, without having absorbed any energy from radiation. The ultimate consequence is that irradiated cells cannot be considered anymore as an independent entity, the final fate of which depends solely on the delivered dose and on their intrinsic radiosensitivity, which is one of the bases of the "target theory." Conversely, the interplays with the microenvironment and even with the whole body through systemic communication that involves the blood and lymphoid compartments have to be considered.

\section{The biology of low dose and low-dose rate might differ from that of high dose and high-dose rate}

Besides bystander effects, several other phenomena, such as inverse dose rate effect and low-dose hypersensitivity, challenge the LNT model and risk assessment. For example, genomic instability frequency is higher at low than at high doses (309), and bystander effects have also been observed at low EBRT doses and after one single alpha particle track. As mentioned above, the RIAR shows that a priming dose (generally $>0.005 \mathrm{~Gy}$ ) reduces the detrimental effects of the challenging dose administered a few hours later (140, 275).
Therefore, it is likely that extrapolating data from high to low dose cannot be corrected solely by considering that cells have more time to repair DNA DSBs at low-dose rate, but by considering to some extent different biological mechanisms.

\section{E. Off-target effects and radiotherapy efficacy}

The existence of off-target effects might be an advantage for tumor eradication, although they are still difficult to control. One of the challenges is now to define the best radiotherapy plan (dose, dose rate, LET) and combination for promoting these effects. There have been several approaches (247) based on gene therapy to introduce NOS2 (328) and to use radiationiNOS promoters (334). Gene therapy with human telomerase promoters associated with targeted radiotherapy using ${ }^{131} \mathrm{I}$ MIBG radionuclides has also been investigated by Boyd et al. (31). Some strategies focused on DNA because DNA repair in bystander cells is different compared with irradiated cells and involves ATR upstream of ATM $(38,96)$, highlighting the role of stalled DNA replication forks. In this respect, BRCA1, FANCD2, and CHK1 have been identified as potential molecular targets in bystander cells (37).

The parameters affected by new clinical practices are dose and fractionation (hypo- and hyperfractionation). In some way, radionuclide therapy could be assimilated to hyperfractionated therapy. It is clear that dose and dose fractionation can modify the contribution of off-target effects to the final outcome. It was shown that the bystander response resulting from fractionated irradiation is different in tumor and healthy tissues (203).

The dose influence on the bystander response was reviewed by Tomita and Maeda (307). Bystander cell death induced by doses as low as 0.01 Gy of low LET radiation $(\gamma$ rays from ${ }^{60} \mathrm{Co}$ ) is similar to the cell death caused by exposure of nonirradiated cells to conditioned medium from cells irradiated at the same dose. It seems that there is a threshold above 2-3 $\mathrm{mGy}$ and bystander response reaches a plateau at $0.3 \mathrm{~Gy}(169)$. The influence of dose and dose rate on abscopal effects was reviewed by Rodel et al. (258). Radiationinduced immunosuppressive effects are observed at relatively low and clinically relevant doses $(<0.5-1 \mathrm{~Gy})$ and include depletion of immune cells, polarization of M2 macrophages, and increase in the number of radioresistant Treg cells. Irradiation immunosuppressive effects have been used as early as 1898 to treat chronic inflammatory diseases (X-ray-treated polyarthritis). Currently, radionuclides $\left({ }^{89} \mathrm{SrCl}_{2},{ }^{153} \mathrm{Sm}\right.$ EDTMP, or ${ }^{186 / 188} \mathrm{Re}-\mathrm{HEDP}$ ) are proposed for the palliative treatment of bone metastases. Indeed, the palliative effects of low doses should be mediated by innate immune cells, such as macrophages. In function of their microenvironment, macrophages can behave as proinflammatory actors (classically, the activated $\mathrm{M} 1$ phenotype) that secrete proinflammatory cytokines (IL-6, TNF $\alpha$, IL-1), and chemotactic factors (IL-8 and CCL20), or as anti-inflammatory cells (M2 macrophages). Moreover, both initiation and resolution of inflammation participate in tissue homeostasis. In this way, macrophages are involved in several functions, including phagocytosis (CD31), antigen presentation through CD40 receptors, secretion of cytokines (TNF $\alpha$ or IL-1 under the control of NF- $\kappa \mathrm{B}$ ), ROS release, and RNS production through iNOS.

At doses of 0.5 and $0.7 \mathrm{~Gy}$, secretion of proinflammatory cytokines $(e . g ., \mathrm{TNF} \alpha)$ is reduced in macrophages derived 
from human THP-1 cells and in mouse macrophages stimulated by LPS (313). The TNF family is involved in ROS production required for pathogen killing by phagocytes. In turn, ROS activate NF- $\kappa \mathrm{B}$, leading to additional $\mathrm{TNF} \alpha$ production. However, although iNOS expression in macrophages is increased in inflammation, radiation seems to decrease its expression in some cases (268). This could be mediated by an increase in the stress protein heme oxygenase 1 (HO-1) (123). Therefore, the anti-inflammatory effect of low doses of ionizing radiation could be mediated by reduction in NO production. Moreover, low-dose irradiation can promote secretion of the anti-inflammatory cytokines TGF $\beta 1-3$ by M2 macrophages $(258,312)$. Production of IL$1 \beta$ also is decreased in macrophages of radiosensitive Balb/c mice exposed to 0.5 or 0.7 Gy of ionizing irradiation (X-ray) (88). The authors mentioned that $0.5 \mathrm{~Gy}$ gamma radiation causes upregulation of MAPK phosphatase-1 (MKP-1), leading to inactivation of the p38 MAPK and suppression of $\mathrm{TNF} \alpha$ production.

Conversely and as previously discussed, abscopal effects have been described in preclinical models and in patients at higher doses than those causing bystander effects (2-40 Gy) (258). Their occurrence and contribution to the final antitumor efficacy depend on the tumor and its microenvironment. Moreover, they are more pronounced when using therapeutic combinations that activate the immune system, such as injection of dendritic cells $(87,261)$. Currently, the critical factors orchestrating the overall response of the tumor and of the organism to irradiation are not clearly defined. Nevertheless, it is accepted that there is a synergy between tumor response, radiation toxicity, and immune system.

\section{F. Benefit/risk analysis: conclusion}

The off-target effects of radiation are a major concern both for radiotherapy and radiation protection. The relative contribution of off-target effects to the final therapeutic efficacy and to the detrimental effects of radiation might depend strongly on the type of exposure (e.g., dose, low vs. high LET, protracted $v s$. acute irradiation, homogeneous $v s$. heterogeneous irradiation). Off-target effects are relatively difficult to predict and to control, but they can be advantageous for tumor treatment. In EBRT, bystander effects should be predominant at low dose $(0.5 \mathrm{~Gy})$, compared with targeted effects, the contribution of which increases with dose and becomes predominant at high doses. However, the contribution of off-target effects might vary in function of the radiotherapy type (e.g., radionuclide therapy), although the response is expected to reach a plateau. On the contrary, abscopal effects could be exploited at higher doses, by using appropriate treatment combinations and doses.

Radiation protection systems rely on the LNT model. Although it is now clear that off-target effects (e.g., bystander and abscopal effects) must be considered both at low and high doses, it is still not known whether epidemiologically, these effects will be traduced statistically to an increase or decrease of the risk for healthy tissues. Although new findings highlight the possible role of off-target and delayed cellular effects, UNSCEAR considers that the current risk estimates for irradiation-induced cancer and hereditary effects in humans do not need to be changed.

\section{General Conclusion}

In this review, we presented in an analytical way the current status of knowledge in the area of off-target and awayfrom-target ionizing radiation effects with special emphasis on their role on radiation therapy and clinical applications. After years of intensive in vitro and in vivo (animals) research and circumstantial clinical evidence in humans, the idea of offtarget effects has gained high interest and is increasingly accepted by the scientific community. It is certainly considered a paradigm shift from the target theory in radiation biology where biological important components of the cells must be directly hit from radiation to show a radiation response.

Undoubtedly, radiation harmful effects are linked to the induction of a high percentage of clustered lesions that destroy the target (i.e., any cellular component, but particularly DNA, proteins, and the cell membrane with its lipids). Although in this review, we focused on DNA, we cannot disregard the importance of other cell targets that could contribute to the radiation response and systemic effects in the organism. We also believe that ionizing radiation effects must be evaluated at the whole organism level and not just in the directly hit area. Therefore, we discussed the prevailing mechanisms underlying off-target effects, particularly the release of radical species (ROS/RNS) from the irradiated area, induction of the DDR, and repair and activation of a variety of danger/stress signals that relate to the various forms of radiation injury and apoptosis (Figs. 6 and 14). The result is usually a proinflammatory response and in many cases, the activation of the immune system, a process that shows many similarities with the stress response on damage or pathogen intrusion. We described all the key molecules that participate in this process, such as the NF- $\kappa \mathrm{B} / \mathrm{COX}-2$ signaling pathways, and the relevant experimental evidence. We also discussed the emerging view on the role of complex DNA damage because from an evolutionary point of view, this is the only discriminating factor between irradiation-induced and endogenous oxidative stress-induced damage (Fig. 15).

We then discussed the clinical importance of these molecular mechanisms and of the association between targeted and off-target radiation mechanisms. We described the existing evidence for the systemic nature of radiation effects (i.e., abscopal phenomenon). In our opinion, abscopal effects are a genuine manifestation of the holistic nature of the body response to radiation, even when administered to a localized area. Strong in vivo evidence in various model organisms (from animals to humans) supports the induction of radiation effects at sites distant from the irradiation site. Many of these studies reported tumor regression and the involvement of the innate immune system, thus underlying the strong links between the radiation response mechanisms (e.g., DNA damage sensing, DNA repair, and apoptosis) and immune system activation. The involvement of the immune system is supported by the finding that the combination of radiation with immune system-boosting drugs, such as the anti-PD-1 (MEDI0680) or anti-CTLA-4 (AGEN1884) monoclonal antibodies, led to a reduction of the size of a metastatic nonirradiated tumor and of cancer spread in the body. These new treatments that combine radiation and immunotherapies are based on radiation biology data showing that the radiation response occurs at the wholeorganism level, something which was often disregarded up to few years ago. Although many questions on the propagation 
mechanisms of off-target effects still exist, these new concepts open the way for the development of more efficient radiationbased immunotherapies and other adjuvant therapies.

\section{Key Points}

Cell damage is mediated by the direct interaction of ionizing radiation with water and cellular constituents, such as DNA, lipids, and proteins.

Radiation generates "danger" signals that propagate from irradiated to nonirradiated cells, leading to off-target (bystander and abscopal/distant) effects.

Redox mechanisms also play a key role in both targeted and off-target radiation effects.

$\mathrm{NF}-\kappa \mathrm{B}$ is essential for triggering the self-sustained production of reactive oxygen and nitrogen species (ROS and RNS) that are involved in both targeted and off-target radiation effects.

The level of damage produced by radiation is relatively lower than that caused by endogenous oxidative stress.

The harmful effects of radiation are explained not only by the induction of closely spaced (clustered) DNA lesions but also by the amplification of the initial radiation-induced cellular response.

Immune cells can be recruited and contribute to the distant (abscopal) effects of irradiation with potential clinical implications.

Differently from targeted effects (e.g., the induction of DNA damage), off-target effects are not strictly dose related.

Although there is evidence of off-target effects existence in vivo through the mediation of the immune system and of their applicability in cancer immunotherapy (e.g., use of immune checkpoint inhibitors), they are still difficult to predict and control.

Off-target effects contribution is likely to depend on the irradiation physical parameters (type and level of damage) as well as on the type of tissue and organism.

Radiation-induced systemic phenomena (as opposed to localized, direct damage) represent a radiobiology paradigm shift and must be taken into account in radiation protection as well as in radiotherapy.

\section{Acknowledgments}

This research has been financed by Action Nu1.1 of Plan Cancer 2009-2013 (ASC 13038FSA), the French National Research Agency under the program "Investissements d'avenir" Grant agreement LabEx MabImprove: ANR-10LABX-53, Labex PRIMES: ANR-11-LABX-0063, Ligue Nationale Contre le Cancer, Electricité de France Comité de Radioprotection, Le segment Radiobiologie du CEA, by "Research Projects for Excellence IKY/SIEMENS" and DAAD grant "DNA Damage and Repair and Their Relevance to Carcinogenesis”, (No. 57339330).

\section{References}

1. Abdelrazzak AB, Pottgiesser SJ, Hill MA, O'Neill P, and Bauer G. Enhancement of peroxidase release from nonmalignant and malignant cells through low-dose irradiation with different radiation quality. Radiat Res 185: 199213, 2016.
2. Abuodeh Y, Venkat P, and Kim S. Systematic review of case reports on the abscopal effect. Curr Probl Cancer 40: 25-37, 2016.

3. International Atomic Energy Agency (IAE). Radiation Dose in Radiotherapy-Dose-Effect Relationship. 1996. Radiation Dose in Radiotherapy from Prescription to Delivery, IAEATECDOC-896, ISSN 1011-4289, Vienna, 1996, pp. 273.

4. Ahmed KM, Nantajit D, Fan M, Murley JS, Grdina DJ, and Li JJ. Coactivation of ATM/ERK/NF-kappaB in the low-dose radiation-induced radioadaptive response in human skin keratinocytes. Free Radic Biol Med 46: 15431550, 2009.

5. Akudugu JM, Azzam EI, and Howell RW. Induction of lethal bystander effects in human breast cancer cell cultures by DNA-incorporated Iodine-125 depends on phenotype. Int J Radiat Biol 88: 1028-1038, 2012.

6. Ameziane-El-Hassani R, Talbot M, de Souza Dos Santos MC, Al Ghuzlan A, Hartl D, Bidart JM, De Deken X, Miot F, Diallo I, de Vathaire F, Schlumberger M, and Dupuy C. NADPH oxidase DUOX1 promotes long-term persistence of oxidative stress after an exposure to irradiation. Proc Natl Acad Sci U S A 112: 5051-5056, 2015.

7. Autsavapromporn N, Suzuki M, Funayama T, Usami N, Plante I, Yokota Y, Mutou Y, Ikeda H, Kobayashi K, Kobayashi Y, Uchihori Y, Hei TK, Azzam EI, and Murakami T. Gap junction communication and the propagation of bystander effects induced by microbeam irradiation in human fibroblast cultures: the impact of radiation quality. Radiat Res 180: 367-375, 2013.

8. Azzam EI, de Toledo SM, Gooding T, and Little JB. Intercellular communication is involved in the bystander regulation of gene expression in human cells exposed to very low fluences of alpha particles. Radiat Res 150: 497-504, 1998.

9. Azzam EI, de Toledo SM, and Little JB. Oxidative metabolism, gap junctions and the ionizing radiation-induced bystander effect. Oncogene 22: 7050-7057, 2003.

10. Azzam EI, De Toledo SM, Spitz DR, and Little JB. Oxidative metabolism modulates signal transduction and micronucleus formation in bystander cells from alphaparticle-irradiated normal human fibroblast cultures. Cancer Res 62: 5436-5442, 2002.

11. Azzam EI, Raaphorst GP, and Mitchel RE. Radiationinduced adaptive response for protection against micronucleus formation and neoplastic transformation in $\mathrm{C} 3 \mathrm{H}$ 10T1/2 mouse embryo cells. Radiat Res 138: S28-S31, 1994.

12. Barnes PJ and Karin M. Nuclear factor-kappaB: a pivotal transcription factor in chronic inflammatory diseases. $N$ Engl J Med 336: 1066-1071, 1997.

13. Beckman JS and Koppenol WH. Nitric oxide, superoxide, and peroxynitrite: the good, the bad, and ugly. Am J Physiol 271: C1424-C1437, 1996.

14. Bedard K and Krause KH. The NOX family of ROSgenerating NADPH oxidases: physiology and pathophysiology. Physiol Rev 87: 245-313, 2007.

15. Belyakov OV, Folkard M, Mothersill C, Prise KM, and Michael BD. Bystander-induced differentiation: a major response to targeted irradiation of a urothelial explant model. Mutat Res 597: 43-49, 2006.

16. Belyakov OV, Mitchell SA, Parikh D, Randers-Pehrson G, Marino SA, Amundson SA, Geard CR, and Brenner DJ. Biological effects in unirradiated human tissue in- 
duced by radiation damage up to $1 \mathrm{~mm}$ away. Proc Natl Acad Sci U S A 102: 14203-14208, 2005.

17. Bentzen SM. Radiobiological considerations in the design of clinical trials. Radiother Oncol 32: 1-11, 1994.

18. Bentzen SM, Christensen JJ, Overgaard J, and Overgaard M. Some methodological problems in estimating radiobiological parameters from clinical data. Alpha/beta ratios and electron RBE for cutaneous reactions in patients treated with postmastectomy radiotherapy. Acta Oncol 27: 105-116, 1988.

19. Bergeron F, Auvre F, Radicella JP, and Ravanat JL. HO* radicals induce an unexpected high proportion of tandem base lesions refractory to repair by DNA glycosylases. Proc Natl Acad Sci U S A 107: 5528-5533, 2010.

20. Berridge MJ. The inositol trisphosphate/calcium signaling pathway in health and disease. Physiol Rev 96: 12611296, 2016.

21. Bienert GP, Schjoerring JK, and Jahn TP. Membrane transport of hydrogen peroxide. Biochim Biophys Acta 1758: 994-1003, 2006.

22. Birben E, Sahiner UM, Sackesen C, Erzurum S, and Kalayci O. Oxidative stress and antioxidant defense. World Allergy Organ J 5: 9-19, 2012.

23. Bishayee A, Hill HZ, Stein D, Rao DV, and Howell RW. Free radical-initiated and gap junction-mediated bystander effect due to nonuniform distribution of incorporated radioactivity in a three-dimensional tissue culture model. Radiat Res 155: 335-344, 2001.

24. Biton S and Ashkenazi A. NEMO and RIP1 control cell fate in response to extensive DNA damage via TNF-alpha feedforward signaling. Cell 145: 92-103, 2011.

25. Blair IA. DNA adducts with lipid peroxidation products. $J$ Biol Chem 283: 15545-15549, 2008.

26. Blyth BJ and Sykes PJ. Radiation-induced bystander effects: what are they, and how relevant are they to human radiation exposures? Radiat Res 176: 139-157, 2011.

27. Bock J, Szabo I, Gamper N, Adams C, and Gulbins E. Ceramide inhibits the potassium channel Kv1.3 by the formation of membrane platforms. Biochem Biophys Res Commun 305: 890-897, 2003.

28. Bourbon NA, Yun J, and Kester M. Ceramide directly activates protein kinase $\mathrm{C}$ zeta to regulate a stress-activated protein kinase signaling complex. J Biol Chem 275: 35617-35623, 2000.

29. Bourdat A-G, Douki T, Frelon S, Gasparutto D, and Cadet J. Tandem base lesions are generated by hydroxyl radical within isolated DNA in aerated aqueous solution. $J \mathrm{Am}$ Chem Soc 122: 4549-4556, 2000.

30. Bowser DN and Khakh BS. Vesicular ATP is the predominant cause of intercellular calcium waves in astrocytes. J Gen Physiol 129: 485-491, 2007.

31. Boyd M, Ross SC, Dorrens J, Fullerton NE, Tan KW, Zalutsky MR, and Mairs RJ. Radiation-induced biologic bystander effect elicited in vitro by targeted radiopharmaceuticals labeled with alpha-, beta-, and auger electron-emitting radionuclides. J Nucl Med 47: 1007-1015, 2006.

32. Brach MA, Hass R, Sherman ML, Gunji H, Weichselbaum R, and Kufe D. Ionizing radiation induces expression and binding activity of the nuclear factor kappa B. $J$ Clin Invest 88: 691-695, 1991.

33. Brady D, O'Sullivan JM, and Prise KM. What is the role of the bystander response in radionuclide therapies? Front Oncol 3: 215, 2013.
34. Brennan JT. Closing remarks for session on dose distribution, partial-body exposure and abscopal effects. Ann N Y Acad Sci 114: 339-340, 1964.

35. Brown DA and London E. Functions of lipid rafts in biological membranes. Annu Rev Cell Dev Biol 14: 111136, 1998.

36. Bubici C, Papa S, Pham CG, Zazzeroni F, and Franzoso G. NF-kappaB and JNK: an intricate affair. Cell Cycle 3: 1524-1529, 2004.

37. Burdak-Rothkamm S, Rothkamm K, McClelland K, Al Rashid ST, and Prise KM. BRCA1, FANCD2 and Chk1 are potential molecular targets for the modulation of a radiation-induced DNA damage response in bystander cells. Cancer Lett 356: 454-461, 2015.

38. Burdak-Rothkamm S, Rothkamm K, and Prise KM. ATM acts downstream of ATR in the DNA damage response signaling of bystander cells. Cancer Res 68: 7059-7065, 2008.

39. Burdak-Rothkamm S, Smith A, Lobachevsky P, Martin R, and Prise KM. Radioprotection of targeted and bystander cells by methylproamine. Strahlenther Onkol 191: 248255, 2015.

40. Burlando B and Viarengo A. $\mathrm{Ca}^{2+}$ is mobilized by hydroxyl radical but not by superoxide in RTH-149 cells: the oxidative switching-on of $\mathrm{Ca}^{2+}$ signaling. Cell Calcium 38: 507-513, 2005.

41. Cadet J, Bellon S, Douki T, Frelon S, Gasparutto D, Muller E, Pouget JP, Ravanat JL, Romieu A, and Sauvaigo $S$. Radiation-induced DNA damage: formation, measurement, and biochemical features. J Environ Pathol Toxicol Oncol 23: 33-43, 2004.

42. Cadet J, Berger M, Buchko GW, Joshi PC, Morin B, Raoul S, and Ravanat J-L. Hydroxyl and one-electron oxidation mediated reactions of the purine bases of DNA and model compounds: mechanistic aspects. In: Radiation Damage in DNA: Structure-function relationships at early times, edited by Fuciarelli AF and Zimbrick JD. Columbus, OH: Batelle Press, 1995, pp. 305-312.

43. Cadet J, Delatour T, Douki T, Gasparutto D, Pouget JP, Ravanat JL, and Sauvaigo S. Hydroxyl radicals and DNA base damage. Mutat Res 424: 9-21, 1999.

44. Cadet J, Douki T, Gasparutto D, and Ravanat J-L. Radiation-induced damage to cellular DNA: measurement and biological role. Rad Phys Chem 72: 293-299, 2005.

45. Cadet J, Douki T, and Ravanat JL. Oxidatively generated base damage to cellular DNA. Free Radic Biol Med 49: 921, 2010.

46. Cadet J, Douki T, and Ravanat JL. One-electron oxidation of DNA and inflammation processes. Nat Chem Biol 2: 348-349, 2006.

47. Cadet J, Ravanat JL, TavernaPorro M, Menoni H, and Angelov D. Oxidatively generated complex DNA damage: tandem and clustered lesions. Cancer Lett 327: 5-15, 2012.

48. Castillo SS, Levy M, Thaikoottathil JV, and Goldkorn T. Reactive nitrogen and oxygen species activate different sphingomyelinases to induce apoptosis in airway epithelial cells. Exp Cell Res 313: 2680-2686, 2007.

49. Catala A. Lipid peroxidation of membrane phospholipids generates hydroxy-alkenals and oxidized phospholipids active in physiological and/or pathological conditions. Chem Phys Lipids 157: 1-11, 2009.

50. Chalfant CE, Kishikawa K, Mumby MC, Kamibayashi C, Bielawska A, and Hannun YA. Long chain ceramides 
activate protein phosphatase- 1 and protein phosphatase2A. Activation is stereospecific and regulated by phosphatidic acid. J Biol Chem 274: 20313-20317, 1999.

51. Chandra RA, Wilhite TJ, Balboni TA, Alexander BM, Spektor A, Ott PA, Ng AK, Hodi FS, and Schoenfeld JD. A systematic evaluation of abscopal responses following radiotherapy in patients with metastatic melanoma treated with ipilimumab. Oncoimmunology 4: e1046028, 2015.

52. Chang HHY, Pannunzio NR, Adachi N, and Lieber MR. Non-homologous DNA end joining and alternative pathways to double-strand break repair. Nat Rev Mol Cell Biol 18: 495-506, 2017.

53. Chen S, Zhao Y, Han W, Zhao G, Zhu L, Wang J, Bao L, Jiang E, Xu A, Hei TK, Yu Z, and Wu L. Mitochondriadependent signalling pathway are involved in the early process of radiation-induced bystander effects. $\mathrm{Br} J$ Cancer 98: 1839-1844, 2008.

54. Chiang CS and McBride WH. Radiation enhances tumor necrosis factor alpha production by murine brain cells. Brain Res 566: 265-269, 1991.

55. Choi KM, Kang CM, Cho ES, Kang SM, Lee SB, and Um HD. Ionizing radiation-induced micronucleus formation is mediated by reactive oxygen species that are produced in a manner dependent on mitochondria, Nox1, and JNK. Oncol Rep 17: 1183-1188, 2007.

56. Church LD, Hessler G, Goodall JE, Rider DA, Workman CJ, Vignali DA, Bacon PA, Gulbins E, and Young SP. TNFR1-induced sphingomyelinase activation modulates TCR signaling by impairing store-operated $\mathrm{Ca}^{2+}$ influx. $J$ Leukoc Biol 78: 266-278, 2005.

57. Collett WK, Watson JA, and Wald N. Abscopal and direct effects on calcium mobilization, alkaline phosphatase levels, and dentin formation following $\mathrm{x}$-irradiation of either the rat incisor or the thyroid-parathyroid region. $J$ Dent Res 45: 1529-1538, 1966.

58. Corre I, Guillonneau M, and Paris F. Membrane signaling induced by high doses of ionizing radiation in the endothelial compartment. Relevance in radiation toxicity. Int $J$ Mol Sci 14: 22678-22696, 2013.

59. Corre I, Niaudet C, and Paris F. Plasma membrane signaling induced by ionizing radiation. Mutat Res 704: 6167, 2010.

60. Corvo R and Belgioia L. [Synergy between radiotherapy and immunotherapy in the treatment of advanced malignancies: recent evidences of a new challenge in oncology] [in Italian]. Recenti Prog Med 106: 322-330, 2015.

61. Cotrina ML, Lin JH, Alves-Rodrigues A, Liu S, Li J, Azmi-Ghadimi H, Kang J, Naus CC, and Nedergaard M. Connexins regulate calcium signaling by controlling ATP release. Proc Natl Acad Sci U S A 95: 15735-15740, 1998.

62. Crittenden M, Kohrt H, Levy R, Jones J, Camphausen K, Dicker A, Demaria S, and Formenti S. Current clinical trials testing combinations of immunotherapy and radiation. Semin Radiat Oncol 25: 54-64, 2015.

63. Dale RG. Radiobiological assessment of non-standard and novel radiotherapy treatments using the linear-quadratic model. Med Biol Eng Comput 31: 53-57, 1993.

64. Dale RG. The BJR and progress in radiobiological modelling. Br J Radiol 83: 544-545, 2010.

65. Davies MJ. Protein oxidation and peroxidation. Biochem J 473: 805-825, 2016.

66. Dayal D, Martin SM, Owens KM, Aykin-Burns N, Zhu Y, Boominathan A, Pain D, Limoli CL, Goswami PC, Domann FE, and Spitz DR. Mitochondrial complex II dys- function can contribute significantly to genomic instability after exposure to ionizing radiation. Radiat Res 172: 737745, 2009.

67. de Mendoza D, Klages Ulrich A, and Cronan JE, Jr. Thermal regulation of membrane fluidity in Escherichia coli. Effects of overproduction of beta-ketoacyl-acyl carrier protein synthase I. J Biol Chem 258: 2098-2101, 1983.

68. Decrock E, Hoorelbeke D, Ramadan R, Delvaeye T, De Bock M, Wang N, Krysko DV, Baatout S, Bultynck G, Aerts A, Vinken M, and Leybaert L. Calcium oxidative stress and connexin channels, a harmonious orchestra directing the response to radiotherapy treatment? Biochim Biophys Acta 1864: 1099-1120, 2017.

69. Dedon PC. The chemical toxicology of 2-deoxyribose oxidation in DNA. Chem Res Toxicol 21: 206-219, 2008.

70. Deloch L, Derer A, Hartmann J, Frey B, Fietkau R, and Gaipl US. Modern radiotherapy concepts and the impact of radiation on immune activation. Front Oncol 6: 141, 2016.

71. Demaria S and Formenti SC. Can abscopal effects of local radiotherapy be predicted by modeling $\mathrm{T}$ cell trafficking? J Immunother Cancer 4: 29, 2016.

72. Demaria S, Ng B, Devitt ML, Babb JS, Kawashima N, Liebes L, and Formenti SC. Ionizing radiation inhibition of distant untreated tumors (abscopal effect) is immune mediated. Int J Radiat Oncol Biol Phys 58: 862-870, 2004.

73. Dent P, Reardon DB, Park JS, Bowers G, Logsdon C, Valerie K, and Schmidt-Ullrich R. Radiation-induced release of transforming growth factor alpha activates the epidermal growth factor receptor and mitogen-activated protein kinase pathway in carcinoma cells, leading to increased proliferation and protection from radiation-induced cell death. Mol Biol Cell 10: 2493-2506, 1999.

74. Deshpande A, Goodwin EH, Bailey SM, Marrone BL, and Lehnert BE. Alpha-particle-induced sister chromatid exchange in normal human lung fibroblasts: evidence for an extranuclear target. Radiat Res 145: 260-267, 1996.

75. Dictionary ND. Anti-CTLA-4 monoclonal antibody AGEN1884. 2017. https://www.cancer.gov/publications/ dictionaries/cancer-drug?CdrID=779578. (accessed December 10, 2017).

76. Dijkman WP, de Gonzalo G, Mattevi A, and Fraaije MW. Flavoprotein oxidases: classification and applications. Appl Microbiol Biotechnol 97: 5177-5188, 2013.

77. Dong C, He M, Ren R, Xie Y, Yuan D, Dang B, Li W, and Shao C. Role of the MAPK pathway in the observed bystander effect in lymphocytes co-cultured with macrophages irradiated with gamma-rays or carbon ions. Life Sci 127: 19-25, 2015.

78. Douki T, Ravanat JL, Pouget JP, Testard I, and Cadet J. Minor contribution of direct ionization to DNA base damage inducedby heavy ions. Int J Radiat Biol 82: 119127, 2006.

79. Drago I, De Stefani D, Rizzuto R, and Pozzan T. Mitochondrial $\mathrm{Ca}^{2+}$ uptake contributes to buffering cytoplasmic $\mathrm{Ca}^{2+}$ peaks in cardiomyocytes. Proc Natl Acad Sci U S A 109: 12986-12991, 2012.

80. Droge W. Free radicals in the physiological control of cell function. Physiol Rev 82: 47-95, 2002.

81. Du YC, Gu S, Zhou J, Wang T, Cai H, Macinnes MA, Bradbury EM, and Chen X. The dynamic alterations of H2AX complex during DNA repair detected by a pro- 
teomic approach reveal the critical roles of $\mathrm{Ca}(2+) / \mathrm{cal}$ modulin in the ionizing radiation-induced cell cycle arrest. Mol Cell Proteomics 5: 1033-1044, 2006.

82. Eccles LJ, O'Neill P, and Lomax ME. Delayed repair of radiation induced clustered DNA damage: friend or foe? Mutat Res 711: 134-141, 2011.

83. Emerit I, Khan SH, and Esterbauer H. Hydroxynonenal, a component of clastogenic factors? Free Radic Biol Med 10: 371-377, 1991.

84. Fan M, Ahmed KM, Coleman MC, Spitz DR, and Li JJ. Nuclear factor-kappaB and manganese superoxide dismutase mediate adaptive radioresistance in low-dose irradiated mouse skin epithelial cells. Cancer Res 67: 32203228, 2007.

85. Forrester K, Ambs S, Lupold SE, Kapust RB, Spillare EA, Weinberg WC, Felley-Bosco E, Wang XW, Geller DA, Tzeng E, Billiar TR, and Harris CC. Nitric oxide-induced p53 accumulation and regulation of inducible nitric oxide synthase expression by wild-type p53. Proc Natl Acad Sci U S A 93: 2442-2447, 1996.

86. Franke TF. PI3K/Akt: getting it right matters. Oncogene 27: 6473-6488, 2008.

87. Frey B, Rubner Y, Wunderlich R, Weiss EM, Pockley AG, Fietkau R, and Gaipl US. Induction of abscopal antitumor immunity and immunogenic tumor cell death by ionizing irradiation-implications for cancer therapies. Curr Med Chem 19: 1751-1764, 2012.

88. Frischholz B, Wunderlich R, Ruhle PF, Schorn C, Rodel F, Keilholz L, Fietkau R, Gaipl US, and Frey B. Reduced secretion of the inflammatory cytokine IL-1beta by stimulated peritoneal macrophages of radiosensitive $\mathrm{Balb} / \mathrm{c}$ mice after exposure to 0.5 or $0.7 \mathrm{~Gy}$ of ionizing radiation. Autoimmunity 46: 323-328, 2013.

89. Fu J, Wang J, Wang X, Wang P, Xu J, Zhou C, Bai Y, and Shao C. Signaling factors and pathways of alpha-particle irradiation induced bilateral bystander responses between Beas-2B and U937 cells. Mutat Res 789: 1-8, 2016.

90. Gaillard S, Pusset D, de Toledo SM, Fromm M, and Azzam EI. Propagation distance of the alpha-particle-induced bystander effect: the role of nuclear traversal and gap junction communication. Radiat Res 171: 513-520, 2009.

91. Galabova-Kovacs G, Kolbus A, Matzen D, Meissl K, Piazzolla D, Rubiolo C, Steinitz K, and Baccarini M. ERK and beyond: insights from B-Raf and Raf-1 conditional knockouts. Cell Cycle 5: 1514-1518, 2006.

92. Garinis GA, Schwer B, and Schumacher B. Editorial: DNA damage \& immunity. Mech Ageing Dev 165: 1-2, 2017.

93. Gasser S, Zhang WYL, Tan NYJ, Tripathi S, Suter MA, Chew ZH, Khatoo M, Ngeow J, and Cheung FSG. Sensing of dangerous DNA. Mech Ageing Dev 165: 33-46, 2016.

94. Ghandhi SA, Ming L, Ivanov VN, Hei TK, and Amundson SA. Regulation of early signaling and gene expression in the alpha-particle and bystander response of IMR-90 human fibroblasts. BMC Med Genomics 3: 31, 2010.

95. Ghandhi SA, Yaghoubian B, and Amundson SA. Global gene expression analyses of bystander and alpha particle irradiated normal human lung fibroblasts: synchronous and differential responses. BMC Med Genomics 1: 63, 2008.

96. Ghosh S, Ghosh A, and Krishna M. Role of ATM in bystander signaling between human monocytes and lung adenocarcinoma cells. Mutat Res Genet Toxicol Environ Mutagen 794: 39-45, 2015.

97. Ghosh S, Maurya DK, and Krishna M. Role of iNOS in bystander signaling between macrophages and lymphoma cells. Int J Radiat Oncol Biol Phys 72: 1567-1574, 2008.

98. Giorgi C, Missiroli S, Patergnani S, Duszynski J, Wieckowski MR, and Pinton P. Mitochondria-associated membranes: composition, molecular mechanisms, and physiopathological implications. Antioxid Redox Signal 22: 995-1019, 2015.

99. Goda N, Suematsu M, Mukai M, Kiyokawa K, Natori M, Nozawa S, and Ishimura Y. Modulation of mitochondrionmediated oxidative stress by nitric oxide in human placental trophoblastic cells. Am J Physiol 271: H1893H1899, 1996.

100. Golden EB, Demaria S, Schiff PB, Chachoua A, and Formenti SC. An abscopal response to radiation and ipilimumab in a patient with metastatic non-small cell lung cancer. Cancer Immunol Res 1: 365-372, 2013.

101. Gompertz RH, Man WK, Li SK, Baron JH, Spencer J, and Michalowski AS. Gastric histamine in a chronic duodenal ulcer model induced by partial thoracic irradiation. Agents Actions 27: 177-179, 1989.

102. Goodhead DT. Initial events in the cellular effects of ionizing radiations: clustered damage in DNA. Int $J$ Radiat Biol 65: 7-17, 1994.

103. Gorman S, Tosetto M, Lyng F, Howe O, Sheahan K, O'Donoghue D, Hyland J, Mulcahy H, and O'Sullivan J. Radiation and chemotherapy bystander effects induce early genomic instability events: telomere shortening and bridge formation coupled with mitochondrial dysfunction. Mutat Res 669: 131-138, 2009.

104. Gow MD, Seymour CB, Byun SH, and Mothersill CE. Effect of dose rate on the radiation-induced bystander response. Phys Med Biol 53: 119-132, 2008.

105. Grivennikov S, Karin E, Terzic J, Mucida D, Yu GY, Vallabhapurapu S, Scheller J, Rose-John S, Cheroutre H, Eckmann L, and Karin M. IL-6 and Stat3 are required for survival of intestinal epithelial cells and development of colitis-associated cancer. Cancer Cell 15: 103-113, 2009.

106. Grivennikov SI and Karin M. Dangerous liaisons: STAT3 and NF-kappaB collaboration and crosstalk in cancer. Cytokine Growth Factor Rev 21: 11-19, 2010.

107. Grivennikova VG and Vinogradov AD. Generation of superoxide by the mitochondrial Complex I. Biochim Biophys Acta 1757: 553-561, 2006.

108. Guichard C, Pedruzzi E, Fay M, Ben Mkaddem S, Coant N, Daniel F, and Ogier-Denis E. [The Nox/Duox family of ROS-generating NADPH oxidases] [in French]. Med Sci (Paris) 22: 953-959, 2006.

109. Hagan M, Yacoub A, and Dent P. Ionizing radiation causes a dose-dependent release of transforming growth factor alpha in vitro from irradiated xenografts and during palliative treatment of hormone-refractory prostate carcinoma. Clin Cancer Res 10: 5724-5731, 2004.

110. Haghdoost S, Sjolander L, Czene S, and Harms-Ringdahl $\mathrm{M}$. The nucleotide pool is a significant target for oxidative stress. Free Radic Biol Med 41: 620-626, 2006.

111. Haimovitz-Friedman A, Kan CC, Ehleiter D, Persaud RS, McLoughlin M, Fuks Z, and Kolesnick RN. Ionizing radiation acts on cellular membranes to generate ceramide and initiate apoptosis. J Exp Med 180: 525-535, 1994.

112. Hallahan DE, Bleakman D, Virudachalam S, Lee D, Grdina D, Kufe DW, and Weichselbaum RR. The role of 
intracellular calcium in the cellular response to ionizing radiation. Radiat Res 138: 392-400, 1994.

113. Halliwell B and Gutteridge JM. Oxygen toxicity, oxygen radicals, transition metals and disease. Biochem J 219: 114, 1984.

114. Halliwell B and Gutteridge JMC, Eds. Free Radicals in Biology and Medicine. Oxford, UK: Clarendon, 1989.

115. Han W, Wu L, Chen S, Bao L, Zhang L, Jiang E, Zhao Y, $\mathrm{Xu} \mathrm{A}$, Hei TK, and Yu Z. Constitutive nitric oxide acting as a possible intercellular signaling molecule in the initiation of radiation-induced DNA double strand breaks in non-irradiated bystander cells. Oncogene 26: 2330-2339, 2007.

116. Hanna GG, Coyle VM, and Prise KM. Immune modulation in advanced radiotherapies: targeting out-of-field effects. Cancer Lett 368: 246-251, 2015.

117. He M, Ye S, Ren R, Dong C, Xie Y, Yuan D, and Shao C. Cytochrome-c mediated a bystander response dependent on inducible nitric oxide synthase in irradiated hepatoma cells. Br J Cancer 106: 889-895, 2012.

118. Hehlgans $\mathrm{S}$ and Cordes N. Caveolin-1: an essential modulator of cancer cell radio-and chemoresistance. Am J Cancer Res 1: 521-530, 2011.

119. Hei TK, Zhou H, Chai Y, Ponnaiya B, and Ivanov VN. Radiation induced non-targeted response: mechanism and potential clinical implications. Curr Mol Pharmacol 4: 96-105, 2011.

120. Heinrich M, Wickel M, Schneider-Brachert W, Sandberg C, Gahr J, Schwandner R, Weber T, Saftig P, Peters C, Brunner J, Kronke M, and Schutze S. Cathepsin D targeted by acid sphingomyelinase-derived ceramide. $E M B O$ J 18: 5252-5263, 1999.

121. Hellweg CE. The Nuclear Factor kappaB pathway: a link to the immune system in the radiation response. Cancer Lett 368: 275-289, 2015

122. Hernandez-Corbacho MJ, Salama MF, Canals D, Senkal CE, and Obeid LM. Sphingolipids in mitochondria. Biochim Biophys Acta 1862: 56-68, 2017.

123. Hildebrandt G, Seed MP, Freemantle CN, Alam CA, Colville-Nash PR, and Trott KR. Mechanisms of the antiinflammatory activity of low-dose radiation therapy. Int $J$ Radiat Biol 74: 367-378, 1998.

124. Hinz M, Stilmann M, Arslan SC, Khanna KK, Dittmar G, and Scheidereit C. A cytoplasmic ATM-TRAF6-cIAP1 module links nuclear DNA damage signaling to ubiquitinmediated NF-kappaB activation. Mol Cell 40: 63-74, 2010.

125. Hodge JW, Sharp HJ, and Gameiro SR. Abscopal regression of antigen disparate tumors by antigen cascade after systemic tumor vaccination in combination with local tumor radiation. Cancer Biother Radiopharm 27: 12-22, 2012.

126. Hofer T, Badouard C, Bajak E, Ravanat JL, Mattsson A, and Cotgreave IA. Hydrogen peroxide causes greater oxidation in cellular RNA than in DNA. Biol Chem 386: 333-337, 2005.

127. Holley AK, Miao L, St Clair DK, and St Clair WH. Redox-modulated phenomena and radiation therapy: the central role of superoxide dismutases. Antioxid Redox Signal 20: 1567-1589, 2014.

128. Hong $\mathrm{H}, \mathrm{Cao} \mathrm{H}$, and Wang Y. Formation and genotoxicity of a guanine-cytosine intrastrand cross-link lesion in vivo. Nucleic Acids Res 35: 7118-7127, 2007.

129. Hsu H, Shu HB, Pan MG, and Goeddel DV. TRADDTRAF2 and TRADD-FADD interactions define two distinct TNF receptor 1 signal transduction pathways. Cell 84: 299-308, 1996.
130. Huang W, Ravikumar KM, Chance MR, and Yang S. Quantitative mapping of protein structure by hydroxyl radical footprinting-mediated structural mass spectrometry: a protection factor analysis. Biophys $J$ 108: 107-115, 2015.

131. Huo L, Nagasawa H, and Little JB. HPRT mutants induced in bystander cells by very low fluences of alpha particles result primarily from point mutations. Radiat Res 156: 521-525, 2001.

132. Huwiler A, Johansen B, Skarstad A, and Pfeilschifter J. Ceramide binds to the CaLB domain of cytosolic phospholipase A2 and facilitates its membrane docking and arachidonic acid release. FASEB $J$ 15: 7-9, 2001.

133. Iademarco MF, McQuillan JJ, Rosen GD, and Dean DC. Characterization of the promoter for vascular cell adhesion molecule-1 (VCAM-1). J Biol Chem 267: 1632316329, 1992.

133a. ICRP (The International Commission on Radiological Protection). Low-dose extrapolation of radiation-related cancer risk. ICRP Publication 99. Elsevier: International Commission on Radiological Protection, 2006.

134. Ivanov VN, Zhou H, Ghandhi SA, Karasic TB, Yaghoubian B, Amundson SA, and Hei TK. Radiation-induced bystander signaling pathways in human fibroblasts: a role for interleukin-33 in the signal transmission. Cell Signal 22: 1076-1087, 2010.

135. Jaamaa S, Af Hallstrom TM, Sankila A, Rantanen V, Koistinen H, Stenman UH, Zhang Z, Yang Z, De Marzo AM, Taari K, Ruutu M, Andersson LC, and Laiho M. DNA damage recognition via activated ATM and p53 pathway in nonproliferating human prostate tissue. Cancer Res 70: 8630-8641, 2010.

136. Jackson SP and Bartek J. The DNA-damage response in human biology and disease. Nature 461: 1071-1078, 2009.

137. Jansen CR, Bond VP, Rai KR, and Lippincott SW. Abscopal effects of localized irradiation by accelerator beams. Ann N Y Acad Sci 114: 302-315, 1964.

138. Jones B and Dale RG. Radiobiological modeling and clinical trials. Int J Radiat Oncol Biol Phys 48: 259-265, 2000.

139. Jones PL, Ping D, and Boss JM. Tumor necrosis factor alpha and interleukin-1beta regulate the murine manganese superoxide dismutase gene through a complex intronic enhancer involving C/EBP-beta and NF-kappaB. Mol Cell Biol 17: 6970-6981, 1997.

140. Kadhim M, Salomaa S, Wright E, Hildebrandt G, Belyakov OV, Prise KM, and Little MP. Non-targeted effects of ionising radiation-implications for low dose risk. Mutat Res 752: 84-98, 2013.

141. Kakarougkas A, Ismail A, Klement K, Goodarzi AA, Conrad S, Freire R, Shibata A, Lobrich M, and Jeggo PA. Opposing roles for 53BP1 during homologous recombination. Nucleic Acids Res 41: 9719-9731, 2013.

142. Kakarougkas A and Jeggo PA. DNA DSB repair pathway choice: an orchestrated handover mechanism. Br J Radiol 87: 20130685, 2014.

143. Kam WW and Banati RB. Effects of ionizing radiation on mitochondria. Free Radic Biol Med 65: 607-619, 2013.

144. Kaminski JM, Shinohara E, Summers JB, Niermann KJ, Morimoto A, and Brousal J. The controversial abscopal effect. Cancer Treat Rev 31: 159-172, 2005.

145. Kanai T, Furusawa Y, Fukutsu K, Itsukaichi H, EguchiKasai $\mathrm{K}$, and Ohara $\mathrm{H}$. Irradiation of mixed beam and design of spread-out Bragg peak for heavy-ion radiotherapy. Radiat Res 147: 78-85, 1997. 
146. Karakasilioti I, Kamileri I, Chatzinikolaou G, Kosteas T, Vergadi E, Robinson AR, Tsamardinos I, Rozgaja TA, Siakouli S, Tsatsanis C, Niedernhofer LJ, and Garinis GA. DNA damage triggers a chronic autoinflammatory response, leading to fat depletion in NER progeria. Cell Metab 18: 403-415, 2013.

147. Kastan MB and Berkovich E. p53: a two-faced cancer gene. Nat Cell Biol 9: 489-491, 2007.

148. Kellerer AM and Rossi HH. A generalized formulation of dual radiation action. Radiat Res 178: AV204-AV213, 2012.

149. Kim GJ, Chandrasekaran K, and Morgan WF. Mitochondrial dysfunction, persistently elevated levels of reactive oxygen species and radiation-induced genomic instability: a review. Mutagenesis 21: 361-367, 2006.

150. Kim KW, Kim SH, Shin JG, Kim GS, Son YO, Park SW, Kwon BH, Kim DW, Lee CH, Sol MY, Jeong MH, Chung $\mathrm{BS}$, and Kang CD. Direct injection of immature dendritic cells into irradiated tumor induces efficient antitumor immunity. Int J Cancer 109: 685-690, 2004.

151. Klammer H, Mladenov E, Li F, and Iliakis G. Bystander effects as manifestation of intercellular communication of DNA damage and of the cellular oxidative status. Cancer Lett 356: 58-71, 2015.

152. Kopylov VA, Narimanov AA, and Kuzin AM. [Abscopal action of gamma radiation in the death of lymphoid cells] [in Russian]. Radiobiologiia 27: 20-23, 1987.

153. Koturbash I, Rugo RE, Hendricks CA, Loree J, Thibault B, Kutanzi K, Pogribny I, Yanch JC, Engelward BP, and Kovalchuk O. Irradiation induces DNA damage and modulates epigenetic effectors in distant bystander tissue in vivo. Oncogene 25: 4267-4275, 2006.

154. Kumareswaran R, Ludkovski O, Meng A, Sykes J, Pintilie $\mathrm{M}$, and Bristow RG. Chronic hypoxia compromises repair of DNA double-strand breaks to drive genetic instability. $J$ Cell Sci 125: 189-199, 2012.

155. Kurnick NB and Nokay N. Abscopal effects and bonemarrow repopulation in man and mouse. Ann N Y Acad Sci 114: 528-537, 1964.

156. Kurnick NB and Nokay N. Abscopal effects of X-irradiation on mouse bone marrow. Radiat Res 23: 239-248, 1964.

157. Lakshmanagowda PB, Viswanath L, Thimmaiah N, Dasappa L, Supe SS, and Kallur P. Abscopal effect in a patient with chronic lymphocytic leukemia during radiation therapy: a case report. Cases J 2: 204, 2009.

158. Lam RK, Han W, and Yu KN. Unirradiated cells rescue cells exposed to ionizing radiation: activation of NF-kappaB pathway in irradiated cells. Mutat Res 782: 23-33, 2015.

159. Law AW and Mole RH. Direct and abscopal effects of $x-$ radiation on the thymus of the weanling rat. Int $J$ Radiat Biol Relat Stud Phys Chem Med 3: 233-248, 1961.

160. Lea DE. Ed. Actions of Radiations on Living Cells. Cambridge: Cambridge University Press, 1946.

161. Leach JK, Black SM, Schmidt-Ullrich RK, and Mikkelsen RB. Activation of constitutive nitric-oxide synthase activity is an early signaling event induced by ionizing radiation. J Biol Chem 277: 15400-15406, 2002.

162. Leach JK, Van Tuyle G, Lin PS, Schmidt-Ullrich R, and Mikkelsen RB. Ionizing radiation-induced, mitochondriadependent generation of reactive oxygen/nitrogen. Cancer Res 61: 3894-3901, 2001.

163. Lee JH and Paull TT. Activation and regulation of ATM kinase activity in response to DNA double-strand breaks. Oncogene 26: 7741-7748, 2007.
164. Li J, Billiar TR, Talanian RV, and Kim YM. Nitric oxide reversibly inhibits seven members of the caspase family via S-nitrosylation. Biochem Biophys Res Commun 240: 419-424, 1997.

165. Li N, Banin S, Ouyang H, Li GC, Courtois G, Shiloh Y, Karin M, and Rotman G. ATM is required for IkappaB kinase (IKKk) activation in response to DNA double strand breaks. J Biol Chem 276: 8898-8903, 2001.

166. Limoli CL, Hartmann A, Shephard L, Yang CR, Boothman DA, Bartholomew J, and Morgan WF. Apoptosis, reproductive failure, and oxidative stress in Chinese hamster ovary cells with compromised genomic integrity. Cancer Res 58: 3712-3718, 1998.

167. Lingwood D and Simons K. Lipid rafts as a membraneorganizing principle. Science 327: 46-50, 2010.

168. Liu B, Chen Y, and St Clair DK. ROS and p53: a versatile partnership. Free Radic Biol Med 44: 1529-1535, 2008.

169. Liu Z, Mothersill CE, McNeill FE, Lyng FM, Byun SH, Seymour CB, and Prestwich WV. A dose threshold for a medium transfer bystander effect for a human skin cell line. Radiat Res 166: 19-23, 2006.

170. Lobrich $\mathrm{M}$ and Jeggo PA. Harmonising the response to DSBs: a new string in the ATM bow. DNA Repair (Amst) 4: 749-759, 2005.

171. Lock M, Muinuddin A, Kocha WI, Dinniwell R, Rodrigues G, and D'Souza D. Abscopal effects: case report and emerging opportunities. Cureus 7: e344, 2015.

172. Lomax ME, Gulston MK, and O'Neill P. Chemical aspects of clustered DNA damage induction by ionising radiation. Radiat Prot Dosimetry 99: 63-68, 2002.

173. Lorimore SA, Chrystal JA, Robinson JI, Coates PJ, and Wright EG. Chromosomal instability in unirradiated hemaopoietic cells induced by macrophages exposed in vivo to ionizing radiation. Cancer Res 68: 8122-8126, 2008.

174. Ludgate CM. Optimizing cancer treatments to induce an acute immune response: radiation abscopal effects, PAMPs, and DAMPs. Clin Cancer Res 18: 4522-4525, 2012.

175. Lugade AA, Moran JP, Gerber SA, Rose RC, Frelinger $\mathrm{JG}$, and Lord EM. Local radiation therapy of B16 melanoma tumors increases the generation of tumor antigenspecific effector cells that traffic to the tumor. J Immunol 174: 7516-7523, 2005.

176. Lyng FM, Howe OL, and McClean B. Reactive oxygen species-induced release of signalling factors in irradiated cells triggers membrane signalling and calcium influx in bystander cells. Int J Radiat Biol 87: 683-695, 2011.

177. Lyng FM, Maguire P, Kilmurray N, Mothersill C, Shao C, Folkard M, and Prise KM. Apoptosis is initiated in human keratinocytes exposed to signalling factors from microbeam irradiated cells. Int J Radiat Biol 82: 393-399, 2006.

178. Lyng FM, Maguire P, McClean B, Seymour C, and Mothersill $\mathrm{C}$. The involvement of calcium and MAP kinase signaling pathways in the production of radiation-induced bystander effects. Radiat Res 165: 400-409, 2006.

179. Lyng FM, Seymour CB, and Mothersill C. Initiation of apoptosis in cells exposed to medium from the progeny of irradiated cells: a possible mechanism for bystander-induced genomic instability? Radiat Res 157: 365-370, 2002.

180. Lyng FM, Seymour CB, and Mothersill C. Production of a signal by irradiated cells which leads to a response in unirradiated cells characteristic of initiation of apoptosis. Br J Cancer 83: 1223-1230, 2000.

181. MacNaughton WK, Aurora AR, Bhamra J, Sharkey KA, and Miller MJ. Expression, activity and cellular localization 
of inducible nitric oxide synthase in rat ileum and colon post-irradiation. Int J Radiat Biol 74: 255-264, 1998.

182. Maes M, Decrock E, Cogliati B, Oliveira AG, Marques PE, Dagli ML, Menezes GB, Mennecier G, Leybaert L, Vanhaecke T, Rogiers V, and Vinken M. Connexin and pannexin (hemi)channels in the liver. Front Physiol 4: 405, 2014.

183. Mancuso M, Pasquali E, Leonardi S, Rebessi S, Tanori M, Giardullo P, Borra F, Pazzaglia S, Naus CC, Di Majo V, and Saran A. Role of connexin43 and ATP in long-range bystander radiation damage and oncogenesis in vivo. Oncogene 30: 4601-4608, 2011.

184. Maor D and Alexander P. Abscopal stimulation of the thymus of rats by exposure of the head to X-rays. Nature 205: 40-42, 1965.

185. Marechal A and Zou L. DNA damage sensing by the ATM and ATR kinases. Cold Spring Harb Perspect Biol 5, a012716, 2013.

186. Matsumoto H, Hamada N, Takahashi A, Kobayashi Y, and Ohnishi T. Vanguards of paradigm shift in radiation biology: radiation-induced adaptive and bystander responses. J Radiat Res 48: 97-106, 2007.

187. Matsumoto H, Takahashi A, and Ohnishi T. Nitric oxide radicals choreograph a radioadaptive response. Cancer Res 67: 8574-8579, 2007.

188. Mavragani IV, Laskaratou DA, Frey B, Candeias SM, Gaipl US, Lumniczky K, and Georgakilas AG. Key mechanisms involved in ionizing radiation-induced systemic effects. A current review. Toxicol Res 5: 12-33, 2016.

189. Michael JM, Lavin MF, and Watters DJ. Resistance to radiation-induced apoptosis in Burkitt's lymphoma cells is associated with defective ceramide signaling. Cancer Res 57: 3600-3605, 1997.

190. Michalowski A, Uehara S, Yin WB, Burgin J, and Silvester JA. Alternative types of duodenal ulcer induced in mice by partial X irradiation of the thorax. Radiat Res 95: 78-86, 1983.

191. Mihaljevic B, Tartaro I, Ferreri C, and Chatgilialoglu C. Linoleic acid peroxidation vs. isomerization: a biomimetic model of free radical reactivity in the presence of thiols. Org Biomol Chem 9: 3541-3548, 2011.

192. Milligan JR, Aguilera JA, Ly A, Tran NQ, Hoang O, and Ward JF. Repair of oxidative DNA damage by amino acids. Nucleic Acids Res 31: 6258-6263, 2003.

193. Milligan JR, Tran NQ, Ly A, and Ward JF. Peptide repair of oxidative DNA damage. Biochemistry 43: 5102-5108, 2004.

194. Mishra KP. Cell membrane oxidative damage induced by gamma-radiation and apoptotic sensitivity. $J$ Environ Pathol Toxicol Oncol 23: 61-66, 2004.

195. Mogensen TH. Pathogen recognition and inflammatory signaling in innate immune defenses. Clin Microbiol Rev 22: 240-273, 2009.

196. Mole RH. Whole body irradiation; radiobiology or medicine? Br J Radiol 26: 234-241, 1953.

197. Moment GB. Recovery and abscopal effects after inhibitory X-irradiation in earthworm regeneration. J Exp Zool 181: 33-39, 1972.

198. Morgan WF. Non-targeted and delayed effects of exposure to ionizing radiation: I. Radiation-induced genomic instability and bystander effects in vitro. Radiat Res 159: 567-580, 2003.

199. Morgan WF. Is there a common mechanism underlying genomic instability, bystander effects and other nontargeted effects of exposure to ionizing radiation? Oncogene 22: 7094-7099, 2003.
200. Morgan WF. Non-targeted and delayed effects of exposure to ionizing radiation: II. Radiation-induced genomic instability and bystander effects in vivo, clastogenic factors and transgenerational effects. Radiat Res 159: 581596, 2003.

201. Morgan WF and Sowa MB. Non-targeted bystander effects induced by ionizing radiation. Mutat Res 616: 159164, 2007.

202. Mothersill C and Seymour CB. Radiation-induced bystander effects-implications for cancer. Nat Rev Cancer 4: 158-164, 2004.

203. Mothersill C and Seymour CB. Bystander and delayed effects after fractionated radiation exposure. Radiat Res 158: 626-633, 2002.

204. Murata-Kamiya N, Kamiya H, Muraoka M, Kaji H, and Kasai $\mathrm{H}$. Comparison of oxidation products from DNA components by gamma-irradiation and Fenton-type reactions. J Radiat Res 38: 121-131, 1997.

205. Nagasawa $\mathrm{H}$ and Little JB. Induction of sister chromatid exchanges by extremely low doses of alpha-particles. Cancer Res 52: 6394-6396, 1992.

206. Nakano T, Mitsusada Y, Salem AM, Shoulkamy MI, Sugimoto T, Hirayama R, Uzawa A, Furusawa Y, and Ide $\mathrm{H}$. Induction of DNA-protein cross-links by ionizing radiation and their elimination from the genome. Mutat Res 771: 45-50, 2015.

207. Narayanan PK, Goodwin EH, and Lehnert BE. Alpha particles initiate biological production of superoxide anions and hydrogen peroxide in human cells. Cancer Res 57: 3963-3971, 1997.

208. Nauseef WM. Detection of superoxide anion and hydrogen peroxide production by cellular NADPH oxidases. Biochim Biophys Acta 1840: 757-767, 2014.

209. Negre-Salvayre A, Coatrieux C, Ingueneau C, and Salvayre R. Advanced lipid peroxidation end products in oxidative damage to proteins. Potential role in diseases and therapeutic prospects for the inhibitors. $\mathrm{Br} J$ Pharmacol 153: 6-20, 2008.

210. Neuhouser ML, Schenk J, Song YJ, Tangen CM, Goodman PJ, Pollak M, Penson DF, Thompson IM, and Kristal AR. Insulin-like growth factor-I, insulin-like growth factor binding protein-3 and risk of benign prostate hyperplasia in the prostate cancer prevention trial. Prostate 68: 1477-1486, 2008.

211. Nguyen T, Brunson D, Crespi CL, Penman BW, Wishnok JS, and Tannenbaum SR. DNA damage and mutation in human cells exposed to nitric oxide in vitro. Proc Natl Acad Sci U S A 89: 3030-3034, 1992.

212. Nikitaki Z, Hellweg CE, Georgakilas AG, and Ravanat JL. Stress-induced DNA damage biomarkers: applications and limitations. Front Chem 3: 35, 2015.

213. Nikitaki Z, Mavragani IV, Laskaratou DA, Gika V, Moskvin VP, Theofilatos K, Vougas K, Stewart RD, and Georgakilas AG. Systemic mechanisms and effects of ionizing radiation: a new "old" paradigm of how the bystanders and distant can become the players. Semin Cancer Biol 37-38: 77-95, 2016.

214. Nikjoo H. Mechanism of DNA damage by direct and indirect effects-a Review of Experimental and Theoretical Data. Int J Radiat Biol 57: 1257, 1990.

215. Nikjoo H, Emfietzoglou D, Liamsuwan T, Taleei R, Liljequist D, and Uehara S. Radiation track, DNA damage and response-a review. Rep Prog Phys 79: 116601, 2016. 
216. Nobler MP. The abscopal effect in malignant lymphoma and its relationship to lymphocyte circulation. Radiology 93: 410-412, 1969.

217. Nugent S, Mothersill CE, Seymour C, McClean B, Lyng FM, and Murphy JE. Altered mitochondrial function and genome frequency post exposure to rradiation and bystander factors. Int J Radiat Biol 86: 829-841, 2010.

218. Nugent SM, Mothersill CE, Seymour C, McClean B, Lyng FM, and Murphy JE. Increased mitochondrial mass in cells with functionally compromised mitochondria after exposure to both direct gamma radiation and bystander factors. Radiat Res 168: 134-142, 2007.

219. O'Neill P and Wardman P. Radiation chemistry comes before radiation biology. Int J Radiat Biol 85: 9-25, 2009.

220. Ohba K, Omagari K, Nakamura T, Ikuno N, Saeki S, Matsuo I, Kinoshita H, Masuda J, Hazama H, Sakamoto I, and Kohno S. Abscopal regression of hepatocellular carcinoma after radiotherapy for bone metastasis. Gut 43: 575-577, 1998.

221. Ohshima Y, Tsukimoto M, Takenouchi T, Harada H, Suzuki A, Sato M, Kitani H, and Kojima S. gamma-Irradiation induces $\mathrm{P} 2 \mathrm{X}(7)$ receptor-dependent ATP release from B16 melanoma cells. Biochim Biophys Acta 1800: 40-46, 2010.

222. Oike T, Sato H, Noda SE, and Nakano T. Translational research to improve the efficacy of carbon ion radiotherapy: experience of Gunma University. Front Oncol 6: 139, 2016.

223. Olivieri G, Bodycote J, and Wolff S. Adaptive response of human lymphocytes to low concentrations of radioactive thymidine. Science 223: 594-597, 1984.

224. Oyamada M, Oyamada Y, and Takamatsu T. Regulation of connexin expression. Biochim Biophys Acta 1719: 623, 2005 .

225. O-Charoenrat, Rhys-Evans P, and Eccles S. A synthetic matrix metalloproteinase inhibitor prevents squamous carcinoma cell proliferation by interfering with epidermal growth factor receptor autocrine loops. Int J Cancer 100: 527-533, 2002.

226. Pahl HL. Activators and target genes of Rel/NF-kappaB transcription factors. Oncogene 18: 6853-6866, 1999.

227. Paillas S, Boudousq V, Piron B, Kersual N, Bardies M, Chouin N, Bascoul-Mollevi C, Arnaud FX, Pelegrin A, Navarro-Teulon I, and Pouget JP. Apoptosis and p53 are not involved in the anti-tumor efficacy of (1)(2)(5)I-labeled monoclonal antibodies targeting the cell membrane. Nucl Med Biol 40: 471-480, 2013.

228. Paillas S, Ladjohounlou R, Lozza C, Pichard A, Boudousq V, Jarlier M, Sevestre S, Le Blay M, Deshayes E, Sosabowski J, Chardes T, Navarro-Teulon I, Mairs RJ, and Pouget JP. Localized irradiation of cell membrane by auger electrons is cytotoxic through oxidative stress-mediated nontargeted effects. Antioxid Redox Signal 25: 467-484, 2016.

229. Pan L, Zhang X, Song K, Wu X, and Xu J. Exogenous nitric oxide-induced release of calcium from intracellular IP3 receptor-sensitive stores via S-nitrosylation in respiratory burst-dependent neutrophils. Biochem Biophys Res Commun 377: 1320-1325, 2008.

230. Pandey BN and Mishra KP. Modification of thymocytes membrane radiooxidative damage and apoptosis by eugenol. J Environ Pathol Toxicol Oncol 23: 117-122, 2004

231. Panier S and Boulton SJ. Double-strand break repair: 53BP1 comes into focus. Nat Rev Mol Cell Biol 15: 7-18, 2014.

232. Papa S, Zazzeroni F, Bubici C, Jayawardena S, Alvarez K, Matsuda S, Nguyen DU, Pham CG, Nelsbach AH, Melis
T, De Smaele E, Tang WJ, D'Adamio L, and Franzoso G. Gadd45 beta mediates the NF-kappa B suppression of JNK signalling by targeting MKK7/JNKK2. Nat Cell Biol 6: 146-153, 2004.

233. Patel HH, Murray F, and Insel PA. Caveolae as organizers of pharmacologically relevant signal transduction molecules. Anпu Rev Pharmacol Toxicol 48: 359-391, 2008.

234. Pateras IS, Havaki S, Nikitopoulou X, Vougas K, Townsend PA, Panayiotidis MI, Georgakilas AG, and Gorgoulis VG. The DNA damage response and immune signaling alliance: is it good or bad? Nature decides when and where. Pharmacol Ther 154: 36-56, 2015.

235. Perrier S, Hau J, Gasparutto D, Cadet J, Favier A, and Ravanat JL. Characterization of lysine-guanine cross-links upon one-electron oxidation of a guanine-containing oligonucleotide in the presence of a trilysine peptide. $J \mathrm{Am}$ Chem Soc 128: 5703-5710, 2006.

236. Petrovic N, Perovic J, Karanovic D, Todorovic L, and Petrovic V. Abscopal effects of local fractionated X-irradiation of face and jaw region. Strahlentherapie 158: 40-42, 1982.

237. Pilones KA, Vanpouille-Box C, and Demaria S. Combination of radiotherapy and immune checkpoint inhibitors. Semin Radiat Oncol 25: 28-33, 2015.

238. Pinto M, Azzam EI, and Howell RW. Investigation of adaptive responses in bystander cells in $3 \mathrm{D}$ cultures containing tritium-labeled and unlabeled normal human fibroblasts. Radiat Res 174: 216-227, 2010.

239. Poleszczuk J, Krzywon A, Forys U, and Widel M. Connecting radiation-induced bystander effects and senescence to improve radiation response prediction. Radiat Res 183: 571-577, 2015.

240. Polyak K, Xia Y, Zweier JL, Kinzler KW, and Vogelstein B. A model for p53-induced apoptosis. Nature 389: 300305, 1997.

241. Pouget JP, Douki T, Richard MJ, and Cadet J. DNA damage induced in cells by gamma and UVA radiation as measured by HPLC/GC-MS and HPLC-EC and Comet assay. Chem Res Toxicol 13: 541-549, 2000.

242. Pouget JP, Frelon S, Ravanat JL, Testard I, Odin F, and Cadet J. Formation of modified DNA bases in cells exposed either to gamma radiation or to high-LET particles. Radiat Res 157: 589-595, 2002.

243. Pouget JP, Lozza C, Deshayes E, Boudousq V, and Navarro-Teulon I. Introduction to radiobiology of targeted radionuclide therapy. Front Med (Lausanne) 2: 12, 2015.

244. Pouget JP, Navarro-Teulon I, Bardies M, Chouin N, Cartron G, Pelegrin A, and Azria D. Clinical radioimmunotherapy - the role of radiobiology. Nat Rev Clin Oncol 8: 720-734, 2011.

245. Pouget JP, Ravanat JL, Douki T, Richard MJ, and Cadet J. Measurement of DNA base damage in cells exposed to low doses of gamma-radiation: comparison between the HPLC-EC and comet assays. Int J Radiat Biol 75: 51-58, 1999.

246. Pradere JP, Dapito DH, and Schwabe RF. The Yin and Yang of Toll-like receptors in cancer. Oncogene 33: 3485-3495, 2014.

247. Prise KM and O'Sullivan JM. Radiation-induced bystander signalling in cancer therapy. Nat Rev Cancer 9: 351-360, 2009.

248. Prise KM, Schettino G, Folkard M, and Held KD. New insights on cell death from radiation exposure. Lancet Oncol 6: 520-528, 2005. 
249. This reference has been deleted.

250. Qiao Y and Ma L. Predicting efficacy of cancer cell killing under hypoxic conditions with single cell DNA damage assay. Anal Chem 85: 6953-6957, 2013.

251. Qiu H, Edmunds T, Baker-Malcolm J, Karey KP, Estes S, Schwarz C, Hughes H, and Van Patten SM. Activation of human acid sphingomyelinase through modification or deletion of C-terminal cysteine. J Biol Chem 278: 3274432752, 2003.

252. Quan X, Nguyen TT, Choi SK, Xu S, Das R, Cha SK, Kim $\mathrm{N}$, Han J, Wiederkehr A, Wollheim CB, and Park KS. Essential role of mitochondrial $\mathrm{Ca}^{2+}$ uniporter in the generation of mitochondrial $\mathrm{pH}$ gradient and metabolismsecretion coupling in insulin-releasing cells. J Biol Chem 290: 4086-4096, 2015.

253. Ravanat JL, Breton J, Douki T, Gasparutto D, Grand A, Rachidi W, and Sauvaigo S. Radiation-mediated formation of complex damage to DNA: a chemical aspect overview. Br J Radiol 87: 20130715, 2014.

254. Ravanat JL and Douki T. UV and ionizing radiations induced DNA damage, differences and similarities. $J$ Rad Phys Chem 128: 92-102, 2016.

255. Reisz JA, Bansal N, Qian J, Zhao W, and Furdui CM. Effects of ionizing radiation on biological moleculesmechanisms of damage and emerging methods of detection. Antioxid Redox Signal 21: 260-292, 2014.

256. Reynolds CP, Maurer BJ, and Kolesnick RN. Ceramide synthesis and metabolism as a target for cancer therapy. Cancer Lett 206: 169-180, 2004.

257. Rizzuto R, De Stefani D, Raffaello A, and Mammucari C. Mitochondria as sensors and regulators of calcium signalling. Nat Rev Mol Cell Biol 13: 566-578, 2012.

258. Rodel F, Frey B, Gaipl U, Keilholz L, Fournier C, Manda K, Schollnberger H, Hildebrandt G, and Rodel C. Modulation of inflammatory immune reactions by low-dose ionizing radiation: molecular mechanisms and clinical application. Curr Med Chem 19: 1741-1750, 2012.

259. Rossi F and Zatti M. Biochemical aspects of phagocytosis in polymorphonuclear leucocytes. NADH and NADPH oxidation by the granules of resting and phagocytizing cells. Experientia 20: 21-23, 1964.

260. Rothkamm K and Lobrich M. Evidence for a lack of DNA double-strand break repair in human cells exposed to very low x-ray doses. Proc Natl Acad Sci U S A 100: 50575062, 2003.

261. Rubner Y, Wunderlich R, Ruhle PF, Kulzer L, Werthmoller N, Frey B, Weiss EM, Keilholz L, Fietkau R, and Gaipl US. How does ionizing irradiation contribute to the induction of anti-tumor immunity? Front Oncol 2: 75, 2012.

262. Sage E and Shikazono N. Radiation-induced clustered DNA lesions: repair and mutagenesis. Free Radic Biol Med 107: 125-135, 2017.

263. Santana P, Pena LA, Haimovitz-Friedman A, Martin S, Green D, McLoughlin M, Cordon-Cardo C, Schuchman EH, Fuks Z, and Kolesnick R. Acid sphingomyelinasedeficient human lymphoblasts and mice are defective in radiation-induced apoptosis. Cell 86: 189-199, 1996.

264. Sato F, Muramatsu S, and Nakamura W. [Abscopal effect and recovery of splenic weights of mice] [in Japanese]. Nihon Igaku Hoshasen Gakkai Zasshi 30: 136-140, 1971.

265. Sawant SG, Randers-Pehrson G, Metting NF, and Hall EJ. Adaptive response and the bystander effect induced by radiation in $\mathrm{C} 3 \mathrm{H}$ 10T(1/2) cells in culture. Radiat Res 156: 177-180, 2001.

266. Scemes E, Suadicani SO, and Spray DC. Intercellular communication in spinal cord astrocytes: fine tuning between gap junctions and $\mathrm{P} 2$ nucleotide receptors in calcium wave propagation. J Neurosci 20: 1435-1445, 2000.

267. Schaue D. A Century of radiation therapy and adaptive immunity. Front Immunol 8: 431, 2017.

268. Schaue D, Kachikwu EL, and McBride WH. Cytokines in radiobiological responses: a review. Radiat Res 178: 505523, 2012.

269. Schipler A and Iliakis G. DNA double-strand-break complexity levels and their possible contributions to the probability for error-prone processing and repair pathway choice. Nucleic Acids Res 41: 7589-7605, 2013.

270. Schmidt-Ullrich RK, Mikkelsen RB, Dent P, Todd DG, Valerie K, Kavanagh BD, Contessa JN, Rorrer WK, and Chen PB. Radiation-induced proliferation of the human A431 squamous carcinoma cells is dependent on EGFR tyrosine phosphorylation. Oncogene 15: 1191-1197, 1997.

271. Schneider C. An update on products and mechanisms of lipid peroxidation. Mol Nutr Food Res 53: 315-321, 2009.

272. Seth I, Schwartz JL, Stewart RD, Emery R, Joiner MC, and Tucker JD. Neutron exposures in human cells: bystander effect and relative biological effectiveness. PLoS One 9: e98947, 2014.

273. Seyedin SN, Schoenhals JE, Lee DA, Cortez MA, Wang X, Niknam S, Tang C, Hong DS, Naing A, Sharma P, Allison JP, Chang JY, Gomez DR, Heymach JV, Komaki RU, Cooper LJ, and Welsh JW. Strategies for combining immunotherapy with radiation for anticancer therapy. Immunotherapy 7: 967-980, 2015.

274. Seymour CB and Mothersill C. Relative contribution of bystander and targeted cell killing to the low-dose region of the radiation dose-response curve. Radiat Res 153: 508-511, 2000.

275. Shadley JD and Wiencke JK. Induction of the adaptive response by X-rays is dependent on radiation intensity. Int J Radiat Biol 56: 107-118, 1989.

276. Shao C, Folkard M, Michael BD, and Prise KM. Targeted cytoplasmic irradiation induces bystander responses. Proc Natl Acad Sci U S A 101: 13495-13500, 2004.

277. Shao C, Folkard M, and Prise KM. Role of TGF-beta1 and nitric oxide in the bystander response of irradiated glioma cells. Oncogene 27: 434-440, 2008.

278. Shao C, Furusawa Y, Kobayashi Y, Funayama T, and Wada S. Bystander effect induced by counted high-LET particles in confluent human fibroblasts: a mechanistic study. FASEB J 17: 1422-1427, 2003.

279. Shao C, Lyng FM, Folkard M, and Prise KM. Calcium fluxes modulate the radiation-induced bystander responses in targeted glioma and fibroblast cells. Radiat Res 166: 479-487, 2006.

280. Shao C, Stewart V, Folkard M, Michael BD, and Prise KM. Nitric oxide-mediated signaling in the bystander response of individually targeted glioma cells. Cancer Res 63: 8437-8442, 2003.

281. Shao H, Cheng HY, Cook RG, and Tweardy DJ. Identification and characterization of signal transducer and activator of transcription 3 recruitment sites within the epidermal growth factor receptor. Cancer Res 63: 39233930, 2003. 
282. Shiloh Y and Ziv Y. The ATM protein kinase: regulating the cellular response to genotoxic stress, and more. Nat Rev Mol Cell Biol 14: 197-210, 2013.

283. Shueng PW, Lin SC, Chang HT, Chong NS, Chen YJ, Wang LY, Hsieh YP, and Hsieh CH. Toxicity risk of nontarget organs at risk receiving low-dose radiation: case report. Radiat Oncol 4: 71, 2009.

284. Shvartsman SY, Hagan MP, Yacoub A, Dent P, Wiley HS, and Lauffenburger DA. Autocrine loops with positive feedback enable context-dependent cell signaling. Am J Physiol Cell Physiol 282: C545-C559, 2002.

285. Silerme S, Bobyk L, Taverna-Porro M, Cuier C, SaintPierre C, and Ravanat JL. DNA-polyamine cross-links generated upon one electron oxidation of DNA. Chem Res Toxicol 27: 1011-1018, 2014.

286. This reference has been deleted.

287. Simons K and Ikonen E. Functional rafts in cell membranes. Nature 387: 569-572, 1997.

288. Singer JM, Price P, and Dale RG. Radiobiological prediction of normal tissue toxicities and tumour response in the radiotherapy of advanced non-small-cell lung cancer. Br J Cancer 78: 1629-1633, 1998.

289. Singer SJ and Nicolson GL. The fluid mosaic model of the structure of cell membranes. Science 175: 720-731, 1972.

290. Siva S, Lobachevsky P, MacManus MP, Kron T, Moller A, Lobb RJ, Ventura J, Best N, Smith J, Ball D, and Martin OA. Radiotherapy for non-small cell lung cancer induces DNA damage response in both irradiated and outof-field normal tissues. Clin Cancer Res 22: 4817-4826, 2016.

291. Siva S, MacManus MP, Martin RF, and Martin OA. Abscopal effects of radiation therapy: a clinical review for the radiobiologist. Cancer Lett 356: 82-90, 2015.

292. Smith RW, Seymour CB, Moccia RD, and Mothersill CE. Irradiation of rainbow trout at early life stages results in trans-generational effects including the induction of a bystander effect in non-irradiated fish. Environ Res 145: 2638, 2016.

293. Song S, Lippman SM, Zou Y, Ye X, Ajani JA, and Xu $\mathrm{XC}$. Induction of cyclooxygenase- 2 by benzo[a]pyrene diol epoxide through inhibition of retinoic acid receptorbeta 2 expression. Oncogene 24: 8268-8276, 2005.

294. Sorokin A. Nitric oxide synthase and cyclooxygenase pathways: a complex interplay in cellular signaling. Curr Med Chem 23: 2559-2578, 2016.

295. Stadtman ER. Oxidation of free amino acids and amino acid residues in proteins by radiolysis and by metalcatalyzed reactions. Annu Rev Biochem 62: 797-821, 1993.

296. Stark G. The effect of ionizing radiation on lipid membranes. Biochim Biophys Acta 1071: 103-122, 1991.

297. Stevenson MA, Pollock SS, Coleman CN, and Calderwood SK. X-irradiation, phorbol esters, and $\mathrm{H} 2 \mathrm{O} 2$ stimulate mitogen-activated protein kinase activity in NIH-3T3 cells through the formation of reactive oxygen intermediates. Cancer Res 54: 12-15, 1994.

298. Suadicani SO, Iglesias R, Wang J, Dahl G, Spray DC, and Scemes E. ATP signaling is deficient in cultured Pannexin1-null mouse astrocytes. Glia 60: 1106-1116, 2012.

299. Szado T, Vanderheyden V, Parys JB, De Smedt H, Rietdorf K, Kotelevets L, Chastre E, Khan F, Landegren U, Soderberg O, Bootman MD, and Roderick HL. Phosphorylation of inositol 1,4,5-trisphosphate receptors by protein kinase $\mathrm{B} /$ Akt inhibits $\mathrm{Ca}^{2+}$ release and apoptosis. Proc Natl Acad Sci U S A 105: 2427-2432, 2008.

300. Takeshima T, Chamoto K, Wakita D, Ohkuri T, Togashi Y, Shirato H, Kitamura H, and Nishimura T. Local radiation therapy inhibits tumor growth through the generation of tumor-specific CTL: its potentiation by combination with Th1 cell therapy. Cancer Res 70: 2697-2706, 2010.

301. Tang C, Wang X, Soh H, Seyedin S, Cortez MA, Krishnan S, Massarelli E, Hong D, Naing A, Diab A, Gomez D, Ye H, Heymach J, Komaki R, Allison JP, Sharma P, and Welsh JW. Combining radiation and immunotherapy: a new systemic therapy for solid tumors? Cancer Immunol Res 2: 831-838, 2014.

302. Tapio S. Ionizing radiation effects on cells, organelles and tissues on proteome level. Adv Exp Med Biol 990: 37-48, 2013.

303. Tian W, Yin X, Wang L, Wang J, Zhu W, Cao J, and Yang H. The key role of miR-21-regulated SOD2 in the medium-mediated bystander responses in human fibroblasts induced by alpha-irradiated keratinocytes. Mutat Res 780: 77-85, 2015.

304. Todd DG and Mikkelsen RB. Ionizing radiation induces a transient increase in cytosolic free $\left[\mathrm{Ca}^{2+}\right]$ in human epithelial tumor cells. Cancer Res 54: 5224-5230, 1994.

305. Todd DG, Mikkelsen RB, Rorrer WK, Valerie K, and Schmidt-Ullrich RK. Ionizing radiation stimulates existing signal transduction pathways involving the activation of epidermal growth factor receptor and ERBB-3, and changes of intracellular calcium in A431 human squamous carcinoma cells. J Recept Signal Transduct Res 19: 885-908, 1999.

306. Toki Y, Takenouchi T, Harada H, Tanuma S, Kitani H, Kojima S, and Tsukimoto M. Extracellular ATP induces $\mathrm{P} 2 \mathrm{X} 7$ receptor activation in mouse Kupffer cells, leading to release of IL-1beta, HMGB1, and PGE2, decreased MHC class I expression and necrotic cell death. Biochem Biophys Res Commun 458: 771-776, 2015.

307. Tomita $\mathbf{M}$ and Maeda $\mathbf{M}$. Mechanisms and biological importance of photon-induced bystander responses: do they have an impact on low-dose radiation responses. $J$ Radiat Res 56: 205-219, 2015.

308. Tonks NK. Protein tyrosine phosphatases and the control of cellular signaling responses. Adv Pharmacol 36: 91119, 1996.

309. Trott KR, Jamali M, Manti L, and Teibe A. Manifestations and mechanisms of radiation-induced genomic instability in V-79 Chinese hamster cells. Int J Radiat Biol 74: 787791, 1998.

310. Trumpower BL. The protonmotive Q cycle. Energy transduction by coupling of proton translocation to electron transfer by the cytochrome bc1 complex. J Biol Chem 265: 11409-11412, 1990.

311. Tsukimoto M. Purinergic signaling is a novel mechanism of the cellular response to ionizing radiation. Biol Pharm Bull 38: 951-959, 2015.

312. Tsukimoto M, Homma T, Mutou Y, and Kojima S. 0.5 Gy gamma radiation suppresses production of TNF-alpha through up-regulation of MKP-1 in mouse macrophage RAW264.7 cells. Radiat Res 171: 219-224, 2009.

313. Tsukimoto M, Homma T, Ohshima Y, and Kojima S. Involvement of purinergic signaling in cellular response to gamma radiation. Radiat Res 173: 298-309, 2010.

314. UNSCEAR. Effects of Ionizing Radiation. New York, 2008. United Nations Publication Sales No. E.10.XI.3. ISBN 978-92-1-142274-0. 
315. Valerie K, Yacoub A, Hagan MP, Curiel DT, Fisher PB, Grant S, and Dent P. Radiation-induced cell signaling: inside-out and outside-in. Mol Cancer Ther 6: 789-801, 2007.

316. van Gisbergen MW, Voets AM, Starmans MH, de Coo IF, Yadak R, Hoffmann RF, Boutros PC, Smeets HJ, Dubois $\mathrm{L}$, and Lambin P. How do changes in the mtDNA and mitochondrial dysfunction influence cancer and cancer therapy? Challenges, opportunities and models. Mutat Res Rev Mutat Res 764: 16-30, 2015.

317. Ventura J, Lobachevsky PN, Palazzolo JS, Forrester H, Haynes NM, Ivashkevich A, Stevenson AW, Hall CJ, Ntargaras A, Kotsaris V, Pollakis GC, Potsi G, Skordylis K, Terzoudi G, Pateras IS, Gorgoulis VG, Georgakilas AG, Sprung CN, and Martin OA. Localized synchrotron irradiation of mouse skin induces persistent systemic genotoxic and immune responses. Cancer Res 77: 63896399, 2017.

318. Vilenchik MM and Knudson AG. Endogenous DNA double-strand breaks: production, fidelity of repair, and induction of cancer. Proc Natl Acad Sci U S A 100: 12871-12876, 2003.

319. Voehringer DW, Story MD, O'Neil RG, and Meyn RE. Modulating $\mathrm{Ca}^{2+}$ in radiation-induced apoptosis suppresses DNA fragmentation but does not enhance clonogenic survival. Int J Radiat Biol 71: 237-243, 1997.

320. Wachtel LW and Cole LJ. Abscopal effects of whole-body $\mathrm{X}$-irradiation on compensatory hypertrophy of the rat kidney. Radiat Res 25: 78-91, 1965.

321. Wachtel LW and Cole LJ. Abscopal effects of whole-body $\mathrm{X}$-irradiation on compensatory hypertrophy of the rat kidney. USNRDL-Tr-783. Res Dev Tech Rep 11: 1-23, 1964.

322. Waddick KG and Uckun FM. Innovative treatment programs against cancer: II. Nuclear factor-kappaB (NFkappaB) as a molecular target. Biochem Pharmacol 57: 9$17,1999$.

323. Walsh DWM, Siebenwirth C, Greubel C, Ilicic K, Reindl J, Girst S, Muggiolu G, Simon M, Barberet P, Seznec H, Zischka H, Multhoff G, Schmid TE, and Dollinger G. Live cell imaging of mitochondria following targeted irradiation in situ reveals rapid and highly localized loss of membrane potential. Sci Rep 7: 46684, 2017.

324. Wang CK. The progress of radiobiological models in modern radiotherapy with emphasis on the uncertainty issue. Mutat Res 704: 175-181, 2010.

325. Wang CY, Guttridge DC, Mayo MW, and Baldwin AS Jr. NF-kappaB induces expression of the Bcl-2 homologue A1/Bfl-1 to preferentially suppress chemotherapy-induced apoptosis. Mol Cell Biol 19: 5923-5929, 1999.

326. Wang CY, Mayo MW, Korneluk RG, Goeddel DV, and Baldwin AS Jr. NF-kappaB antiapoptosis: induction of TRAF1 and TRAF2 and c-IAP1 and c-IAP2 to suppress caspase-8 activation. Science 281: 1680-1683, 1998.

327. Wang N, De Bock M, Decrock E, Bol M, Gadicherla A, Vinken M, Rogiers V, Bukauskas FF, Bultynck G, and Leybaert L. Paracrine signaling through plasma membrane hemichannels. Biochim Biophys Acta 1828: 35-50, 2013.

328. Wang Z, Cook T, Alber S, Liu K, Kovesdi I, Watkins SK, Vodovotz Y, Billiar TR, and Blumberg D. Adenoviral gene transfer of the human inducible nitric oxide synthase gene enhances the radiation response of human colorectal cancer associated with alterations in tumor vascularity. Cancer Res 64: 1386-1395, 2004.

329. Ward JF. DNA damage as the cause of ionizing radiationinduced gene activation. Radiat Res 138: S85-S88, 1994.

330. Watanabe R, Rahmanian S, and Nikjoo H. Spectrum of radiation-induced clustered non-DSB damage-a monte carlo track structure modeling and calculations. Radiat Res 183: 525-540, 2015.

331. Watson GE, Lorimore SA, Macdonald DA, and Wright EG. Chromosomal instability in unirradiated cells induced in vivo by a bystander effect of ionizing radiation. Cancer Res 60: 5608-5611, 2000.

332. Wennerberg E, Lhuillier C, Vanpouille-Box C, Pilones KA, Garcia-Martinez E, Rudqvist NP, Formenti SC, and Demaria S. Barriers to radiation-induced in situ tumor vaccination. Front Immunol 8: 229, 2017.

333. Wolff S. The adaptive response in radiobiology: evolving insights and implications. Environ Health Perspect 106 Suppl 1: 277-283, 1998.

334. Worthington J, McCarthy HO, Barrett E, Adams C, Robson T, and Hirst DG. Use of the radiation-inducible WAF1 promoter to drive iNOS gene therapy as a novel anti-cancer treatment. J Gene Med 6: 673-680, 2004.

335. Wu LJ, Randers-Pehrson G, Xu A, Waldren CA, Geard $\mathrm{CR}, \mathrm{Yu} \mathrm{Z}$, and Hei TK. Targeted cytoplasmic irradiation with alpha particles induces mutations in mammalian cells. Proc Natl Acad Sci U S A 96: 4959-4964, 1999.

336. Wu ZH, Shi Y, Tibbetts RS, and Miyamoto S. Molecular linkage between the kinase ATM and NF-kappaB signaling in response to genotoxic stimuli. Science 311: 1141-1146, 2006.

337. Xia M, Zhang C, Boini KM, Thacker AM, and Li PL. Membrane raft-lysosome redox signalling platforms in coronary endothelial dysfunction induced by adipokine visfatin. Cardiovasc Res 89: 401-409, 2011.

338. Xu X, Muller JG, Ye Y, and Burrows CJ. DNA-protein cross-links between guanine and lysine depend on the mechanism of oxidation for formation of C5 vs C8 guanosine adducts. J Am Chem Soc 130: 703-709, 2008.

339. Xue LY, Butler NJ, Makrigiorgos GM, Adelstein SJ, and Kassis AI. Bystander effect produced by radiolabeled tumor cells in vivo. Proc Natl Acad Sci U S A 99: 1376513770, 2002.

340. Yakovlev VA. Role of nitric oxide in the radiation-induced bystander effect. Redox Biol 6: 396-400, 2015.

341. Yakovlev VA. Nitric oxide-dependent downregulation of BRCA1 expression promotes genetic instability. Cancer Res 73: 706-715, 2013.

342. Yan J, Khanna KK, and Lavin MF. Defective radiation signal transduction in ataxia-telangiectasia cells. Int $J$ Radiat Biol 76: 1025-1035, 2000.

343. Yan J, Khanna KK, and Lavin MF. Induction of inositol $1,4,5$ trisphosphate receptor genes by ionizing radiation. Int J Radiat Biol 69: 539-546, 1996.

344. Yatagai F, Suzuki M, Ishioka N, Ohmori H, and Honma M. Repair of I-SceI induced DSB at a specific site of chromosome in human cells: influence of low-dose, lowdose-rate gamma-rays. Radiat Environ Biophys 47: 439444, 2008.

345. Yoshida T, Goto S, Kawakatsu M, Urata Y, and Li TS. Mitochondrial dysfunction, a probable cause of persistent oxidative stress after exposure to ionizing radiation. Free Radic Res 46: 147-153, 2012. 
346. Zalba $\mathrm{S}$ and Ten Hagen TL. Cell membrane modulation as adjuvant in cancer therapy. Cancer Treat Rev 52: 48-57, 2017.

347. Zhang AY, Yi F, Jin S, Xia M, Chen QZ, Gulbins E, and Li PL. Acid sphingomyelinase and its redox amplification in formation of lipid raft redox signaling platforms in endothelial cells. Antioxid Redox Signal 9: 817-828, 2007.

348. Zhang B, Davidson MM, Zhou H, Wang C, Walker WF, and Hei TK. Cytoplasmic irradiation results in mitochondrial dysfunction and DRP1-dependent mitochondrial fission. Cancer Res 73: 6700-6710, 2013.

349. Zhang Y, Yao B, Delikat S, Bayoumy S, Lin XH, Basu S, McGinley M, Chan-Hui PY, Lichenstein H, and Kolesnick $\mathrm{R}$. Kinase suppressor of Ras is ceramide-activated protein kinase. Cell 89: 63-72, 1997.

350. Zhang Y, Zhou J, Held KD, Redmond RW, Prise KM, and Liber HL. Deficiencies of double-strand break repair factors and effects on mutagenesis in directly gamma-irradiated and medium-mediated bystander human lymphoblastoid cells. Radiat Res 169: 197-206, 2008.

351. Zhao L, Mi D, Hu B, and Sun Y. A generalized target theory and its applications. Sci Rep 5: 14568, 2015.

352. Zhao QL, Kondo T, Noda A, and Fujiwara Y. Mitochondrial and intracellular free-calcium regulation of radiation-induced apoptosis in human leukemic cells. Int $J$ Radiat Biol 75: 493-504, 1999.

353. Zhou H, Hong M, Chai Y, and Hei TK. Consequences of cytoplasmic irradiation: studies from microbeam. J Radiat Res 50 Suppl A: A59-A65, 2009.

354. Zhou H, Ivanov VN, Gillespie J, Geard CR, Amundson SA, Brenner DJ, Yu Z, Lieberman HB, and Hei TK. Mechanism of radiation-induced bystander effect: role of the cyclooxygenase-2 signaling pathway. Proc Natl Acad Sci U S A 102: 14641-14646, 2005.

355. Zhou H, Ivanov VN, Lien YC, Davidson M, and Hei TK. Mitochondrial function and nuclear factor-kappaB-mediated signaling in radiation-induced bystander effects. Cancer Res 68: 2233-2240, 2008.

356. Zhou H, Randers-Pehrson G, Geard CR, Brenner DJ, Hall $\mathrm{EJ}$, and Hei TK. Interaction between radiation-induced adaptive response and bystander mutagenesis in mammalian cells. Radiat Res 160: 512-516, 2003.

357. Zhou H, Randers-Pehrson G, Waldren CA, Vannais D, Hall EJ, and Hei TK. Induction of a bystander mutagenic effect of alpha particles in mammalian cells. Proc Natl Acad Sci U S A 97: 2099-2104, 2000.

358. Zhou X, Li N, Wang Y, Zhang X, and Zhang H. Effects of $\mathrm{X}$-irradiation on mitochondrial DNA damage and its supercoiling formation change. Mitochondrion 11: 886-892, 2011.

Address correspondence to: Dr. Jean-Pierre Pouget Institut de Recherche en Cancérologie de Montpellier (IRCM) INSERM U1194, 208 rue des apothicaires F-34298 Montpellier Cedex 5

France

E-mail: jean-pierre.pouget@inserm.fr

Date of first submission to ARS Central, July 3, 2017; date of final revised submission, January 13, 2018; date of acceptance, January 15, 2018.

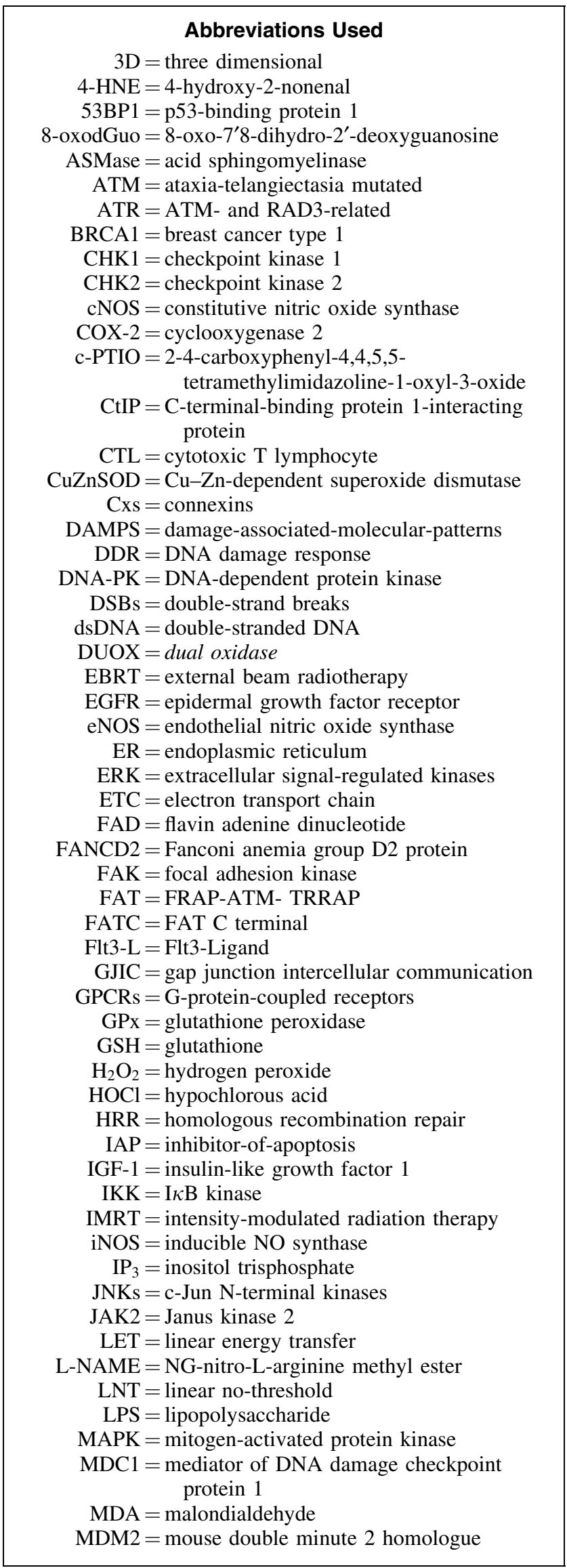




$\begin{aligned} & \text { Abbreviations Used (Cont.) } \\ \mathrm{MDS} & =\text { multiple damage sites } \\ \mathrm{MIBG} & =\text { meta-iodobenzylguanidine } \\ \mathrm{MMP} & =\text { matrix metalloproteinase } \\ \mathrm{MN} & =\text { micronuclei } \\ \mathrm{MnSOD} & =\text { manganese-dependent superoxide } \\ \mathrm{MRN} & =\text { dismutase } \\ \mathrm{m} \mathrm{N} \mathrm{NA} & =\text { mitochondrial DNA } \\ \mathrm{NAD}(\mathrm{P}) \mathrm{H} & =\text { nicotine adenine dinucleotide phosphate } \\ \mathrm{NEMO} & =\text { NF- } \kappa \mathrm{B} \text { essential modulator } \\ \mathrm{NF}-\kappa \mathrm{B} & =\text { nuclear factor kappa B } \\ \mathrm{NHEJ} & =\text { nonhomologous end joining } \\ \mathrm{NO} & =\text { nitric oxide } \\ \mathrm{NOS} & =\text { nitric oxide synthase } \\ \mathrm{NOX} & =\text { NAD }(\mathrm{P}) \mathrm{H} \text { oxidase } \\ \mathrm{O}_{2}^{-} & =\text {superoxide anion } \\ \mathrm{ONOO} & =\text { peroxynitrite } \\ \mathrm{Panxs} & =\text { pannexins } \\ \mathrm{PGE} 2 & =\text { prostaglandin E2 } \\ \mathrm{PI} 3 \mathrm{~K} & =\text { phosphatidylinositol-3-kinase } \\ \mathrm{PIG} & =\text { p53-induced genes } \\ \mathrm{PKC} & =\text { protein kinase C } \\ \mathrm{PLC} & =\text { phospholipase C } \\ & \end{aligned}$

$\mathrm{PP} 2 \mathrm{~A}=$ protein phosphatase 2

PRRs $=$ pattern recognition receptors

PUFA $=$ polyunsaturated fatty acids

PUMA $=$ p53-upregulated modulator of apoptosis

RIAR $=$ radiation-induced adaptive response

$\mathrm{RNS}=$ reactive nitrogen species

ROS $=$ reactive oxygen species

SBRT $=$ stereotactic body radiation therapy

$\mathrm{SOD}=$ superoxide dismutase

$\mathrm{SSBs}=$ single-strand breaks

STAT3 $=$ signal transducer and activator of transcription 3

$\mathrm{TCP}=$ tumor control probability

$\mathrm{TGF}=$ transforming growth factor

TLR $=$ Toll-like receptor

$\mathrm{TNF}=$ tumor necrosis factor

TRADD $=$ TNFR type 1 -associated DEATH domain protein

TRAF2 $=$ TNF receptor-associated factor 2

TRAIL $=$ TNF-related apoptosis-inducing ligand

Treg cells $=$ regulatory $\mathrm{T}$ cells

UNSCEAR = United Nations Scientific Committee on the Effects of Atomic Radiation

VDACs $=$ voltage-dependent anion channels 